\title{
(0) 4
}

DICIEMBRE 2019

REVISTA INTERDISCIPLINAR DE ESTUDIOS FEMINISTAS
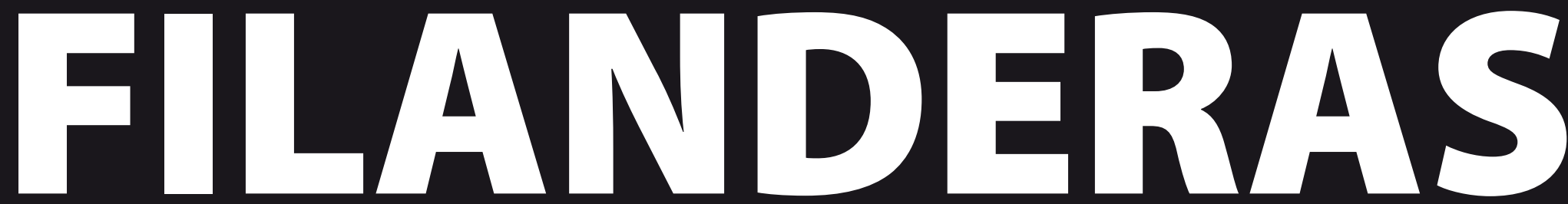

LA GUERRA CIVIL EN LAS CINCO VILLAS

EL AMOR FEMENINO EN EL SHŌJO-AI

HOMBRES Y MOVIMIENTO FEMINISTA

EN LOS SETENTA Y OCHENTA

\section{EL LABERINTO COEDUCATIVO}

RESEÑAS

ENTREVISTA A MARY NASH

IN MEMORIAM.

CONCEPCIÓN TOMÁS AZNAR

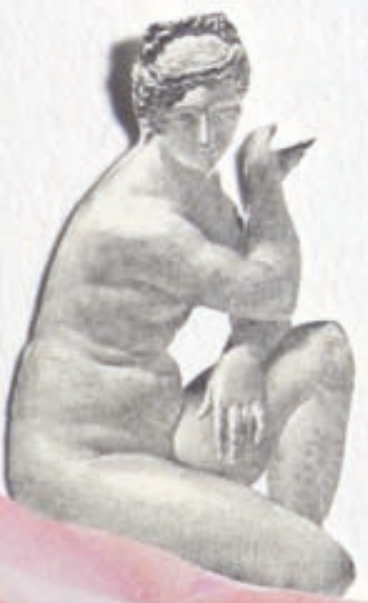




\section{EDITA}

Seminario Interdisciplinar de Estudios de la Mujer (SIEM)

de la Universidad de Zaragoza

\section{PATROCINA}

Instituto Aragonés de la Mujer — Cátedra sobre Igualdad y Género

de la Universidad de Zaragoza

\section{COMITÉ EDITORIAL}

\section{Directora}

Ángela Cenarro (Universidad de Zaragoza)

\section{Secretaria}

Elena Masarah (Universidad de Zaragoza)

\section{Editoras}

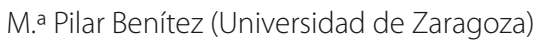

Alicia Brox (Universidad de Zaragoza)

Beatriz Domínguez (Universidad de Huelva)

Maite Escudero (Universidad de Zaragoza)

Régine Illion (SIEM)

Pilar de Luis (Universidad de Zaragoza)

Silvia Pellicer (Universidad de Zaragoza)

M. ${ }^{a}$ Isabel Romero (Universidad de Málaga)

\section{COMITÉ ASESOR}

Amparo Bella (SIEM)

Inmaculada Blasco (Universidad de La Laguna)

María Antonia Callén (SIEM)

Teresa Fernández Turrado (Universidad de Zaragoza)

M. ${ }^{a}$ Eulalia Lerma (Ayuntamiento de Zaragoza)

Carmen Magallón (Fundación SIP)

Consuelo Miqueo (Universidad de Zaragoza)

Esther Moreno (SIEM)

Irene Murillo (SIEM)

Aránzazu Novales (Universidad de Zaragoza)

Sonia Pedrosa (Universidad de Zaragoza)

Asunción Santesteban (SIEM)

Palmira Vélez (Universidad de Zaragoza)

Mercedes Yusta (Université Paris 8)
(C) las y los autores, por los textos.

(c) Editorial Renacimiento, Reservoir Books, MGM/HBO, Oyuki Konno y Reine Hibiki, por las imágenes.

(c) Seminario Interdisciplinar de Estudios de la Mujer (SIEM) de la Universidad de Zaragoza, por la edición.

Imagen de portada y maquetación: Marta Ester Corrección: Ana Hernández de Deza

filanderas@unizar.es

ISSN: 2530-6022

El contenido de esta revista está disponible bajo Licencia Creative Commons Reconocimiento-No Comercial 4.0 Unported (CC-BY-NC 4.0) 


\section{ÍNDICE}

EDITORIAL

\section{ESTUDIOS}

01 PURIFICAR Y PURGAR. LA GUERRA CIVIL EN LAS CINCO VILLAS

DESDE UNA PERSPECTIVA FEMINISTA

Cristina Sánchez

02 ¿LA VIRGEN MARÍA NOS ESTÁ MIRANDO? ALGUNAS NOTAS SOBRE LA IDEALIZACIÓN DEL AMOR FEMENINO EN EL SUBGÉNERO SHŌJO-AI

Antonio Míguez Santa Cruz

03 «MACHOS, PROGRES Y GALANES»: HOMBRES Y MOVIMIENTO FEMINISTA

DURANTE LOS AÑOS SETENTA Y OCHENTA

Carlos Adán Gil

\section{ENSAYOS}

04 CARRERA DE RELEVOS EN EL LABERINTO COEDUCATIVO

Sacha de Ignacio

\section{RESEÑAS}

05 EL CUENTO DE LA CRIADA, ¿UNA DISTOPÍA ACTUAL?

Esther Muñoz González

06 LOQUEMÁS ME GUSTA SON LOS MONSTRUOS

Mara González

07 LA LABOR DE LA EDITORIAL SEVILLANA RENACIMIENTO: MARÍA DE LA O LEJÁRRAGA (MARTÍNEZ SIERRA) Y CECILIA G. DE GUILARTE

Ángeles Ezama Gil

\section{ENTREVISTA}

08 ENTREVISTA A MARY NASH

Inmaculada Blasco

\section{In memoriam. CONCEPCIÓN TOMÁS AZNAR}

09 ¿SE PUEDE EVALUAR LA PERSPECTIVA DE GÉNERO EN LOS PROYECTOS

DE INVESTIGACIÓN?

M. ${ }^{a}$ Dolores Ariño; Concepción Tomás; Mercedes Eguiluz; M. ${ }^{a}$ Luisa Samitier; Teresa Oliveros; Teresa Yago; Gema Palacios; Rosa Magallón 

La madrugada del 31 de mayo de 2019 nos dejaba Concepción Tomás Aznar, Cuca, nuestra querida compañera y amiga, miembro del Comité Editorial de Filanderas. Doctora en Medicina y Cirugía en 1987 por la Universidad de Zaragoza y profesora titular del Departamento de Fisiatría y Enfermería en esta misma universidad, su trayectoria vital estuvo marcada por el doble compromiso social y feminista, del que hizo gala tanto en su carrera profesional como en su faceta más personal, cotidiana y relacional. Desde el editorial de este cuarto número de la revista queremos rendir un sentido y merecido homenaje a una mujer que combinó de manera prodigiosa la ciencia y lo humano, la teoría y la práctica, y cuya muerte prematura ha dejado un hueco inmenso en nuestros corazones.

La dimensión social estuvo ya presente en su tesis doctoral Planificación sanitaria en situaciones de desastre: contribución al análisis de la situación en Aragón. Su labor en el ámbito de la epidemiología y la salud pública fue constante, y de ella fueron magníficas expresiones sus estancias de investigación en Canadá y Reino Unido en los años ochenta y las decenas de artículos que publicó sobre la necesidad de ajustar los recursos a las necesidades reales de las poblaciones, con el fin de ofrecer servicios con el principio de justicia y equidad como ejes vertebradores. Durante el curso 2011-2012 disfrutó de una licencia sabática en Canadá, donde participó en el proyecto International Mobility in Aging Study (IMIAS) para estudiar cómo los roles de género determinan la movilidad en la salud de las personas mayores. Trabajos especialmente relevantes fueron sus investigaciones para validar el cuestionario Bem Sex Role Inventory, un instrumento de medida de rol de género, del que se sirvió para estudiar la asociación entre estereotipos de género y prácticas sexuales de riesgo, y sus artículos derivados del proyecto financiado por el Fondo de Investigación en Salud del Instituto de Salud Carlos III, que abrieron las puertas a la evaluación de la perspectiva de género en la investigación de ciencias de la salud.

Su carácter generoso y entusiasta le llevó a aceptar el cargo de coordinadora del Grado en Enfermería en la primera implantación del Plan Bolonia, labor que desempeñó desde 2008 a 2015. Su intenso trabajo en este ciclo
EDITORIAL

\section{IN MEMORIAM. CONCEPCIÓN TOMÁS AZNAR}

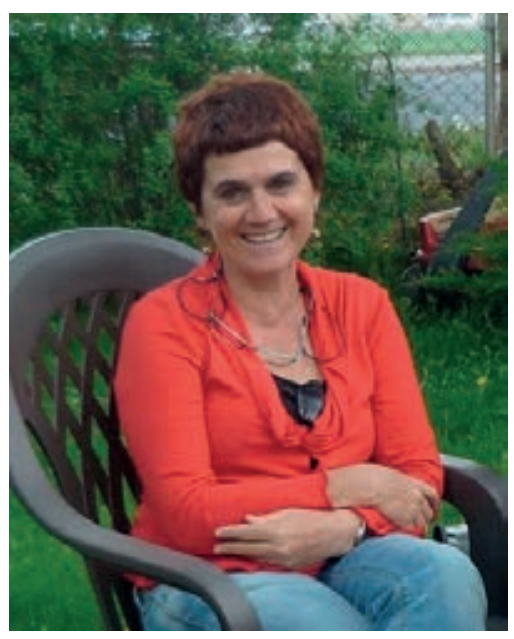


sentó las bases del desarrollo de la disciplina y de la adquisición por parte del alumnado de nuevas competencias, como las humanas, de base científica y centradas en el bienestar de las personas y comunidades. También fue profesora en la formación de posgrado, como en los másteres de Gerontología Social o de Investigación en Ciencias de la Enfermería, y coordinó asignaturas impartidas en diferentes titulaciones centradas en la investigacion y el estudio del impacto de las desigualdades de género en salud. Sus enseñanzas se vieron, asimismo, reflejadas en la dirección de varias tesis doctorales a lo largo de los últimos diez años, sobre temas tan diversos como la incontinencia urinaria en gestación y posparto, la anticoncepción y embarazo no planificado en mujeres jóvenes, la elongación del clítoris y sus implicaciones para la salud de las mujeres o las prácticas de riesgo en hombres que tienen sexo con hombres, entre otros.

Su incansable dedicación a la causa feminista le motivó para ocupar el cargo de coordinadora del Seminario Interdisciplinar de Estudios de la Mujer (SIEM) de la universidad entre 2004 y 2010. Fue una época difícil, con muchas trabas administrativas y problemas de financiación. Cuca nunca se rindió: su gran capacidad de diálogo y perseverancia con todas las instituciones implicadas hicieron que el SIEM siguiese adelante, dejándonos un legado excepcionalmente humano y privilegiado. Junto con otras compañeras del grupo de investigación de género y ciencia Genciana, organizó las primeras Jornadas de Género y Salud (2000), que durarían hasta 2008, y coeditó varios volúmenes con perspectiva de género en salud que siguen siendo referencia obligada en nuestro país: entre ellos, Perspectivas de género en salud (Editorial Minerva, Madrid, 2001) y Diálogos interrumpidos. Investigación en salud y práctica asistencial: una perspectiva de género (SIEM, Zaragoza, 2006), ambos junto a M. a José Barral, Consuelo Miqueo, Teresa Fernández, Cruz Tejero y Teresa Yago. Convencida de la importancia de la difusión científica de calidad para el avance del conocimiento, Cuca se implicó intensamente en la defensa de espacios interdisciplinares como el Seminario, donde, con distintos perfiles e iniciativas variadas, todas teníamos cabida.

La generosidad impregnó todas las facetas de su vida y así fue también con el último proyecto, que acogió con enorme ilusión: la edición, desde hace tan solo cuatro años, de la revista interdisciplinar feminista Filanderas. En un estadio avanzado de su enfermedad, sacó fuerzas para felicitarnos por la reciente indexación de la publicación y nos transmitió su energía para seguir adelante en esta empresa, cuyos avances cotidianos aguardaba, muy interesada, a través del correo electrónico. Mujer brillante, resolutiva, cariñosa y alegre. «Ha sido un placer; la vida, sigue, sigue, sigue...», dejó grabado en nuestros corazones para siempre. Querida Cuca: muchas gracias por todo; el placer ha sido nuestro. 


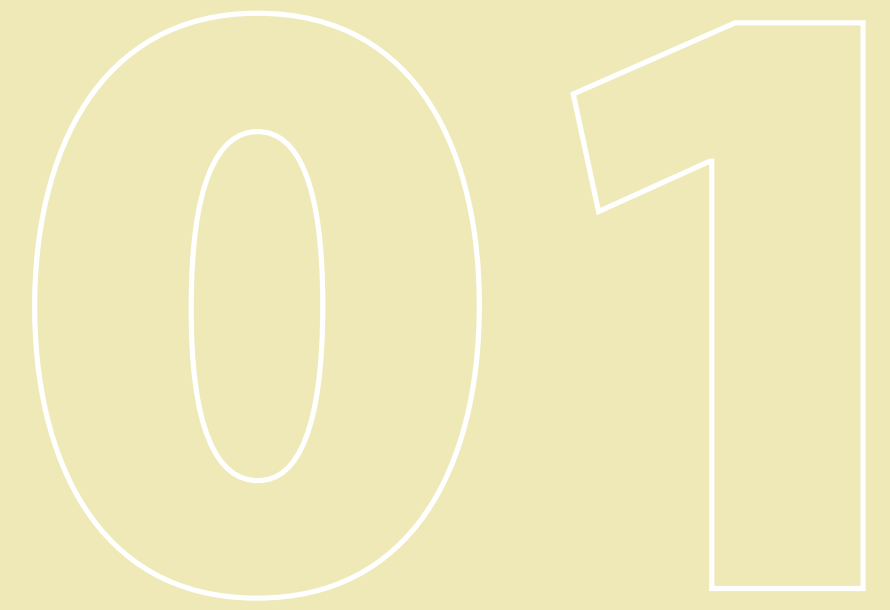

RESUMEN

\section{PURIFICAR Y PURGAR.}

\section{LA GUERRA CIVIL EN LAS}

CINCO VILLAS DESDE UNA

PERSPECTIVA FEMINISTA

Purify and purge. The Civil War in Cinco Villas

from a feminist perspective

\section{CRISTINA SÁNCHEZ}

\section{Universidad de Zaragoza}

Fecha de recepción: 5 de abril de 2019

Fecha de aceptación: 6 de septiembre de 2019
En las últimas décadas la historiografía tradicional ha recibido un notable impulso de la perspectiva feminista, haciendo que el estudio de la Guerra Civil española se vea favorecido por la incorporación de las mujeres al relato común.

Aragón, por la especificidad de su situación y contexto bélico, es uno de los territorios donde mejor puede estudiarse este conflicto. Las Cinco Villas tuvieron un fuerte arraigo del republicanismo y el socialismo. Eso las convirtió en terreno abonado para que el franquismo desplegara sus violencias con la máxima fuerza. La comarca se mantuvo siempre en retaguardia, ya que desde el primer momento cayó en manos franquistas. Las mujeres fueron objeto de todas sus formas de represión, muchas de las cuales no sufrieron los hombres. Hubo cortes de pelo al cero, humillantes paseos, violaciones, detenciones y asesinatos en Ejea de los Caballeros, Sos del Rey Católico, Tauste, Farasdués o Uncastillo.

\section{Palabras clave}

Guerra Civil española, franquismo, violencia política, violencia sexuada, Cinco Villas.

\section{ABSTRACT}

In the last decades the feminist perspective has contributed to change traditional historiography, improving Spanish Civil War studies by the incorporation of women into the common narrative. 
Due to its specified situation and war context, Aragón is one of the best territories to study and better understand the Spanish conflict. Because of its strong republicanism and socialisms, las Cinco Villas was severely subdued by the Francoism and its violence. The region stayed always in rearguard, because it fell into Franco's hands from the beginning. Women were object of all that repression, including some particular violence that men did not suffered. There were head shaves, humiliating exhibitions, rapes, detentions and murders in Ejea de los Caballeros, Sos del Rey Católico, Tauste, Farasdués or Uncastillo.

\section{Keywords}

Spanish Civil War, francoism, political violence, sexed violence, Cinco Villas.

La introducción de la perspectiva de género (Scott, 1986)' en el estudio de la Guerra Civil a finales de la década de los setenta del siglo xx (Segura, 2006a: 85 y 2006b: 14-16) permitió discernir que las republicanas fueron camaradas y familiares (asesinato, persecución, multas, saqueos, palizas...), si bien en menor porcentaje y con causas y objetivos distintos. Fruto de la conceptualización franquista, meras transgresiones de su moral se convirtieron en delitos (Prieto, 2007: 95), provocando que las mujeres engrosaran las listas de todas las persecuciones. Por otro lado, tuvieron lugar violencias específicas por su sexo conocidas como violencias sexuadas (Joly, 2008): violaciones, el rapado de la cabeza, humillantes paseos e ingestas forzadas de aceite de ricino, torturas que tenían como objeto el vientre, la vagina o los pechos, el ingreso en prisión con sus hijos e hijas más pequeños en condiciones de absoluta insalubridad, ${ }^{2}$ viendo cómo morían hasta por decenas a la semana como según los testimonios ocurrió en la cárcel de Torrero de Zaragoza (Cuevas, 1986: 64); ser insultadas aludiendo a su condición de mujeres y republicanas, o ser obligadas a limpiar iglesias, cuarteles, calles o casas de terratenientes y caciques (Abad, 2009).

Todas estas represiones cuentan con una ingente carga simbólica, relativa al rol que han transgredido y al modelo que se espera que desempeñen en la nueva nación en construcción. Algunas de estas violencias se utilizaron también en el momento de la «Liberación» por parte de las fuerzas antifascistas tras la Segunda Guerra Mundial contra las acusadas de colaboracionismo con los nazis. Las violaciones han sido siempre utilizadas como arma de guerra, y otras humillaciones no son solo eso, sino correctivos a modo de purga simbólica, como las ingestas de aceite de ricino. Lo más significativo de estas represiones radica en que ni las violencias que se aplican

\section{INTRODUCCIÓN}

1. En España fue editado por AMELANG, James S. y NASH, Mary (1990). Historia y género: las mujeres en la Europa moderna y contemporánea. Valencia: Edicions Alfons el Magnànim, Institució Valenciana d'Estudis i Investigació.

2. Para conocer la situación de las mujeres en prisión resultan fundamentales las obras de VInYES, Ricard (2002). Irredentas. Barcelona: Temas de hoy; los trabajos de Hernández Holgado para la cárcel de Ventas; los numerosos relatos recogidos por Cuevas, Tomasa (2005) en Testimonios de mujeres en las cárceles franquistas. Barcelona: Icaria y, para el caso de Aragón: Aragües, Rosa María, Las rojas y sus hijos, víctimas de la legislación franquista. El caso de la cárcel de Predicadores (1939-1945). Madrid: Sanz y Torres.

Para las violencias sexuadas, destaca el reciente trabajo de Prada Rodríguez (2017).

Otra de las nuevas realidades que trajo la guerra fue un altísimo número de huérfanos, volviéndose más dramático cuando lo eran de ambos progenitores. Solo fruto de los asesinatos tras pasar por la cárcel de Ejea de los Caballeros quedaron en esta situación más de setecientos dieciséis niños y niñas (Remón, 2006: 117). 
también contra los hombres, ni obviamente las de carácter sexuado, son una variante de las sufridas por ellos. Al dirigirse contra ellas, constituyen un fenómeno con reglas y rasgos propios en cuanto a la cantidad, la manera en que se manifestó y sus objetivos (Sánchez, 2011: 88).

Para documentar estos fenómenos, nos enfrentamos a problemas evidentes: con el paso del tiempo, cada vez son menos los testimonios orales de primera mano. Por otro lado, trabajar con fuentes orales tiene dificultades específicas: la distancia temporal distorsiona o al menos difumina los recuerdos, como lo hace haberlos vivido en la niñez y recordarlos en la vejez. Asimismo es complejo distinguir cuándo la persona entrevistada ha presenciado lo narrado, lo ha escuchado, o incluso lo ha leído con sumo interés y ha acabado haciendo suyo el recuerdo. Sin embargo, la mayor dificultad en este terreno es la negativa a hablar no ya de quienes vivieron la Guerra Civil, sino de sus descendientes. El dolor, el miedo, la rabia y la inseguridad atravesaron personas y generaciones y construyeron un silencio con sombra alargada. La documentación archivística no es tan accesible como desearíamos y está cargada de lagunas. Fueron muchos los asesinatos que no se inscribieron en el registro civil, ${ }^{3}$ los legajos que se hicieron desaparecer o las trabas que convierten en tarea titánica hallar lo buscado.

La guerra desgarró el tejido social y dislocó la vida cotidiana tal y como se conocía. Quienes acudían al frente sabían qué podía ocurrir. Todas las personas contra las que se dirigió la violencia en este caso eran civiles que hasta el preciso momento de la sublevación fascista continuaban con su vida cotidiana.

En el presente artículo abordaremos distintas represiones a las que el franquismo sometió a las mujeres consideradas enemigas centrándonos especialmente en los asesinatos y las violencias sexuadas. El objetivo principal es profundizar, desde una perspectiva de género, en el análisis de las causas, protagonistas y lógicas de estas violencias. El marco espacial será la comarca aragonesa de las Cinco Villas durante, fundamentalmente, la Guerra Civil.

Entre las fuentes utilizadas destacan las entrevistas orales a protagonistas o familiares directos de estas mujeres; monografías sobre cada tipo de violencia, obras de carácter general sobre la Guerra Civil en Aragón, las Cinco Villas y municipios concretos, así como memorias de los propios protagonistas de la contienda.

Este artículo expone el contexto sociopolítico de la región tras la sublevación para, a continuación, presentar casos concretos de asesinadas, municipio a municipio. Pretende mostrar los rasgos comunes de todos ellos, a partir de lo concreto. Lo mismo ocurre después con casos de represión sexuada, particularmente con el rapado de la cabeza por ser quizá el más visible y utilizado. El balance final del artículo es parcial y provisional, a la espera de continuar con la presente investigación.
3. Según los datos aportados por José Antonio Remón en Ejea 1936: La sombra de una guerra, de las veintiocho asesinadas previamente encarceladas en Ejea, quince no aparecen en el listado publicado en El pasado oculto. Desglosadas por localidad de residencia eran seis de Farasdués, tres de Uncastillo, dos de Alagón, una de Pinseque y una de Castiliscar. Estos datos muestran hasta qué punto las cifras de víctimas mortales que manejamos hasta ahora en función de las defunciones inscritas en los Registros de Defunción podrían engrosarse. 
Aragón es un espacio desgraciadamente ideal para analizar la Guerra Civil. A los pocos días de la sublevación quedó dividido por un eje de norte a sur, siendo un espacio en el que se desarrolló tanto la revolución, como el control férreo por parte de los rebeldes.

Una de las zonas más castigadas por la represión fascista fue la comarca de las Cinco Villas, situada en el extremo noroccidental de la provincia de Zaragoza.

Sus habitantes habían estado muy implicados en la lucha por los montes comunales y la reforma agraria promulgada en 1932. Era una zona con notable tradición republicana y fuerte implantación socialista (Ruiz, 2008a: 9-29). La sindicación se agrupaba a principios de los años treinta, mayoritariamente, en la Unión General de Trabajadores (UGT) y la Federación Nacional de Trabajadores de la Tierra (FNTT). El anarquismo había comenzado a difundirse más tarde y hacia 1936 empezaba a desarrollarse (Remón, 2009: 36). La vida política era entusiasta, con continuas reuniones y actividades en la Casa del Pueblo de cada localidad. Las reformas del gobierno republicano, pese a todo, no permeaban hasta el campo por la negativa del cacicado a aplicarlas (Preston, 2011).

Con la Segunda República, las mujeres se implicaron públicamente en la vida social y política más que antes y de forma más visible. Siempre habían sido sujetos con conciencia política, pero no con derechos; ahora tenían más libertad y herramientas dentro y fuera de su hogar. Un ejemplo llamativo es la asamblea antifascista celebrada en Ejea de los Caballeros el 8 de marzo de 1936, que concentró a cientos de mujeres para luchar contra la guerra y el fascismo; intuían cercana una Segunda Guerra Mundial (Remón, 2006: 20).

Muchas se posicionaron en pro de la República porque además del derecho al sufragio, al matrimonio laico o el acceso a una educación igualitaria, el nuevo Estado se comprometió con el campo al menos discursivamente. Pese a todo, durante los años treinta fueron comunes los conflictos que iban desde ocupaciones de fincas a enfrentamientos armados con las fuerzas de seguridad. Zaragoza era, después de Cáceres, la segunda provincia española en la que la nobleza poseía más propiedades, especialmente en Ejea, Sos, La Almunia o Zaragoza (Casanova et al, 2010: 88). Los sucesos de octubre de 1934 se vivieron con intensidad en toda la comarca (Pueyo, s. f.: 13-14). Aquellas brasas no se habían apagado a la altura de julio de 1936.

Todo lo anterior hace de las Cinco Villas un escenario idóneo para observar las concurrencias de las características propias de la punición femenina por parte de los sublevados desde el inicio de la contienda.

El 17 de julio de 1936 se inició en Marruecos la sublevación militar que llevaba tiempo tramándose. La noticia llegó pronto a Zaragoza, donde el gobernador civil Ángel Vera Coronel se negó a repartir armas entre los 
sindicatos siguiendo órdenes del gobierno central. La madrugada del 19 de julio Miguel Cabanellas, capitán general de la Quinta División, decretó el estado de guerra y se sumó a la sublevación desde Zaragoza (Maldonado, 2007: 25-26). El capitán Miguel Sánchez Blázquez (Barrachina, 2010: 86) partió de allí comandando una columna militar formada por una sección de guardias de la Séptima Compañía de Asalto y por la Cuarta Compañía del Primer Batallón del Regimiento de Infantería Aragón n. 17 para someter las Cinco Villas (Ruiz, 2016:53).

Huidos, presos y asesinados empezaron a pintar un cuadro con pinceladas también femeninas. Los civiles derechistas, armados, se prestaron raudos a organizarse para ejercer la represión que de otra forma hubiera sido imposible realizar. Alistados en Falange, la protagonista principal de aplicar el odio de clase de los terratenientes en esta comarca; pero también como requetés o miembros de Acción Ciudadana, recorrieron cada localidad sembrando muerte y miseria. La columna fascista que primero intervino partió de Ejea de los Caballeros comandada por el teniente y jefe de línea de la guardia civil Eugenio Hernández Santamaría, compuesta por varios camiones que trasladaban soldados, guardias civiles y voluntarios falangistas. Con el beneplácito castrense y de la cúpula religiosa, fue este teniente (Combalía, 2011: 67 y 118), quien facilitó armas a los civiles y uno de los que más fervientemente encabezó la represión. ${ }^{5}$

No se trataba de violencias espontáneas producidas por elementos aislados sino que eran conocidas, instigadas y también perpetradas por elementos militares y quienes se habían hecho con los resortes de poder.

En toda la comarca de las Cinco Villas hubo, inscritos en registro civil, seiscientos treinta y siete asesinatos (Casanova et al., 2010). Más de medio centenar de mujeres fueron asesinadas, con ocupaciones que pasan desde maestras a jornaleras, costureras o amas de casa, de edades muy variadas y desde ateas a firmes devotas. ${ }^{6}$ Forman un conjunto con rasgos comunes pero heterogéneo, teniendo estas violencias un carácter transversal.

Igual que ocurre en el caso de los varones, destacan Uncastillo y Sos del Rey Católico con diecisiete y diez mujeres asesinadas respectivamente (Casanova et al., 2010). En Farasdués, las nueve asesinadas representan el 18\% del total (Remón, 2009: 161). En Zaragoza capital, por ejemplo, son el 4\% para 1936 y algo más del 7\% para el año siguiente. Para la provincia de Teruel en total son el 9,6\% y en Huesca algo más del 11\% (Barrado, 1999: 7-11).

En todos los municipios había prisión, generalmente localizada en la planta baja del ayuntamiento. El centro penitenciario más grande de la comarca fue Ejea de los Caballeros, donde se produjeron quinientos tres ingresos en los primeros cinco meses y medio de guerra (Remón, 2006: 87-88). Las causas de las detenciones eran tan variadas como arbitrarias (Gil, 2010: 294). En el caso de las mujeres iban desde una activa militancia
4. En la memoria colectiva de los familiares de víctimas, Hernández Santamaría ha quedado fijado como una de las cabezas visibles de la represión y responsable de numerosas atrocidades. Así aparece en Cavero, 2005: 39-40 o en Combalía, 2011: 118 , y en las entrevistas orales.

5. José Antonio Remón no da su nombre en op. cit., p. 119, pero es a él a quien alude como responsable de entregar las armas al requeté y Acción Ciudadana.

6. De Cándida Bueno Iso, maestra asesinada, se recoge «en Ejea se le llegó a envolver popularmente con un cierto "halo de santidad", por la profunda devoción religiosa que mostró hacia la Virgen hasta el momento de su muerte [...]» (Remón, 2009: 14 [CD-ROM]). 
a cualquier significación política con la Segunda República por nimia que fuera: haber cosido una bandera republicana, leer prensa a sus vecinos y vecinas, haber asistido a un mitin, haber realizado un comentario considerado ofensivo a la religión o las derechas, su implicación en los sucesos de octubre de 1934, hasta uno de los motivos más comunes: ser pariente o mantener relación próxima con un varón significado de filiación izquierdista: todas tenían en común que sobre ellas recaía la certeza o sospecha de ser «desafectas al Glorioso Movimiento Nacional». El mito de las «feroces rojas», de perversas y sucias salvajes con fascinación por la crueldad, la violencia y el vicio (Ramos, 2007: 96) fundamentó el carácter ejemplarizante de estos castigos.

Por dar algunos datos representativos, en la cárcel de Ejea hubo cincuenta y nueve mujeres detenidas pertenecientes a once municipios distintos. Como ocurre en el caso de los varones, los pueblos más afectados son la propia Ejea con diecisiete reas, Uncastillo con quince y Farasdués con once.

Entre las asesinadas una figura emblemática fue Cándida Bueno Iso, maestra de Castiliscar, que con veintitrés años fue torturada y violada (Remón, 2009:162) antes de fusilada el 16 de septiembre de 1936 junto a su hermano Manuel (Casanova et al., 2010). Ejeana era Julia Abadía Navarro, «la Curra», activa socialista que tuvo que escapar con su hermano y su compañero. Había dejado una hija muy pequeña y el remordimiento la hizo regresar. Fue asesinada el 14 de agosto de 1936, pero su defunción no consta en el registro civil.

De Bagüés era la joven Desideria Giménez Moner, de dieciséis años, militante de las Juventudes Socialistas Unificadas (JSU) y del Socorro Rojo Internacional. Había portado la bandera roja en la manifestación del 1 de mayo. La asesinaron junto con Pilar Vizcarra, embarazada (Remón, 2009: 162). Lo estaba también, de gemelos, la joven uncastillera Basilisa Casaus. Su novio era uno de los dirigentes locales de la Confederación Nacional del Trabajo (CNT), y aunque ella vivía con su familia, habían comprado ya muebles para su nueva casa (Ruiz, 2008b: 22). Le faltaban una o dos semanas para alumbrar según el médico del pueblo, por lo que tanto la guardia civil como los falangistas decidieron esperar para matarla. Según los testimonios fue un primo suyo, sacerdote, quien se interpuso para que el asesinato se cometiera cuanto antes, como así fue: «muerto el animal, muerta la rabia» (Pueyo, s. f.: 21). Desconocemos cuándo la asesinaron pero sabemos que hicieron lo mismo con su hermano.

En Sos del Rey Católico la columna comandada por Miguel Sánchez Blázquez encontró resistencia, produciéndose dos tiroteos el 20 de julio de 1936 entre la guardia civil, apoyada por voluntarios locales y vecinos de izquierdas. Saturnina Arbea Villacampa, con doce hijos, fue alcanzada por los disparos y falleció poco después en su casa. En el primer tiroteo resultó asesinado Mariano Legarre Mínguez; al acabar la jornada hubo más de noventa

7. Este episodio se narra también en Remón, 2006: 125. 
detenidos. Ambos fueron enterrados de forma anónima y sin que se informara a sus familias de la localización del enterramiento y sus restos fueron exhumados en 2013 (Ruiz et al., 2015: 165-170).

Después fueron asesinadas al menos diez mujeres sosienses más: tres de la misma familia (Asunción, Adela y su hija Pilar). Quizá el caso más conocido sea el de Pilar Bueno Ibáñez, modista de veintisiete años y afiliada al Partido Comunista de España (PCE) al poco de iniciarse la guerra. La eligieron para formarse en la Escuela de Cuadros del Partido y al finalizar la contienda le encomendaron formar parte de la reorganización de los comunistas y constituir ocho sectores en Madrid. Fue una de las «Trece Rosas» asesinadas en el cementerio del Este de Madrid el 5 de agosto de 1939 (Remón, 2009: 165-166). Antes habían perdido la vida, entre otras, Clementina Remón Soteras, de treinta y ocho años ${ }^{8}$ y la joven Encarnación Compains Bandrés, de tan solo dieciséis, el 3 de agosto de 1936 —dos días antes habían asesinado a sus padres en Zaragoza- Las dos fueron detenidas en Sos y conducidas junto a diecisiete hombres ${ }^{9}$ hasta Sádaba para ser arrojadas a una fosa común con todos ellos.

En Sádaba asesinaron a varias vecinas: Martina Luna, de treinta y cuatro años, era apodada «la Calderona», por su esposo José Calderón Bermejo. Fue detenida junto a Elena Cortés, de cuarenta y siete años, conocida como «la Churrera», por robar remolacha en el campo. Las obligaron a pasear por el pueblo con un cartel en el que se leía «por robar remolacha», escoltadas por falangistas. Fueron después encarceladas en el ayuntamiento de Sádaba. Tras raparlas, las fusilaron el 29 de agosto de 1936 en el cementerio de Castiliscar. Martina tenía tres niñas pequeñas; Elena Cortés supo de la muerte de su hijo diecisiete días antes de ser asesinada (Cavero, 2005: 22-24).

La sadabense asesinada más conocida fue Pilar Salvo Jiménez, maestra en Zaragoza y reconocida miembro del Partido Socialista. Se encontraba veraneando en su pueblo natal en compañía de su esposo y sus tres hijos pequeños. Fue allí detenida para fusilarla en Zaragoza el 22 de agosto de 1936 (Ibidem: 20). Había destacado como militante feminista en Zaragoza, alentando a las mujeres a invadir la esfera pública. En el gran mitin organizado en 1931 por la Asociación del Magisterio Nacional Primario ${ }^{10}$ de los partidos Zaragoza-Sos, Pilar comenzó su discurso diciendo que «para organizar la España del orden, la España que está en el corazón de todo buen patriota, se precisa que la mujer esté al lado del hombre», abordando después lo que llamó «el deber de la mujer en el momento actual»." En el periódico República escribió su opinión favorable al divorcio (Remón, 2009: 165). Para el primer aniversario de la República, Vida nueva publicó reflexiones de militantes de la izquierda zaragozana sobre el nuevo gobierno. Ahí lanzó una crítica a las que no se posicionaban del lado progresista: «Y tú mujer, sal de tu letargo; si no amas aún a la República como ideal sentido,
8. En el Registro de Defunción de Sos figura con una edad de cincuenta años. Su familia y otra documentación certifican que no era así. Entrevista a Á. R. D.

9. Entrevista a Á. S. L.

10. El magisterio fue uno de los sectores profesionales más atacado por el franquismo, especialmente el de primaria, sufriendo una de las depuraciones más severas. Morente Valero, Francisco (1997). La depuración del magisterio nacional (1936-1943). Valladolid: Ámbito. También en este caso los maestros fueron cuantitativamente más sancionados que las docentes. Fernández Soria, Juan Manuel y Agulló Diaz, María del Carmen. «Depuración de maestras en el franquismo». Studia historica (17), 259. RAmos, Sara (2013). «Educadoras, maestras: depuradas por su profesión». En Nash, Mary (ed.), Represión, resistencias, memoria. Las mujeres bajo la dictadura franquista. Granada: Comares, 66.

11. «El domingo se celebró el gran mitin organizado por la Asociación del Magisterio nacional primario de los partidos Zaragoza-Sos» (16 de junio de 1931), La Voz de Aragón, 1. Disponible en: https://prensahistorica. mcu.es/es/catalogo imagenes/grupo. do?path $=1000377576$ 
tienes la obligación de amarla por gratitud».12 El 4 de mayo de 1933, en el Casino del Arrabal de Zaragoza, había impartido una conferencia bajo el título «Consideraciones sobre los derechos ciudadanos que la mujer ha recibido de la República» (Illion, 2002: 297-298). También su militancia fue muy activa en el ámbito de la educación. ${ }^{13}$

Uncastillo fue uno de los municipios que más población perdió. Diecisiete fueron las mujeres a las que se dio caza; a diez de ellas las detuvieron falangistas del pueblo la noche del 30 de agosto de 1936, yendo de casa en casa, para encerrarlas en los calabozos del ayuntamiento y conducirlas, al amanecer, a la cárcel de Ejea en un camión. El 31 de agosto las llevaron al cementerio de Farasdués, donde se encuentran en la actualidad sus restos en una fosa común. Según parece, pidieron rezar el rosario antes de ser fusiladas.

La primera de ellas era Lorenza Arilla Pueyo, de sesenta y un años. Tenía tres hijos, convencidos izquierdistas, que servían en ese momento en el ejército republicano. Narcisa Pilar Aznárez Lizalde era la hermana de dos destacados militantes cenetistas huidos. Con treinta y dos años, era una mujer culta que no pudo despedirse de sus tres hijas. Inocencia Aznárez Tirapo tuvo ocho hijos. Al menos uno de ellos, José, era un conocido socialista que combatió en el batallón Cinco Villas. Solía leer el periódico a sus vecinas, con las que se juntaba asiduamente a coser ganchillo. Doce días antes que ella fue asesinada su hermana Agapita, que residía en Ejea de los Caballeros. Estaba afiliada a la UGT y su hijo mayor, Julián, además de ser de UGT era miembro del PCE. Fue detenida el 18 de agosto, el mismo día que otros nueve uncastilleros, pero por el momento desconocemos el lugar en el que fueron asesinados.

Julia Claveras Martínez vivió durante los primeros días de guerra el asesinato de su esposo Antonio, jornalero socialista, y de su hermano Florencio. Los dos habían estado implicados en la revolución de octubre de 1934, siendo condenado el segundo a veinte años y un día de reclusión mayor. Julia fue detenida el 30 de agosto de 1936 y asesinada al día siguiente junto a sus nueve vecinas. Su casa fue posteriormente desvalijada. La esposa de Florencio, Isidora Gracia Arregui, era también una reconocida socialista y dos de sus hermanos habían huido a zona republicana. Tras perder a su esposo fue asesinada dejando tres hijos pequeños: Sara, a la que se llevó una familia de militares a Zaragoza, Lisardo y Rubén.

Melania Lasilla Pueyo era hermana del teniente de alcalde socialista de Uncastillo, Manuel. Asistió al asesinato de dos de sus seis hijos, Antonio y Jesús, antes de recibir ella la misma suerte. Otra de las diez detenidas y asesinadas el mismo día fue Felisa Palacios Burguete, de cincuenta y tres años. A pesar de ser religiosa, en el expediente de Responsabilidades Políticas incoado contra ella la acusan de «libertaria» y de distinguirse «por sus ideas
12. «También yo contesto a esta pregunta: ¿Qué impresión le ha causado el primer año de República?», Vida Nueva, 2, 16 de abril de 1932. Disponible en: https://ifc. dpz.es/recursos/publicaciones/28/58/ vidanueva092.pdf

13. Siendo directora de las escuelas Jimeno Rodrigo, fundó una biblioteca en el barrio de las Delicias de Zaragoza (Illion, 2002: 298). 
avanzadas». Dos de sus hijos y una hija eran afiliados a las Juventudes Socialistas, mientras otro pertenecía a la CNT.

Andresa Viartola García no tenía filiación política y tuvo un solo hijo con Marcos Arregui Pérez, ugetista preso en la cárcel de Torrero (Zaragoza) tras octubre de 1934. Después del golpe de Estado intentó huir a Francia, pero fue asesinado. Marcos ya había escapado al monte cuando fueron a buscarlo a su casa; probablemente por eso se llevaron a Andresa.

Leonor Villa Guinda tenía tres hijos y vivía también con sus hermanos, socialistas, Pablo y Santos. El primero logró alcanzar Francia, pero el segundo fue asesinado (Ruiz, 2008b: 10-45).

Josefa Casalé Suñén dejó seis hijos. Con treinta y nueve años bordaba y cosía para mantener la economía familiar. De formación autodidacta, daba clases nocturnas en su domicilio a quienes por trabajar no habían podido ir a la escuela. Tan republicana como católica, tenía su propio reclinatorio en la iglesia que tras asesinarla tiraron a la calle. Ella y la esposa de su hermano Juan Pablo, también asesinado, hicieron unas rosas rojas de papel tras la revolución de 1934 que vendían para ayudar con el beneficio a los presos (Idem). Cuando se encontraba junto a las demás en la prisión de Ejea, escribió una carta de despedida que pudo llegar a sus familiares porque tenía parentesco con uno de los guardianes de la cárcel:

Queridos esposo, madre e hijos:

Os escribo desde Ejea para deciros que no os apuréis por nada, que Dios no desampara a nadie. Yo estoy muy conformada, pues bien sabéis lo que he sido.

María, te escribo a ti más que a nadie para encargarte cuides mucho a tus hermanos. Si no puedes no vayas a la escuela y cuida muy bien de casa y de la abuela, que cuando seas mayor ya aprenderás [... .]

Manolo, hijo mío, no faltes a nadie como lo has hecho hasta ahora y cuida de tus hermanos y no riñáis. Sed buenos hermanos.

María, rézale a la Virgen todos los días por tu madre y enséñales a tus hermanicos todas las cosas buenas que yo te he enseñado a ti. Sobre todo lleva a tus hermanos bien limpios y del vestido de lana que hay en el baúl que te hagan un vestido a ti y todo lo que no te valga a ti guárdalo para tu hermanica. Tenéis muy buen padre y os cuidará mucho $[\ldots]$

Os repito que seáis buenos, que sigáis los consejos de vuestra madre, y tú, María, déjate corregir por tus tíos y primos y sé obediente, pues tus tíos se portarán bien con vosotros, pues yo tengo la tranquilidad que no os dejarán solos, y la abuela que no llore, que son cosas que Dios las prepara así y tenemos que tener conformación [...]

Recibid, pues, muchos besos y abrazos para vosotros, para la abuela, para los hermanos y para tu padre igual le digo pues como es bueno nada tengo que advertirle.

A casa tía Ramona lo que quieran, pues nada les digo.

Quien os quiere mucho.

Josefa Casalé

(Ruiz, 2008a: 66-67). 
Con la certeza de que iba a morir, traspasaba la responsabilidad del mantenimiento de la vida del hogar a su hija mayor, María. Encomendaba a su hijo respeto y buen comportamiento y daba las directrices básicas de lo que ella hacía hasta entonces.

Algunas, antes de ser asesinadas, sufrieron más violencias. Otras se enfrentaron a ellas pero pudieron seguir viviendo a pesar de ello. El rapado de la cabeza destaca por haber sido utilizado como humillación pública desde la Antigüedad, para retomarse en este contexto (Buil, Heredia, Marías, 2012: 9). Según uno de los mayores especialistas, el historiador Fabrice Virgili, «el rapado es una violencia punitiva que opera mediante la mutilación de la cabellera. Es violencia porque se ejerce bajo conminación, punitiva porque siempre hace referencia a un acto anterior reprensible, y es una mutilación porque se trata, por cierto, de una lesión a la integridad física» (Virgili, 2007: 100). Lo que se les arranca es el símbolo externo de feminidad por antonomasia en aquel contexto, dándoles un aspecto andrógino, dado el marcado dimorfismo sexual entre el peinado de hombres y mujeres, que visibilice que no son consideradas auténticamente mujeres sino seres contaminados por el virus marxista.

Rapadas hubo en prácticamente todas las localidades cincovillesas, documentándose cincuenta y seis en Sádaba (Cavero, 2005: 35), dos en Longás, veintidós en Urriés (Ripalda, 2013: 183), las mismas en Rivas (Gil, 2011: 173), otras tantas en un solo día en Ejea de los Caballeros (Remón, 2009: 163), más de cincuenta en Luesia (Pueyo, 2008: 124), unas veinte en Orés (Peiró, 2017: 22) y casi medio centenar para Uncastillo.

Para Sádaba, Ismael Cavero cita seis parejas de hermanas, varias madres e hijas, una joven de quince años y una anciana de setenta. Entre ellas se encontraban las asesinadas Martina Luna y Elena Cortés, o las jóvenes hermanas Rosa y Elisa Senao Echegoyen. Sus rapadores eran naturales y vecinos de Sádaba. Rosa, tras casarse, vivió en Argentina; Elisa residió en Barcelona, pero veraneaba en su pueblo. En uno de esos periodos se encontró a su «peluquero», ya con una espesa melena negra, y se enfrentó a él: «Mira qué pelo más largo. ¿Qué pensabas, que no me iba a crecer?».14 Teniendo en cuenta el contexto de posguerra, el poder de las fuerzas vivas de la localidad y la sucesión de violencias que estas familias habían sufrido, estos actos constituyeron auténticos ejercicios de resistencia civil. Quienes ejercían la violencia eran hombres pero también mujeres. En ocasiones se obligaba a los republicanos a raparlas, llevando la degradación al límite. En el caso de Rosa y Elisa Senao Echegoyen, como ocurrió masivamente, su padre y su hermano se encontraban luchando en el frente republicano, lo que pudo resultar decisivo para que fueran rapadas. Dada la relevancia de la familia como célula del tejido social en aquel contexto —-siendo una realidad potenciada además por el discurso franquista y la Iglesia católica-, estos castigos no parecen responder a un ataque meramente físico

14. Entrevista a Antonio Senao, sobrino de Rosa y Elisa. 
contra quien se impone directamente, sino que su enorme carga simbólica irradia esa violencia contra los familiares y, por extensión, contra todas y todos los republicanos y antifascistas pero, principalmente, contra los parientes varones que no estaban para defenderlas.

Jacinta Murillo Arnalé era la mayor de siete hermanas. Su padre, el ejeano Fermín Murillo Morlana, fue asesinado dejando a una viuda con una dificilísima situación para mantener tal familia. Poco después, con algo menos de veinte años, Jacinta dio a luz tras un parto de nalgas en el que casi pierde la vida. Tras ello su madre fue al río Arba a lavar las ropas del parto. Al regresar, Jacinta no estaba. Guardias civiles junto a algunos vecinos se la habían llevado al cuartel de la guardia civil de Ejea para raparla. Como era habitual allí, fueron falangistas ejeanas quienes lo hicieron. ${ }^{15}$ Cuando la levantaron de la silla, estaba empapada en sangre. Después la pasearon haciéndole cruzar todo el pueblo. Jacinta tardó meses en salir de casa. El trigo almacenado, los animales y otros bienes de la familia fueron saqueados. ${ }^{16}$

Fue precisamente que el rapado fuera una práctica más bien arbitraria al utilizarse contra mujeres de distintos perfiles y con niveles muy diferentes de implicación republicana, así como el hecho de que ninguna fuera inmune a sufrirlo, lo que acrecentó el terror que generaba la posibilidad de ser víctima de ello, sirviendo como poderoso mecanismo de control social.

De las veintidós rapadas de Rivas, una estaba embarazada de siete meses: era Victoria Jiménez Lafita. Junto a más mujeres, fue conducida a pie a Ejea, a unos seis kilómetros, bajo la amenaza de sus propios vecinos de que además de raparlas les cortarían la cabeza. Una vez allí, tras cortarles el pelo, fueron paseadas por las calles principales del pueblo. A su regreso, fueron obligadas a repetir el macabro espectáculo por Rivas, custodiada cada una por dos guardias civiles. Los vecinos lo presenciaron, unos con gozo; otros con horror y rabia. Mientras no tuvieron pelo, no les dejaron cubrirse la cabeza; debían llevarla al descubierto. Se trata de una práctica común asociada a esta violencia; permitirles taparse con un pañuelo anula su carácter punitivo: la visibilidad pública del castigo y la humillación que eso conlleva son las piedras angulares del objetivo del rapado. El cuerpo de la agredida queda marcado como excluido del tejido social. Puede ocultar su ideología, esconder sus insignias o sus lecturas habituales, pero no logrará no ser vista por toda la comunidad como una roja.

Victoria sabía leer y escribir y no estaba implicada en política. Su boda con Ramiro Caudevilla Pérez fue el primer matrimonio civil de Rivas, celebrado junto al de otra pareja más. El mismo día del enlace tuvo que enfrentarse a dos mujeres que invadieron su casa amenazándola duramente y sobornándola para que cejase en su empeño de desposarse sin pasar por la Iglesia. ${ }^{17}$ Ramiro era una de las figuras emblemáticas del socialismo riverano. Había sido alcalde pedáneo de Rivas con la Segunda República desde
15. Lo mismo ocurrió en el caso de Luesia, donde mujeres se ofrecieron a cometer esta purga, aunque en este caso no hicieron desfilar a sus vecinas. En esta localidad no hubo agresiones sexuales; sí quienes pensaron en hacerlas (Pueyo, 2008: 124).

16. Entrevista a Rosablanca Lapuente Murillo, sobrina de Jacinta Murillo.

17. «Rivas. Dos bodas». Vida Nueva, 3, 29 de abril de 1933. Disponible en: https:// ifc.dpz.es/recursos/publicaciones/28/58/ vidanueva146.pdf 
1934 (Gil, 2011:47) y era concejal (Ibidem: 111) en el ayuntamiento de Ejea en el momento de la sublevación (Lambán y Sarriá, 2001: 108-109). El matrimonio regentaba un horno de pan, y aunque falangistas de la localidad fueron a buscarlo a él en incontables ocasiones, pudo sobrevivir escondido varios años en la bóveda del horno. Tras saquear sus bienes, la familia se veía obligada a entregar seis panes de un kilo cada uno a los falangistas que les acosaban. ${ }^{18}$

Ascensión Lasilla recordaba una coplilla que, como en tantos pueblos, las rapadas y sus familias tenían que soportar en Rivas:
A todas las de esta casa;
les hemos cortado el pelo
y si tomamos Madrid
les cortaremos el cuello.
(Ibidem: 173)

Se trata del hecho más conocido de violencia contra las mujeres en Aragón, y con seguridad el más difundido en las Cinco Villas. Las hermanas Lourdes y Rosalio Malón Pueyo, de dieciocho y veintitrés años respectivamente, eran vecinas de Uncastillo. Costureras y afiliadas a las JSU, vivían con su madre, Francisca, su padre Francisco y su hermano Mariano, estos últimos también socialistas.

El novio de Lourdes era Ricardo Lalanza Ruiz, implicado en los sucesos revolucionarios de 1934. Rosario salía con Leandro Rived Palacios, conocido socialista que logró salvar la vida durante la Guerra Civil pero perdió a su madre, Felisa Palacios Burguete, asesinada en el cementerio de Farasdués.

Varios falangistas se personaron en el hogar familiar preguntando a Francisca dónde estaban los demás miembros de la familia: «No lo sé, pero aunque lo supiera no os lo diría». Tras abofetearla la llevaron a la cárcel de Uncastillo. Fue fusilada en las tapias del cementerio de Luesia y enterrada allí (Ruiz, 2017: 84), probablemente el 2 de agosto de 1936, junto a otros de sus vecinos como el matrimonio de Josefa Guinda Micaley y Juan Arregui Biota, que dejó tres hijos pequeños (Ruiz, 2008b: 33-37).

Para entonces una veintena de uncastilleros decidió refugiarse en las Peñas de Santo Domingo, a más de 1500 metros de altura, en la cercana localidad de Longás. Entre ellos se encontraba la familia Malón. Con el paso de los días se corrió la voz y se organizó una batida de falangistas procedentes de pueblos de la Valdonsella al mando de Francisco Ripalda Roncalés, teniente retirado de la guardia civil, y de Juan Jiménez Ruesta, jefe local de Falange en Urriés. Alcanzaron la cota la madrugada del 20 de agosto de 1936 (Ruiz, 2016: 53).
El caso de las hermanas Malón

18. Entrevista a Ramiro Caudevilla Giménez, hijo de Victoria Jiménez Lafita y Ramiro Caudevilla Pérez. 
Lourdes, Rosario, Mariano y Francisco dormían en una pequeña cueva. Tras dar la voz de alarma, las jóvenes fueron las primeras en salir: Rosario recibió la primera descarga y murió en el acto; Lourdes quedó malherida. Tras intentar refugiarse en unos matorrales, fue de nuevo alcanzada por los disparos. ${ }^{19}$ Según los testimonios recogidos, a la mañana siguiente izquierdistas de Longás fueron obligados a enterrar los restos con orden de prenderles fuego primero.

Padre e hijo lograron escapar, siguiendo rumbo hacia Huesca, leal a la República. Francisco murió al poco tiempo, agotado y destrozado tras haber vivido el asesinato de su esposa y sus dos hijas. Mariano logró alcanzar la capital oscense y se alistó en la 127 Brigada Mixta, conocida como «la Roja y Negra», en la que combatió hasta el final de la guerra.

La familia ha mantenido muy vivo el recuerdo de todos ellos. Guardan trabajos de costura de las jóvenes y otros objetos. Siempre han querido recuperar los restos, lo que no fue posible en el caso de Francisca Pueyo. Dos campañas de localización en el cementerio de Luesia en 2016 y 2017 resultaron negativas. En el caso de las Peñas de Santo Domingo fueron necesarias cuatro campañas de excavación. En el interior de la cueva se encontraron unas tijeras de costura que en la actualidad los familiares guardan enmarcadas. Ambas hermanas fueron las encargadas de coser una bandera republicana por petición del Partido Socialista (Pueyo, s. f.: 16) que la propia Rosario portó en la gran manifestación del 14 de abril de 1932 en Uncastillo. Es este un lugar común de muchas de las víctimas mortales femeninas de la violencia franquista. En una época en la que coser era una labor cotidiana, muchas mostraron su afecto al progreso elaborando las banderas que luego se lucieron en manifestaciones y casas del pueblo. ${ }^{20}$

Finalmente, en 2017, se localizaron los restos de Rosario Malón enterrados en una fosa individual.

La historia oral y los rumores difundidos por la comarca han recogido que fueron violadas. Así consta también en la multitud de publicaciones tanto locales como de carácter más general. Existieron incluso declaraciones directas de testigos que dijeron presenciarlo, transmitidas por sus hijos. ${ }^{21}$ Por el contrario, la familia lo niega. Mariano Malón regresó ese mismo día al lugar de lo ocurrido para cubrir a sus hermanas con losas; así no las atacarían las alimañas. Según transmitió a su hijo, se detuvo a mirar bajo las ropas si sus hermanas habían sido sexualmente agredidas, sin encontrar evidencia alguna. Rosario murió en el acto; parece descartable que fuera violada. En el caso de Lourdes, que quedó malherida, sería verosímil dado el modus operandi de las fuerzas franquistas en otros escenarios. Además, por su juventud y compromiso político era la figura idónea para recibir esta violencia. Por otro lado, los testimonios recopilados no pueden obviarse. Que todas las personas ajenas a la familia, incluso algún miembro de la misma, difieran de la versión de
19. Entrevista a Félix Onco López.

20. Entrevista a Mariano Malón Mendi, hijo de Mariano Malón Pueyo.

21. Entrevista a O. A. B. 
los parientes directos de Lourdes y Rosario, hace pensar en lo que tiene de protección hacia ellas negar un suceso así por parte de los familiares más cercanos. En una sociedad profundamente puritana, era el acto más vergonzoso al que una mujer y su familia podían enfrentarse. Atacaba su dignidad hasta la médula en una sociedad en la que el decoro no entendía de ideologías, siendo insignia de presentación pública para cualquiera. De ahí precisamente que se utilice como castigo tanto contra ellas como hacia sus parientes varones $y$, por otro lado, que sea una violencia habitual. Quizá por eso se dio por hecho que se había cometido y la versión convertida en rumor masivo haya calado hasta la última aldea de las Cinco Villas.

Todos los aquí recogidos son solo algunos de los datos de cómo el franquismo intentó aniquilar a muchas familias a través de la persecución de sus mujeres. Al asfixiarlas a ellas la vulnerabilidad se extendía sobre sus allegados. Resistieron macabras humillaciones para después tener que convivir durante décadas con sus verdugos. Sin embargo, estas son solo algunas historias femeninas de entre los miles que se vivieron en la comarca, pero ejemplifican lo vivido en Aragón y todo el Estado.

Aunque en las Cinco Villas no hubo frentes ni se dieron combates salvo pequeños focos de resistencia los primeros días tras el 18 de julio de 1936, las violencias que se aplicaron fueron durísimas, de todos los espectros posibles, y alcanzaron absolutamente a toda la población.

Las causas de la violencia contra ellas, como hemos visto, radican en su participación, de ellas o sus parientes más cercanos, en actividades de carácter sociopolítico. Sufrieron mecanismos represivos que demuestran tener en el género el engranaje principal de su maquinaria. Lo que se regulaba era la relación entre ambos sexos y el lugar que cada persona debía ocupar en la sociedad en función de ello. Todo respondía a una marcada ideología de género que expresaba los intereses del que sería un Estado virilizado, jerárquico y patriarcal. Lo pretendido era crear una nueva nación con una base social de la que se hubiera extirpado toda contaminación marxista o judeomasónica: purificada. Las revoluciones y conflictos bélicos (Cenarro e Illion, 2014: 14) son escenarios en los que las categorías sexo y género se vuelven tan relevantes como la religión, la etnia o la raza según el contexto. Los porcentajes de asesinadas son por ello menores en el caso de las mujeres; el objetivo no era aniquilarlas físicamente, salvo en un primer momento de máxima pulsión violenta y en el caso de considerarlas individuas que se deben eliminar. Se las anulaba moral, psicológica y socialmente (Sánchez, 2009).

Respecto a los asesinatos, siguen la misma lógica que en el caso de los varones: durante toda la guerra se distinguen dos etapas fundamentales. 
La primera, de «terror caliente» (Casanova, 1999), alude a la intensidad de la violencia; durante ella mueren entre el 70 y el $80 \%$ de las víctimas totales ${ }^{22}$ y dura hasta el invierno de 1936. Se caracteriza por dos rituales que de nuevo se dan en el caso de las mujeres que aparecen aquí: el paseo y la saca. Las presas eran sacadas del lugar de reclusión y conducidas en camiones, generalmente al amanecer, hasta el lugar de fusilamiento. En noviembre de 1936 daría comienzo el segundo periodo de «terror frío» en el que la mayor parte de las víctimas pasan un consejo de guerra integrado por militares sublevados sin ninguna garantía legal. La represión de retaguardia se ralentiza a partir de entonces, dosificándose..$^{23}$

Fruto de tanta muerte, se perdió notable mano de obra joven y miles de familias quedaron sin el sustento principal del jornal paterno, habitualmente con un alto número de hijos pequeños, con hogares saqueados y/o haciendo frente a incautaciones o multas fruto de expedientes de responsabilidades políticas: una situación límite de supervivencia para las raquíticas economías de posguerra (Álvarez, 2017). Cuando ellas sobrevivieron, se enfrentaron además a mantener la vida de los suyos que se encontraban en prisión. Crearon sus redes de supervivencia y solidaridad ${ }^{24}$ y resistieron los embates de un gobierno y de una sociedad que continuaría acechando y persiguiendo con cada oportunidad.

Como se indicaba en la introducción, la investigación desde una perspectiva de género de la Guerra Civil choca con muros particulares, como una carencia añadida de documentación, ya que ni violaciones, rapados o acosos dejaron esta huella. Si ellos callaron, ellas enmudecieron en la mayoría de los casos. Las violaciones prácticamente se han transmitido solo cuando hubo testigos y estos no fueron de la familia, o se han hecho evidentes cuando fruto de ellas hubo embarazos.

El caso de los rapados se documenta con algo más de facilidad porque fueron visibles, o porque al ser una agresión traumática pero de relativamente fácil recuperación física y no atacar el pudor de forma tan férrea como una violación, sí fue recordado por ellas o contado a sus descendientes. El acoso cotidiano, los insultos, la opresión y el desprecio de clase patente en cada rincón de la vida fueron más aparentes en la memoria de estas mujeres.

Por todos esos motivos es complejo llegar a un acuerdo de cifras en cuanto a la represión a gran escala; se requieren estudios minuciosos. Lo que sí destaca siempre al desagregar los datos por sexo es el porcentaje menor de violencia contra las mujeres. Se concluye de estas investigaciones que «el estudio de la represión es [...] un ejemplo excelente de las insuficiencias que ofrece el método cuantitativo. Así, el recuento de víctimas debe ir acompañado necesariamente de unas consideraciones cualitativas» (Ortiz, 2004: 210).

Si ha habido guerras civiles en España, la Guerra Civil con mayúsculas es sin duda la ocurrida entre 1936 y 1939. Es Ilamativo el nivel de filiación,
22. El $80 \%$ de los asesinatos ocurridos en la provincia de Zaragoza tuvieron lugar en 1936. En otros casos como Navarra la cifra aumenta hasta el $90 \%$. Los porcentajes de Zaragoza se repiten en el caso de las demás provincias más sangrientas en aquellos meses, como Córdoba, Granada, Sevilla o Badajoz (Casanova, 1999: 64-65).

23. Lo mismo señala para el caso de las islas Baleares, aunque situándolo algunos meses después, el historiador David Ginard. Como él indica, este fenómeno forma parte del proceso de centralización del poder político que se experimenta en ambas retaguardias (Ginard, 2011: 16).

24. Para profundizar en esta cuestión es imprescindible la publicación de MURiLLo Abad, Irene (2013). En defensa de mi hogar y mi pan: Estrategias femeninas de resistencia civil y cotidiana en la Zaragoza de posguerra, 1936-1945. Zaragoza: Prensas Universitarias de Zaragoza. 
organización y músculo que tenía la política izquierdista en los años treinta, sus reivindicaciones y movilizaciones. Conocemos numerosos episodios en los que el enfrentamiento entre patronos, terratenientes y caciques con los jornaleros adquirió tintes dramáticos. Los primeros no estaban dispuestos a reducir mínimamente sus privilegios ni déspotas actitudes; los segundos no podían sobrevivir más en sus condiciones de miseria, sumisión y esclavitud. Existían soluciones para mejorar las condiciones de vida de la clase obrera, pero una parte de la sociedad no iba a permitirlo. Si hubo guerra fue porque un sector poderoso de la sociedad la gestó y otro muy amplio la apoyó; solo con el uso de la violencia, por muy desmedida que esta fuera, ningún régimen podría haberse sustentado tan largo tiempo. La oligarquía, de la mano de la Iglesia y el ejército, afianzó de nuevo su hegemonía.

Por último, podríamos decir que el 1 de abril no acabó realmente la guerra para quienes tuvieron que sobrevivir en un clima absolutamente hostil y habiendo perdido familiares y bienes. Tras décadas de dictadura llegaron otras de pasividad y atisbos de reparación, pero decenas de miles de personas continúan sin recuperar los restos de sus familiares, y muchas de ellas sin saber ni siquiera dónde se encuentran.

\section{ENTREVISTAS ORALES}

Entrevista a Antonio Senao

Entrevista a Á. R. D.

Entrevista a Á. S. L.

Entrevista a Félix Onco López

Entrevista a Mariano Malón Mendi

Entrevista a O. A. B.

Entrevista a Ramiro Caudevilla Giménez

Entrevista a Rosablanca Lapuente Murillo

\section{FUENTES DOCUMENTALES}

Periódico La Voz de Aragón

Periódico Vida Nueva

\section{BIBLIOGRAFÍA}

Abad BuIL, Irene (2009). «Las dimensiones de la "represión sexuada" durante la dictadura franquista». Jerónimo Zurita (84), 64-86. Disponible en: https://ifc.dpz.es/recursos/publicaciones/29/60/05abad.pdf 
—, Heredia Urzáiz, Iván y Marías Cadenas, Sescún (2012). «Castigos "de género"y violencia política en la España de Posguerra. Hacia un concepto de "represión sexuada" sobre las mujeres republicanas». En IBArRA AguirREGABIRIA, Alejandra (coord.), No es país para jóvenes: Actas Encuentro Jóvenes Investigadores de la Asociación de Historia Contemporánea, 1-18.

Álvarez, M. ${ }^{a}$ Concepción (2017). «Las víctimas ocultas del expolio: Las mujeres ante la represión económica durante el primer franquismo». Historia del Presente (30), 35-48.

BarRachina, Pedro (2010). «La guerra de columnas en el frente de Zaragoza (verano e invierno de 1936)». En Martínez de Baños, Fernando (coord.), Guerra Civil en Aragón VII. Zaragoza: Delsan, 65-179.

BarRado Gracia, Javier (1999). «Mujeres y derrota. La represión de la mujer en el Teruel de la posguerra». Tiempos de silencio: Actas del IV Encuentro de Investigadores del Franquismo. Valencia: Universitat de València, 7-11.

Casanova Ruiz, Julián (1999). «Verano sangriento». En JuliA, Santos (coord.), Víctimas de la Guerra Civil. Madrid: Temas de hoy, 57-80.

- et al. (2010). El pasado oculto: Violencia y fascismo en Aragón (1936-1939). Zaragoza: Mira Editores.

CAVERo, Ismael (2005). Memoria de la Guerra Civil en Sádaba. Edición propia.

CenarRo, Ángela e luıon, Régine (2014). Feminismos: Contribuciones desde la historia. Zaragoza: Prensas Universitarias de la Universidad de Zaragoza.

Combalía Pérez, Marino (2011). Uncastillo, 1918 - Río de Janeiro, 2000. Zaragoza: Asociación Charata para la Recuperación de la Memoria Histórica de Uncastillo.

Cuevas, Tomasa (1986). Mujeres de la resistencia. Barcelona: Siroco.

Fernandez Soria, Juan Manuel y Agulló Diaz, María del Carmen. «Depuración de maestras en el franquismo». Studia historica (17), 249-270.

GIL MoYA, Emilio (2011). Historia del sindicalismo y el socialismo en Rivas: 19291939, una década que dejó huella. Zaragoza: editorial desconocida.

GIL VICO, Pablo (2010). «Derecho y ficción: la represión judicial militar». En EsplNosA, Francisco (ed.), Violencia roja y azul: España 1936-1950. Barcelona: Crítica, 251-368.

GINARD, David (2011). «Dona i repressió sota el franquisme. El cas de les Illes Balears». En GINARD, David (coord.), Dona, Guerra Civil i franquisme. Palma: Documenta Balear, 147-194.

ILıon, Régine (2002). Mujer, política y sindicalismo: Zaragoza 1931-1936. Zaragoza: Institución «Fernando el Católico».

Joly, Maud (2008). «Las violencias sexuadas de la Guerra Civil española: paradigma de una lectura cultural del conflicto». Historia Social (61), 89-107.

Lambán Montañés, Javier y Sarriá Contín, Jesús (2001). La ll República en Ejea de los Caballeros: Las ideas y los personajes. Ejea: Círculo de opinión «González Gamonal». 
Maldonado Mora, José María (2007). El frente de Aragón: La Guerra Civil en Aragón (1936-1938). Zaragoza: Mira Editores.

Morente Valero, Francisco (1997). La depuración del magisterio nacional (19361943). Valladolid: Ámbito.

Ortiz HeRAs, Manuel (2004). «Instrumentos "legales" del terror franquista». Historia del Presente (3), 203-220.

Peiró Arroyo, Antonio (2017). Eva en los infiernos: Mujeres asesinadas en Aragón durante la Guerra Civil y la posguerra. Zaragoza: Comuniter.

Prada Rodríguez, Julio (2017). «Escarmentar a algunas y disciplinar a las demás: Mujer, violencia y represión sexuada en la retaguardia sublevada». Historia Social (87), 67-83.

Preston, Paul (2011). El holocausto español: Odio y exterminio en la Guerra Civily después. Barcelona: Debate.

Prieto, Lucía (2007). «Mujer y anticlericalismo: la justicia militar en Marbella, 1937-1939». HAOL (12), 95-106.

Pueyo Ezquerra, Casiano (2008). Luesia en mi memoria. Zaragoza: Diputación Provincial de Zaragoza.

Pueyo Maisterra, Jesús (s. f.). Memorias de Jesús Pueyo Maisterra. «Del infierno al paraíso». Disponible en: http://jesus.pueyo.pagesperso-orange.fr/ MEMORIAS\%20DE\%20JESUS\%2OPUEYO.pdf

Ramos, Sara (2013). «Educadoras, maestras: depuradas por su profesión». En NASH, Mary (ed.), Represión, resistencias, memoria: Las mujeres bajo la dictadura franquista. Granada: Comares, 63-69.

Remón Aísa, José Antonio (2006). Ejea 1936: La sombra de una guerra. Ejea de los Caballeros: Círculo «González Gamonal» y Foro de Mujeres Progresistas.

- (2009). Cinco Villas 1936. Del protagonismo reformista a la violencia reaccionaria. Zaragoza: Gobierno de Aragón. Departamento de Educación, Cultura y Deporte.

RIPALDA GaBÁs, Carlos (2013). Navardún, historia de la Valdonsella. Edición propia.

Ruzz Ruzz, Francisco Javier (2008a). Las voces del silencio. Zaragoza: Asociación Charata para la Recuperación de la Memoria Histórica de Uncastillo.

- (2008b). Uncastillo, mujeres del 36: un retrato, una historia, una vida. Zaragoza: Asociación Charata para la Recuperación de la Memoria Histórica de Uncastillo.

- et al. (2015). «Exhumación en el cementerio municipal de Sos del Rey Católico (Zaragoza). Arqueología de la Guerra Civil en las Cinco Villas». Revista Arkeogazte (5), 165-188.

- (2016). «La búsqueda de las hermanas Malón en las Peñas de Santo Domingo (Longás)». El Mirador (49), 53-57.

- (2017). «Trabajos arqueológicos de localización de fosas comunes en el cementerio municipal de Luesia». El Mirador (50), 84-89. 
Sanchez, Pura (2009). Individuas de dudosa moral: La represión de las mujeres en Andalucía (1936-1958). Barcelona: Crítica.

- (2011). «Individuas y sujetas: las mujeres andaluzas represaliadas desde los tribunales militares». Memòria antifranquista del Baix Llobregat (11), 88-91.

Scott, Joan (1986). «Gender: A useful category of historical analysis». American Historical Review (91), 1053-1075.

Segura Graî̃o, Cristina (2006a). «Veinticinco años de historia de las mujeres en España». Memoria y Civilización (9), 85-117. Disponible en: https://core. ac.uk/download/pdf/83569348.pdf

- (2006b). «Recepción y evolución de la historia de las mujeres: Introducción y desarrollo en relación con la Historia de España». Vasconia (35), 13-30. Disponible en: http://www.euskomedia.org/PDFAnlt/vasconia/ vas35/35013030.pdf

VIRGILI, Fabrice (2007). «Le sexe blessé». En Rovquet, François, VIRGILI, Fabrice y Voldmann, Danièle (eds.), Amours, guerres et sexualité, 1941-1945. Paris: Gallimard BDIC / Musée de l'Armée, 138-145. 

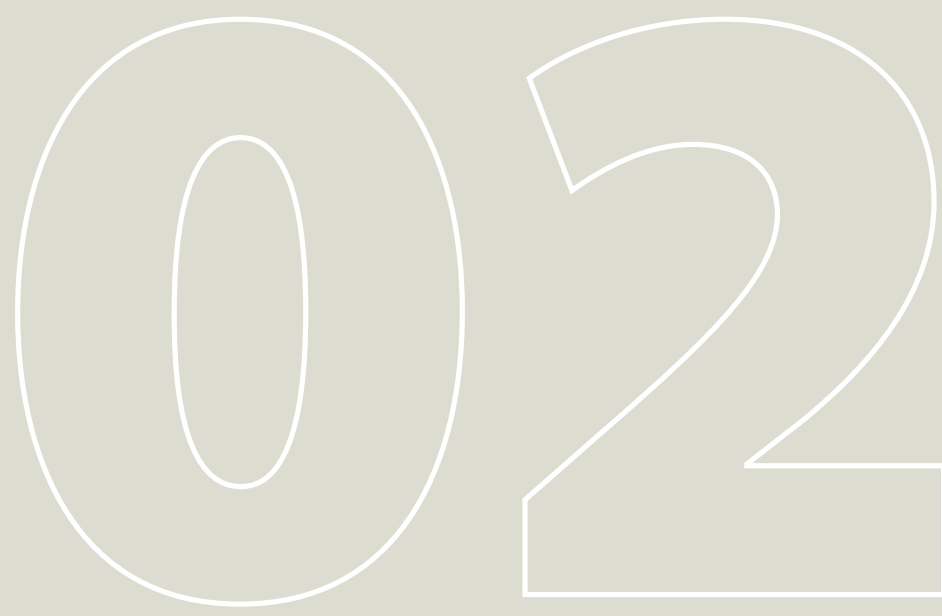

\section{¿LA VIRGEN MARÍA}

NOS ESTÁ MIRANDO?

ALGUNAS NOTAS SOBRE

LA IDEALIZACIÓN DEL

AMOR FEMENINO EN EL

SUBGÉNERO SHŌJO-AI

Is Virgin Mary looking at us? Some notes on the

idealization of feminine love in the sub-genre

shōjo-ai

\section{ANTONIO MÍGUEZ SANTA CRUZ}

\section{Universidad de Córdoba}

Fecha de recepción: 15 de marzo de 2019

Fecha de aceptación: 9 de septiembre de 2019

\section{RESUMEN}

Maria-sama ga miteru es probablemente una de las ficciones de temática yuri más exitosas en lo que llevamos de siglo xx. En ella, las pasiones y anhelos ocultos de las protagonistas confrontan entre los muros de un estricto instituto católico para señoritas. Pero si hay un elemento llamativo a ojos del espectador es sin duda la ambigua y exacerbada amistad que demuestran las alumnas del centro, estructurada a partir de un sistema de relaciones por parejas Ilamado soeurs. Ahora bien, ¿hasta qué punto dicho concepto enmascara una vinculación mucho más íntima que la simple amistad? El objetivo de nuestro texto será utilizar Maria-sama ga miteru y sus personajes como plataformas para discernir qué circunstancias culturales, éticas, sociales y religiosas actúan a la hora de configurar el llamado shōjo-ai, la línea más blanda dentro del yuri.

\section{Palabras clave}

Yuri, juventud, amor, catolicismo, falofobia.

\section{ABSTRACT}

Marla-sama ga miteru is probably one of the most successful yuri of the 21st century. In it, the passions and hidden desires of the protagonists confront inside the walls of a strict Catholic institute for young ladies. But if there is a striking element in the eyes of the viewer it is undoubtedly the ambiguous and exacerbated 
friendship shown by the students of the center, structured from a system of relationships in pairs called soeurs. Now, to what extent does this concept mask a much more intimate connection than mere friendship? The aim of our text will be to use Maria-sama ga miteru and her characters as platforms to discern what cultural, ethical, social and religious circumstances act when configuring the so-called shöjo-ai, the softest line within the yuri.

\section{Keywords}

Yuri, youth, love, catholicism, phallophobia.

La ganadora en 1993 del concurso de novelas patrocinado por la revista Cobalt, Oyuki Konno, publicó cuatro años después una serie de historias de temática shōjo² llamadas Maria-sama ga miteru, que literalmente vendría a decir «La Virgen María nos está mirando». El relato giraba en torno a las vivencias de varias estudiantes en el austero y elitista colegio Lillian para señoritas. De manera inesperada aquellos textos obtuvieron un éxito sin precedentes, por lo que en 1998 la misma Konno se decidió a lanzar una novela gráfica junto a la ilustradora Hibiki Reine, conocida por sus trabajos en algunos dōjinshi ${ }^{3}$ de la época. El círculo se cerraría en 2004 con el estreno de una adaptación al anime a manos de Studio DEEN que constaría de trece episodios emitidos desde enero hasta marzo. Las expectativas se cumplieron con creces, hasta el punto de que se produjeron otras tres temporadas junto a todo un caudal de material relacionado, como audiohistorias en cedé, programas de radio donde las seiyū ${ }^{4}$ hablaban sobre las intimidades de sus personajes, o varias bandas sonoras originales. En general existe una gran fidelidad entre las novelas originales y su reescritura al anime, que prescinde del tan temido relleno e incluso elimina algunas tramas irrelevantes para la línea argumental principal (Konno, 1998: 4).

Refiriéndonos a la narración, destaca por desarrollarse en un contexto católico y sobre todo porque las relaciones de amistad se administran a partir del llamado «sistema soeur», según el cual una alumna de segundo o tercer año (grande soeur) adopta de mutuo acuerdo a una recién matriculada (petite soeur $)^{5}$. La liturgia suele consistir en la ofrenda de un rosario a la hermana pequeña por parte de la mayor, normalmente delante de una estatua de la Virgen situada en los jardines de las instalaciones o en presencia de otras «hermanas».

Así ocurrió con Yumi y Sachiko, la pareja protagonista, pese a que sus inicios no fueran sencillos. Durante uno de los primeros días de curso, Sachiko, de segundo año, advirtió que una de las alumnas recién ingresadas no llevaba convenientemente atado el lazo del uniforme. A continuación se acercó a la

\section{INTRODUCCIÓN}

1. Revista bimestral japonesa de ficción shöjo dependiente de Shueisha desde mayo de 1976. Cabe destacar que Shueisha también acostumbra publicar novelas ligeras de temática femenina bajo el sello de Cobalt. Además de Konno, han participado en la revista autoras como Mizue Tani con Hakushaku to Yôsei - Mizune Kuwabara con Migare of Blazes; y Jirô Akawa, uno de los pocos hombres, con el shōjo de misterio San Shimai Tanteidan.

2. Categoría de manganime destinada a un público femenino y juvenil, lo cual no impide que pueda ser consumida también por los chicos. Literalmente viene a significar «niña joven».

3. Se trata de narrativas visuales de estética manga autopublicadas. De alguna manera podían compararse a los fanzines.

4. Actor de doblaje en Japón. En ocasiones llegan a ser celebridades equiparables a los mismos autores de manga o actores convencionales.

5. Respectivamente hermana mayory hermana pequeña. 


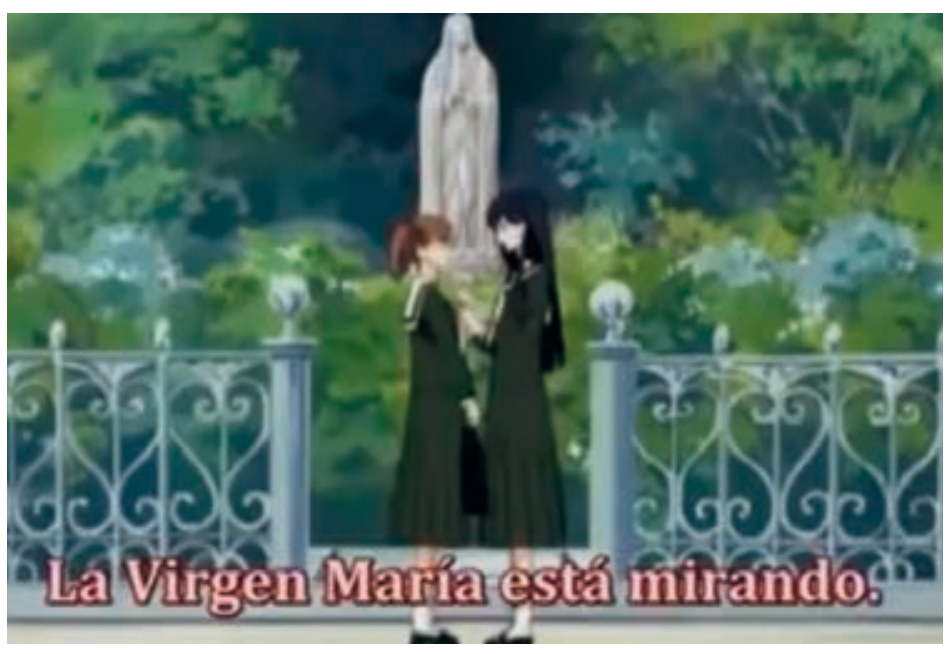

jovencita (llamada Yumi) y procedió a poner a punto el nudo, al tiempo que decía: «Debes tener el lazo bien atado... la Virgen María nos está mirando...».

En ese instante Yumi se sintió halagada por el hecho de que una alumna tan popular y experimentada le prestase atención. Las circunstancias evolucionaron de tal forma que Sachiko acabó solicitándole a Yumi que fuera su petit soeur, pero esta se negaría por suponer que en la petición no había ni un ápice de sentimiento real, y sí un interés eventual. De cualquier forma Yumi acabó cediendo al «cortejo» de Sachiko, ${ }^{6}$ dando lugar a la pareja desde la que se distribuye y articula la narrativa; esto es así especialmente en el caso de Yumi, la única alumna dotada por la autora de voz en off. Tampoco hemos de olvidar la importancia de otros tándems de soeurs, especialmente los formados por Sei Satō y Shiori Kubo o Rei Hasekura y Yoshino Shimazu.

María nos está mirando es un slice of life de tipo dramático, de estética shōjo y con varios elementos de yuri. ${ }^{8} \mathrm{Y}$ es que las relaciones entre soeurs, ${ }^{9}$ si bien sustentadas en una especie de amistad sublime, llegan a introducir deliberadamente ciertos tipos de insinuaciones románticas. En la mayoría de las ocasiones dicho romance se desliza en un sentido críptico, platónico y ahogado, casi se deja a la imaginación del lector/espectador, pero podemos hallar un caso abiertamente lésbico en las ya citadas Sei Satō y Shiori Kubo.

Dando por sentada la existencia tangible de un suave componente homoerótico, es importante reseñar la total inexistencia de cualquier tipo de manifestación fantástica, surrealista o de tipo mágico, tan común a los distintos géneros de manganime.

Asimismo, las hermanas mayores adoptan comúnmente un comportamiento arquetípico semejante al de los varones y son más vitales,
Fig. 1. Screen shot del primer episodio del anime de Marla-sama ga Miteru.

6. Dada la popularidad de Sachiko Ogasawara, el rechazo por parte de Yumi supuso toda una convulsión mediática para el resto de las alumnas. Incluso el periódico de la escuela se hizo eco de esta noticia, por lo que Sachiko se propuso desde el primer momento conseguir la aceptación de Yumi y de esta forma restituir el daño hecho a su imagen pública.

\section{CARACTERÍSTICAS FUNDAMENTALES}

\begin{abstract}
7. Literalmente, rebanada de vida, aunque sería más correcto traducirlo como recuentos de la vida. Se trata de un género próximo al costumbrismo que pone el foco sobre la cotidianeidad de los personajes que forman la historia, sin centrarse en grandes hitos o situaciones extraordinarias.
\end{abstract}

8. Subgénero de manganime que aborda el amor entre mujeres. Los hay de diversas tipologías, principalmente considerando el grado de explicitud sexual existente.

9. Anteriormente apuntamos que la expresión significaba «hermanas» en lengua francesa. Más adelante explicaremos por qué existe esta relación entre el colegio Lillian y el país galo. 
decididas y carismáticas. Por su parte, las hermanas pequeñas incurren en una conducta más errática o ingenua (Esteban y Távora, 2008: 64) y predomina sobre su personalidad más limitada la estética kawaii. ${ }^{10}$

La relación entre la mujer y la flor, constante en la serie, se pone de manifiesto desde la misma naturaleza del consejo de estudiantes, configurado a partir de tres alumnas de tercer año que se hacen llamar «las rosas», cada una de ellas designada mediante un nombre técnico según la ciencia botánica: a saber, Rosa chinensis (rosa roja), Rosa gigantea (rosa blanca gigante) y Rosa foetida (rosa amarilla). A las petit soeurs de estas rosas se las conoce del mismo modo que a sus hermanas mayores, pero añadiendo después del nombre en bouton, que significa «en brote». A su vez, se le suma el epíteto petit soeur a las hermanas pequeñas de las rosa en bouton, que son conocidas por el intrincado título de rosa en bouton petite soeur. En ocasiones, cuando las rosas se gradúan e ingresan en la universidad las hermanas en brote asumen su papel. Promocionan de igual forma sus petite soeurs y adoptan estas como hermanas menores a jovencitas de primer año.

Es muy interesante cómo el edificio donde se desarrolla la acción, el instituto, se erige en un personaje más, monopolizando los contextos de la serie y poniendo en común la procedencia, origen o destino de los diferentes protagonistas femeninos. Tampoco podemos obviar el nombre de la institución académica, Lillian, remedo del vocablo lirio en latín," símbolo a su vez de la virtud encarnada por la Virgen María y por ende aspiración de todas las alumnas o profesoras que integran la institución (Swenson, 2002: 37).

Virtud que por otro lado prospera en medio de la ausencia masculina, un leitmotiv tan solo roto por la aparición del prometido de Sachiko durante los primeros episodios o, en un plano periférico, el hermano menor de Yumi.

Otra de las cuestiones que sobresalen en el texto son los complejos e inseguridades de las alumnas de instituto, hasta el punto de ocultar sus sentimientos y emociones por miedo al rechazo incluso en sus relaciones de soeurs. No olvidemos el acentuado sentido melodramático del anime, pues problemas aparentemente triviales, como por ejemplo la elección de un regalo de San Valentín, se convierten en verdaderos trastornos para gran parte de las protagonistas. Observamos en este punto una grotesca deformación del tradicional dramatismo japonés y su gusto por las situaciones melancólicas comunes al aware y el yugen, aunque a través de un cruel mestizaje donde predominan los valores propiamente occidentales y la aflicción adolescente (Tomasi, 1993: 18).

A continuación haremos un repaso concienzudo de los puntos anteriores y algunos otros, con el objetivo de dirimir las cuestiones fundamentales que definen a Maria-sama ga miteru como una serie compleja.
10. Concepto estético propio de la cultura visual japonesa contemporánea que vendría a significar «mono» o «adorable».

11. No olvidemos que yuri significa lirio. 


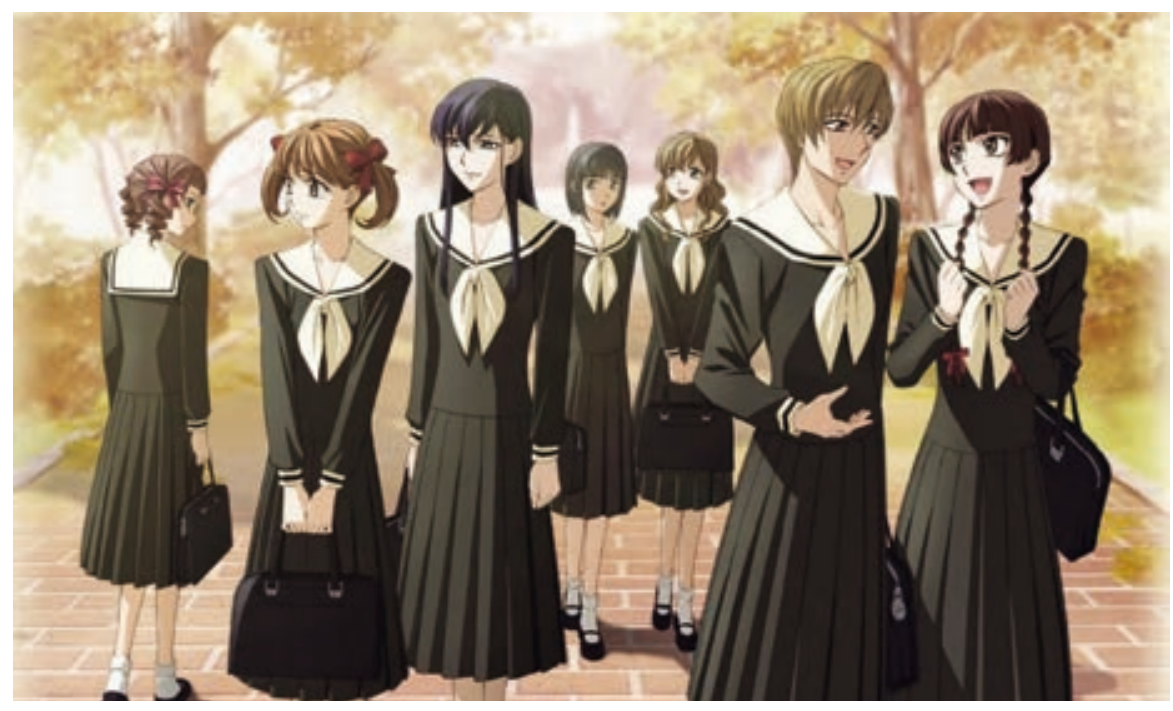

El trazo de Hibiki Reine no se distancia demasiado del canon asentado en el shōjo clásico, lo cual sea tal vez su único defecto destacable, ya que adivinamos poca personalidad e innovación. Sobresale la estructura de los ojos, grandes y expresivos, en contraste con una fisonomía facial afilada en las formas. La estilización se puede aplicar además a la morfoestructura de los cuerpos, muy delgados y altos en apariencia, aunque en la mayoría de los casos los personajes no superen el 1,60 de estatura. Como es natural se concede gran importancia a los complementos de la ropa, entre los que podemos encontrar lacitos, zapatos o broches, sin duda con el objetivo de conferir a las alumnas un aire encantador.

La animación podríamos considerarla estándar, con un bajo número de episodios por temporada. Los fotogramas son vistosos y tendentes al ocre o al blanco, tamizados por un aire nebuloso y decolorado, en una época en la que aún no estaba generalizado el uso del CGI'12 o el empleo de programas informáticos como el RETAS. ${ }^{13}$ A ojos aviesos queda la poca movilidad de los personajes, un mal aplicable a muchos animes del siglo xxı, a diferencia de como sucedía en la segunda mitad de los ochenta y primera de los noventa, la considerada por algunos expertos la edad de oro de la animación japonesa. Pero podríamos revertir el sentido de ese estatismo hasta convertirlo en otro ítem a la hora de conformar el orden y sobriedad propios de la escuela Lillian, o incluso una manera de subrayar la acción en momentos donde se rompe ese ritmo pausado de la narrativa debido a algún conflicto emocional o romántico en concreto.

A muchos lectores podría parecerles que María nos está mirando pertenece indefectiblemente al subgénero manganime conocido como yuri. Pero no siempre las cuestiones se resuelven tan fácilmente, máxime cuando

\section{DIBUJO Y ANIMACIÓN}

Fig. 2. En la imagen se observa cómo los diseños conceptuales son los arquetípicos del shōjo.

12. Del inglés Computer Generated Imagery, o imagen generada por computadora.

13. En la actualidad más del $90 \%$ de la animación japonesa utiliza el RETAS (Revolutionary Engineering Total Animation System) como herramienta de producción.

\section{¿SHŌJO-AI O YURI?}




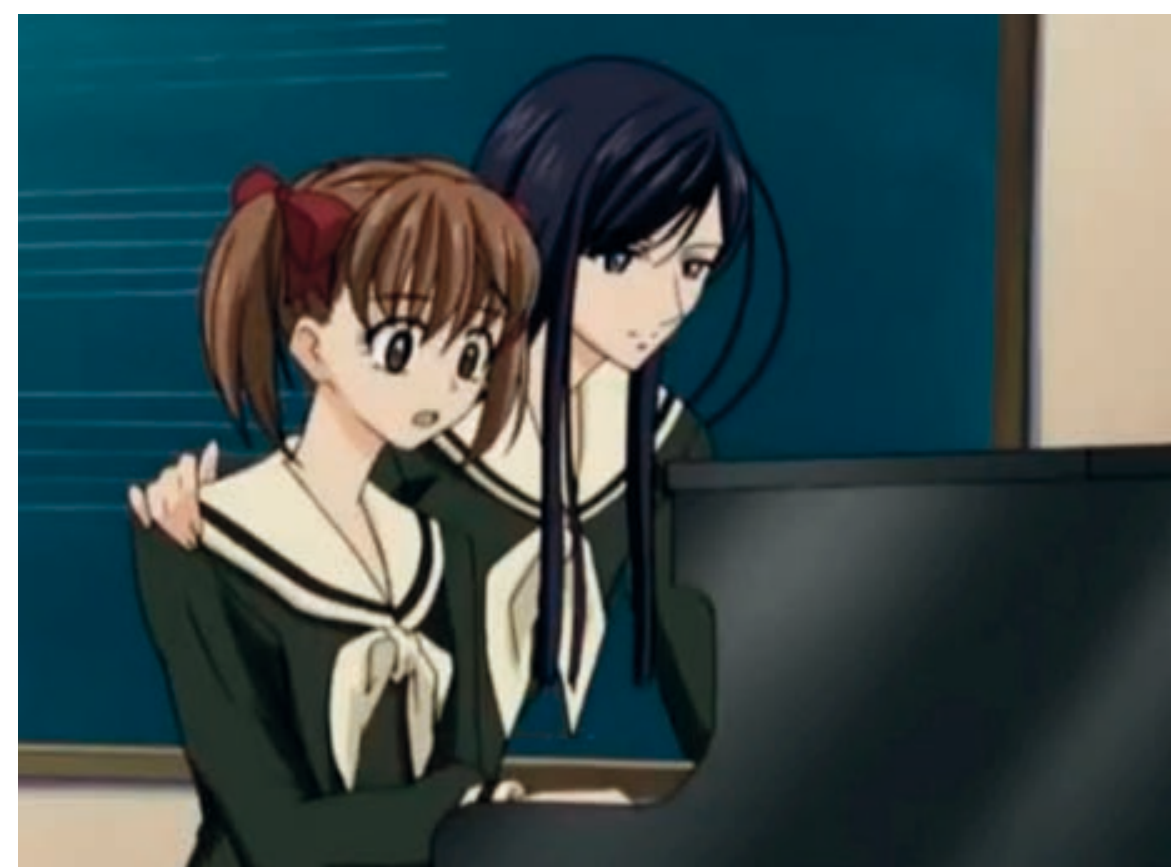

las tipificaciones son una organización arcaica y subjetiva, y suelen incurrir en varias suertes de contradicción. Si nos atenemos a la realidad, el yuri ${ }^{14}$ exigiría, más allá del consabido lesbianismo, un factor erótico o sexual de mayor o menor grado y llegaría en algunos casos a emparentarse con el ecchi $i^{15}$ o directamente con el hentai. ${ }^{16} \mathrm{~A}$ esta rama pertenecerían multitud de manganimes conocidos por todos, tales como Stainless Night (Ryunosuke Otonashi, 1995) con efluvios de terror y futanari, ${ }^{17}$ Shōjo Sect (Ken Kurogane. 2003), que nos narra la aventura sexual de dos jovencitas a lo largo de los años, o Ice (Makoto Kobayashi, 2007), ambientada en un mundo postapocalíptico habitado casi exclusivamente por mujeres. Por su parte, el shōjo ai aborda por convenio ${ }^{18}$ las relaciones entre mujeres aunque desde un cariz más romántico, amortiguado y, en suma, despojado de la explicitud sexual (Ogi, 2009: 245). Con ello no estamos negando los sentimientos erotizantes o las pulsiones de cualquier tipo, pero es cierto que estos siempre suelen esconderse tras códigos formales similares a la amistad, la ética, la educación, etc.

Si echamos un ojo a las soeurs de Maria-sama ga miteru el componente lésbico oscila en una fina línea que se decanta en gran medida gracias a la sensibilidad del espectador. Ahí tenemos la vez en que Sachiko cayó encima de Yumi al salir del consejo de estudiantes, o cuando ambas tocaron el piano de manera tan seductora y sugerente, al menos por parte de la onee-sama. ${ }^{19}$ En ambos ejemplos el elemento lésbico puede estar presente o no, ya que la creadora se preocupa de explotar la ambigüedad intercalando emociones de rubor, sorpresa y apasionamiento con otras más cercanas al respeto y la fascinación. Sin embargo, cualquiera de las primeras sensaciones podría ser aplicable a quien admire a otra persona por sus valores y virtudes. Y no hay
Fig. 3. Screen shot del episodio tres. Se observa cómo Yumi se sorprende al sentir la mano de Sachiko en su hombro.

14. Según Erica Friedman, reconocida especialista y autora de Yuri Monogatari, si la aventura versa sobre una jovencita que asume su naturaleza queer, podríamos hablar de una ficción LGBTQ; ahora bien, si se siente atracción hacia otra mujer pero no se padece presión social o prejuicios de algún tipo, entonces es yuri.

15. Aplicado a los géneros manganime de tendencia erótica o picante. En la mayoría de las ocasiones se suele administrar como fanservice y por lo general no implica la aparición de sexo explícito.

16. Literalmente «pervertido» 0 «perversión». Aplicado al manganime suele referirse a subgéneros de temática pornográfica. Se incluye todo tipo de fetichismos y desviaciones como el bondage o el tentacle rape, en contraposición al más ligero ecchi.

17. Vendría a significar «hermafroditismo» en japonés. En este contexto puede referirse a las temáticas impulsadas por algunos yuri o incluso dar nombre a un subgénero en sí mismo. No es extraño que se use también la palabra fuera del universo otaku: su ejemplo máximo es el caso de la Sadako de Koji Suzuki y su Ringu literario.

18. A pesar de que obviamente estemos ante un término de origen japonés, shōjo ai se usa fundamentalmente en EE. UU. y Europa. Las razones para hacerlo pueden ser las mismas que lleven a los nipones a catalogar estas ficciones en su país como Girls love; es decir, la convicción o creencia de que una expresión extranjera suena más cool o moderna.

19. Hermana mayor. 


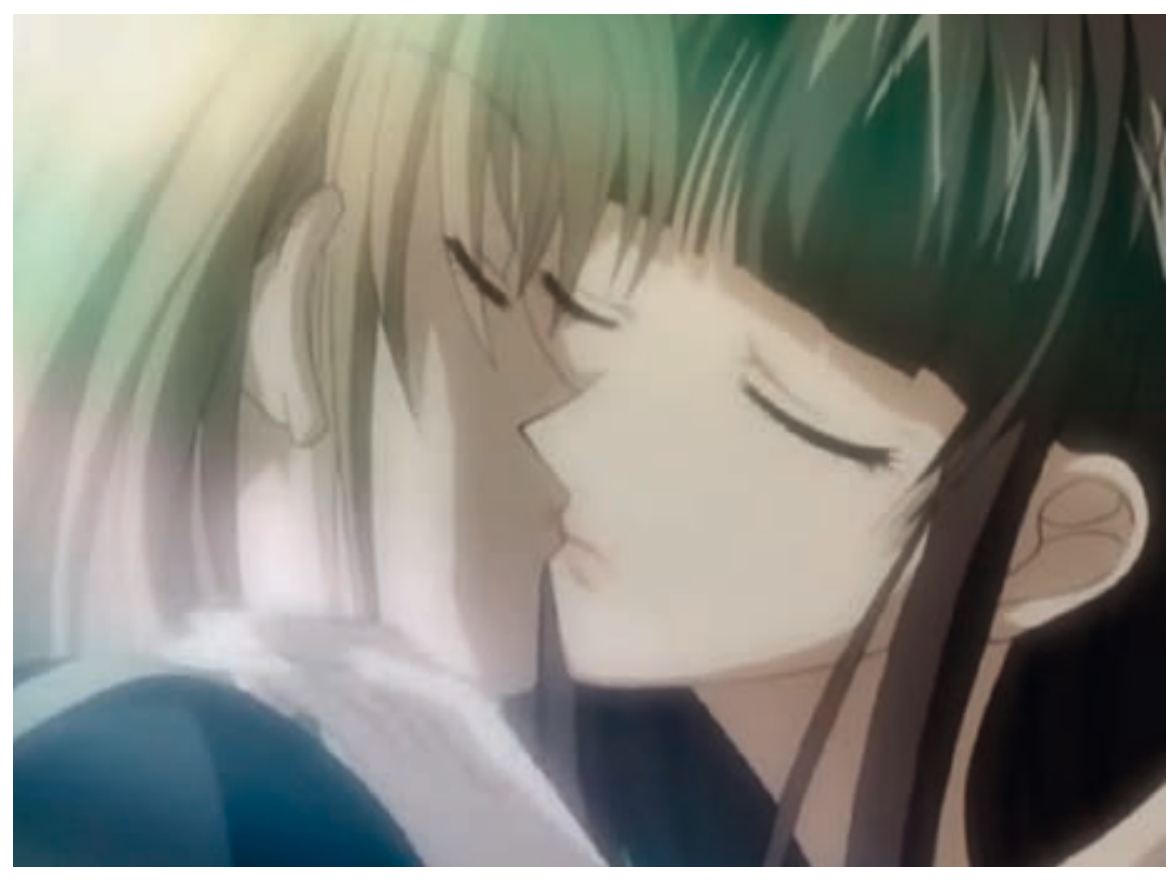

mejor ejemplo para encarnar ese perfil que Sachiko, recordémoslo, una muchacha bella y popular, dotada para las artes musicales y, por si fuera poco, maestra en la ceremonia del té y el arte floral japonés o ikebana.

Un caso muy distinto ocurre con la alumna Sei Satō, integrante del Yamayurikai ${ }^{20}$ como Rosa gigantea, y sin ningún tipo de dudas la rara avis más evidente dentro de Lillian. Desde el comienzo Sei mostró un interés por Yumi en el que cabían insinuaciones atrevidas, abrazos poco o nada fraternales e incluso tocamientos. Una actitud fruto de su carácter díscolo, independiente, a priori desenfadado y, ni que decir tiene, alejadísimo de los estrictos códigos de comportamiento practicados en el instituto. Y decíamos «a priori» porque su índole divertida y espontánea esconde una experiencia lésbica en cierto modo traumática.

De hecho, uno de los episodios más memorables de la primera temporada de Maria-sama ga miteru corresponde al flashback donde se narra aquel desamor. Todo empezó cuando se hizo popular entre el alumnado un libro de género melodramático llamado El bosque de las espinas. La razón de su éxito se explicaba en función del extraordinario parecido entre el relato y la historia vivida un año atrás por Sei, lo cual hizo creer a sus compañeras que en realidad ella misma era la autora, si bien escribiendo bajo un seudónimo. Pese a que finalmente Rosa gigantea no tuviera relación alguna con aquella novela, el rumor serviría de excusa para que esta les contara su difícil vivencia a algunas de sus compañeras del Yamayurikai.

La «culpable» de todo fue una alumna de primer año llamada Shiori, a quien Sei conoció un día de primavera. La joven pronto supuso una vía de escape para Sei, por aquel entonces Rosa gigantea en bouton, ya que literalmente «se hallaba en un sitio de ángeles pero ella no era un ángel»,
Fig. 4. Screen shot del episodio once. Aquí vemos una de las pocas evidencias explícitas de lesbianismo de toda la serie.
20. Consejo de estudiantes de la escuela Lillian integrado por las Rosas. 
o que la hizo sentirse «abandonada en un inmenso páramo». Shiori resultó ser el hálito necesario para que Sei recobrase la positividad y llegó a afirmar de ella que era «un brillante ser de luz amado por todo el mundo». Sin ni siquiera llegar a establecerse como soeurs, comenzaron a verse a solas en el interior de un bosque próximo a Lillian, también a abrazarse en un sentido romántico y, finalmente, a besarse en la capilla del colegio. Shiori, quien tenía vocación de monja, pronto retiró sus labios de Sei, para a continuación avergonzarse de ese comportamiento porque la Virgen María las estaba mirando.

He aquí la crónica de un amor frustrado en el que Dios y la Virgen prevalecieron sobre los sentimientos terrenales. Nada de lo anterior es baladí, puesto que constituye la pieza básica para entender su clasificación como shōjo ai. La cuestión que cabe plantearse ahora es si Sei fue la única transgresora que pudo confesar su amor, saltándose el estricto protocolo moral de Lillian. Eso podríamos deducir, al menos, del reproche de Shiori y su alusión a la sempiterna vigilancia de la Virgen, una sensación de opresión que quizá compartiría con otras alumnas, incapaces como ella de admitir sus verdaderos sentimientos.

El trasfondo católico romano del instituto Lillian representa una absoluta dicotomía respecto a los vaivenes románticos existentes entre sus alumnas. Al fin y al cabo el cristianismo es una de las religiones más conservadoras respecto a la moral sexual: prohíbe expresamente el fornicio, la pornografía, la prostitución, el sexo oral e incluso censura los métodos anticonceptivos. La razón se debe a que las relaciones íntimas solo se entienden con vistas a concebir y se condena cualquier tipo de conducta alternativa. Es ahora cuando le toca a la lujuria aparecer como uno de los grandes pecados capitales, puesto que el libertinaje sexual induce a la relajación mental y despista del amor a Dios.

Precisamente María encarna el radical opuesto a la concupiscencia, ya que fue capaz de subvertir las leyes naturales al quedarse encinta y mantener su virtud incólume. Porque aunque la palabra se haga carne es difícil imaginarse a un dios cuyo origen se encuentre en una mezcla de fluidos, sudor y coagulamientos, mucho menos si es placentera. Así las cosas, el alumbramiento sin intercesión de varón junto al hecho de ser elegida por Dios como matriz de su hijo constituyen los «únicos» méritos para recibir culto por parte de millones de fieles. ${ }^{21}$

Es hora de resaltar la analogía establecida entre la virtud virginal y la flor del lirio que, recordémoslo, da nombre tanto a la institución donde se desarrolla nuestra historia como al género (yuri) que está siendo objeto de

\section{LA VIRGEN MARÍA}

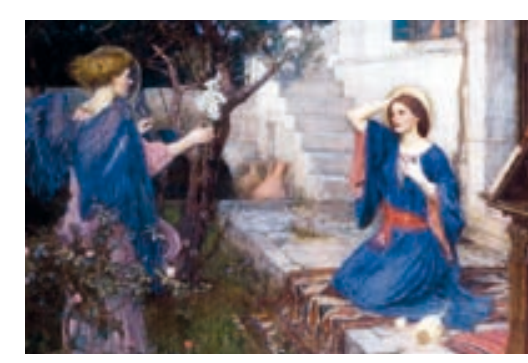

Fig. 5. La Anunciación de John William Waterhouse, c. 1890. En la pintura se observa al arcángel Gabriel ofreciendo un lirio a la Virgen María en metáfora de su pureza.

21. No se conocen milagros realizados por la Virgen María en vida aparte de la consabida Inmaculada Concepción. La enorme cantidad de advocaciones marianas que reciben culto se justifican a partir de apariciones y supuestos milagros post mortem. 
estudio en nuestro texto. Fue hacia 650 d. C. cuando el santo Beda asemejó por primera vez a la Virgen María con el lirio blanco, representando los pétalos la pureza intacta de su físico, y sus doradas anteras, la brillantez de su espíritu. Asimismo san Bernardo definió a María como «lirio de castidad y rosa de pureza». San Pedro, por su parte, nos enseñó que la Anunciación acaeció en época de primavera, o más concretamente «cuando florece la tierra» (Swenson, 2002: 182).

Virtud virginal e impulso hacia el mismo sexo como dos caras de una misma moneda: el lirio. Ahora bien, ¿cómo encajaría el catolicismo la homosexualidad? El lector podría imaginarse la respuesta al releer el espeluznante decálogo de unas líneas atrás, pero lo cierto es que oficialmente la Iglesia no censura la homosexualidad, sino más bien el acto homosexual en sí mismo. Es decir, se da por hecho el inmenso número de creyentes gais y se explica su condición a partir del instinto primitivo y las tentaciones más ordinarias. Igualmente se parte de la base de que el gay no elige su condición, por lo que si el creyente consiguiera controlar sus emociones debería ser acogido en la comunidad con comprensión y respeto.

Repasemos por un instante el idealizado prefacio que antecede a los openings de la primera temporada de Maria-sama ga miteru. En él se reza:

Las doncellas que se reúnen en el jardín de la Virgen María hacen gala de una sonrisa tan angelical que es imposible que pasen desapercibidas. Sus puros cuerpos y mentes relucen bajo los oscuros uniformes escolares. Los pliegues de sus faldas apenas se dejan ver, mientras que sus blancos pañuelos nunca se mancillan. Aquí se prefiere caminar lentamente porque la escuela femenina Lillian es un jardín de doncellas.

Como es fácil observar los principios estéticos y morales de la escuela se fundamentan a partir de esa idea de pureza transmitida por María. En este sentido, sería poco o nada importante que ciertas alumnas sintieran una admiración romántica hacia sus soeurs, siempre y cuando dicha atracción no se consumara desde un punto de vista sexual. De ahí ese eslogan de María nos está mirando, que sirve como paradigma de a lo que una alumna de Lillian debería aspirar y, al mismo tiempo, como advertencia vigilante contra toda inclinación más allá del amor platónico.

\section{EL AMOR}

Dijo Platón en su diálogo El banquete que la belleza del alma es siempre más relevante que la derivada de cualquier cuerpo. La virtud espiritual, por tanto, se situaría en la cima de la escala de valores para cualquier amante platónico, huyendo de otros tipos de razonamientos obtusos relacionados 
con el sexo o la simple procreación (Platón, trad. 1993: 95). Quien alguna vez se viera embargado por esa emoción entraría en un proceso paulatino en el que la belleza del cuerpo solo actuaría como reclamo transitorio, ya que el enamoramiento real comenzaría cuando se percibiera el esplendor del alma en la persona amada. Dicho de otro modo, la cuestión no consiste en amar lo imposible como se ha pensado tradicionalmente, sino en enamorarse de lo ideal según nuestra perspectiva, incluso cayendo en la subjetividad o abrazando estereotipos extraños. Por consiguiente, si el enamorado tiene como objeto de veneración el espíritu de otro ser, hemos de relativizar la importancia del sexo en este tipo de relaciones (Ackerman, 2000: 19). Y es así porque el amor verdadero es para Platón el que se proyecta hacia quien trasciende lo material y mundano.

Con el objetivo de evidenciar la esencia platónica en las relaciones existentes entre la enorme mayoría de soeurs, elegiremos a Yoshino y Rei por la complejidad añadida de su caso: son primas hermanas. La primera ejercería el rol de inexperta y vulnerable,22 algo agravado por una enfermedad congénita del corazón que la incapacitaba para desempeñar ejercicios físicos, aparte de su estética kawaii. Rei, de aspecto andrógino y gran talla, representaba el eterno opuesto, destacando en los deportes y especialmente en el kendo. ${ }^{23}$ Llegado a un punto la relación entre ambas se deterioró debido al complejo de inferioridad de Yoshino respecto a Rei, pues según llegó a afirmar la joven, «suponía una merma para el desarrollo personal de su onee-sama». Como resultado de esta crisis Yoshino devolvió su rosario a Rei, representando simbólicamente una escena comparable a la devolución de una alianza matrimonial. Hemos de subrayar la relevancia del gesto porque supuso un estado muy próximo a la depresión para ambas muchachas, algo imposible de suceder si nos hubiéramos referido a una simple relación de amistad o parentesco. La sensación se acercaría más al compromiso en exclusiva de dos personas que se lo deben todo, hasta el punto de autoexigirse de manera desproporcionada.

Los eventos se desarrollaron de tal forma que Yoshino decidió operarse de su afectación cardiaca el mismo día en que Rei disputaba la final del torneo escolar de esgrima japonesa. La antigua petit soeur rogó a Yumi su presencia en el combate de Rei con el deseo de que la apoyase en su lugar. Como no podía ser de otra forma, Rei Hasekura se impuso a una alumna de técnica superior, sin duda inspirada por su amada prima, así como por el deseo de transmitirle la felicidad de su victoria. Incapaces de resistir la situación de indefinición por más tiempo, las dos muchachas reafirmaron sus sentimientos y repitieron la ceremonia del rosario delante de la estatua de la Virgen María. Salta a la vista de cualquiera: este episodio estaría mucho más cerca de una relación de índole marital o de un noviazgo formal que de una mera amistad, por muy elevada que esta fuere. Si a lo anterior sumamos los
22. Aunque a lo largo de la serie dicho estereotipo va evolucionando hasta el punto de plantearnos cuál de las dos hermanas es la más fuerte emocionalmente.

23. Esgrima japonesa moderna en contraposición al kenjutsu, esgrima tradicional. Se suele practicar con un sable de bambú muy maleable llamado shinai. 
celos, tan comunes a las relaciones entre soeurs, nos percataremos de algo que hemos deseado transmitir desde el principio: no es amistad; el sexo no importa; en realidad, es amor platónico.

Tal y como apuntamos unas páginas atrás Sachiko Ogasawara es la estrella innegociable de Maria-sama ga miteru. Primeramente porque es la grande soeur de Yumi, principal protagonista, y segundo porque se erige en un dechado de virtud y perfeccionamiento femeninos. Bajo esa definición Sachiko podría acercarse a la idea tradicional de la Yamato Nadeshiko, o mujer ideal japonesa, salvo por dos motivos esenciales: no congenia con el proceder de su poderosa familia y padece androfobia.

Este odio a los hombres queda manifiesto dada su reticencia a interpretar la obra Romeo y Julieta junto a su primo, estudiante de la Universidad de Hanadera, y a la postre también su prometido. Hablamos, pues, de un matrimonio concertado, algo no tan atípico en el Japón de unas décadas atrás y aún posible hoy día en casamientos estratégicos de familias importantes. Precisamente el clan Ogasawara posee una gran cantidad de empresas y se caracteriza por un talante conservador y tradicionalista. No sería tan extraño entonces que el padre de Sachiko, Tôru, acordase el enlace de su hija con su propio sobrino en búsqueda del beneficio familiar. Ello, unido al carácter déspota y mujeriego de Tôru, terminó de configurarle a Sachiko una personalidad fuerte, independiente y con el único anhelo de vivir en un mundo aparte del masculino.

La anterior circunstancia es una ejemplificación de manual del sistema neoconfucionista, una suerte de doctrina a medio camino entre la filosofía social y la religión que lleva estructurando la sociedad japonesa durante siglos. Es famosa la ley de «las tres dependencias», según la cual una mujer ha de obedecer a su padre cuando nace, a su esposo cuando contrae matrimonio y finalmente a su hijo durante la etapa de senectud (Míguez, 2012: 209). Añadamos aquí la idiosincrasia de un país absolutamente militarista, cuyos símbolos por antonomasia son, por un lado, el samurái o su trasunto, la katana, símbolo fálico de poder masculino, y por el otro la geisha, mujer refinada en las artes pero objeto servil, expuesta al abuso de aquellos que puedan permitírselo. Recapitulando, cómo podría una mujer moderna e ilustrada ceder ante un sistema tan injusto y desproporcionado. O dicho de otra forma, cómo aceptar vivir en un mundo construido por y para hombres (Butler, 2007: 41). Ahora será fácil entender por qué la escuela de señoritas Lillian supone un bálsamo, una burbuja si queremos, donde Sachiko puede desarrollarse sin temor a la intercesión masculina: exactamente igual que la Virgen María.

\section{LA AUSENCIA} DE HOMBRES 

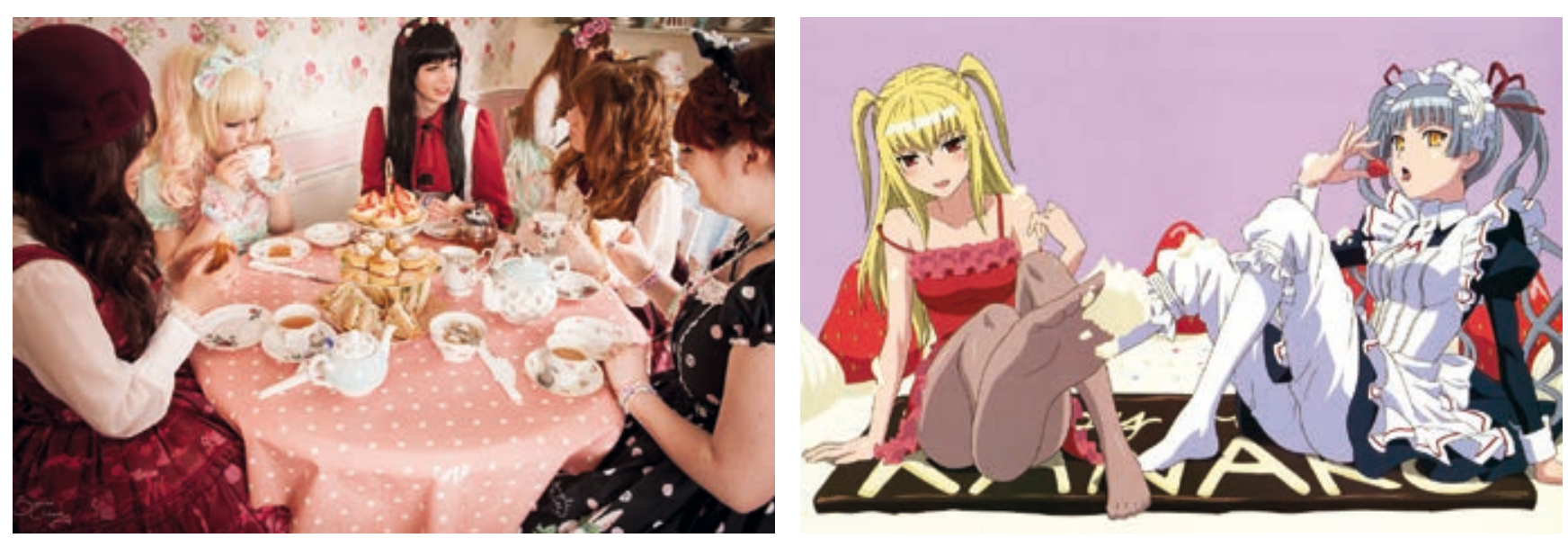

María-sama ga miteru, como es natural, se apoya en una estética absolutamente europea. La influencia se aprecia tanto en los uniformes del alumnado como en la arquitectura de los edificios o en la distribución de los jardines. Por si fuera poco se explotan una serie de expresiones propias del idioma francés, se utilizan los cubiertos en vez de los típicos palillos orientales a la hora de comer y varias alumnas tocan el piano. En cuanto a la banda sonora original, predominan los temas melódicos que se entremezclan con efluvios sonoros del barroco e incluso alguna obra de Johann Sebastian Bach.

El té cobra especial importancia en la serie, aunque en un sentido anglosajón muy lejano de la ritualística propia de los usos japoneses. No obstante, a su forma, la hora del té y las pastas se pueden entender asimismo como un estilo de ceremonia entre las soeurs, ya que constituye una ocasión inmejorable para el intercambio social de una manera agradable, estilosa y elegante. Al hilo de lo anterior, no debemos obviar toda la parafernalia que rodea a esta actividad, ya que las tazas o los dulces llegan a ser complementos esenciales a la hora de conformar una estampa idealizada de la cultura lolita24 (Romero, 2017: 2).

El contexto europeo y más concretamente francés del colegio Lillian no deja de ser un trasunto de la Escuela del Sagrado Corazón, toda una sucursal internacional de colegios concertados femeninos con origen en Francia, e inspiración para una multitud de instituciones similares en suelo japonés a partir de 1908. He aquí otra consecuencia de aquel fervor occidentalista tan común en el periodo Meiji tardío, que además de importar tecnología, ciencia e industria occidental, se interesó por la educación extranjera. Estamos ante una cuestión habitual en el género que nos ocupa, y ahí disponemos de ejemplos evidentes para demostrarlo como Strawberry Panic! (Sakurako Kimino, 2003), donde el amor entre jovencitas brota en medio de un estricto campus católico, o Maria + Holic (Minari Endō, 2006) igualmente con una acentuada falofobia de por medio.

24. Subcultura femenina de origen japonés que, por medio de una estética victoriana o rococó, manifiesta una situación de libertad e independencia. Existen decenas de subgrupos de lolitas, pero todas ellas tienen en común ser una reacción ante el sistema conservador japonés, así como un síntoma palmario de la autodeterminación femenina. 
A lo largo de las páginas anteriores perseguíamos evidenciar la com-

plejidad de un género desconocido a ojos del gran público a través del anime Maria-sama ga miteru. De él podríamos afirmar que establece una especie de canon para el llamado shōjo ai, una vertiente light del más erotizado yuri, en gran medida por el cariz romántico imperante en las relaciones mostradas. Detrás de este subgénero podría esconderse un frontal alegato profeminista, así como se deslizaría una crítica abierta al obtuso sistema de castas confuciano. Y es que, como hemos visto en el caso de Sachiko, a la mujer de nada le serviría alcanzar la plenitud cívica o moral, disfrutar de la excelencia artística o ser admirada por todo el mundo, si todas esas virtudes acaban opacándose bajo la dictadura del desequilibrado matrimonio japonés. Nuestra serie sería, por tanto, un eslabón más de aquella cadena iniciada hace casi un siglo por Kenji Mizoguchi o Yasujiro Ozu, que se perpetúa en el tiempo, a través de Nobuhiro Yamashita y la inolvidable animación de Hayao Miyazaki, en un paulatino empoderamiento de la mujer del que también participó activamente Oyuki Konno.

Pero no nos olvidemos de lo más importante: el amor, aunque sea en su vertiente espiritual, existe en Maria-sama ga miteru. Así se demuestra en las múltiples relaciones de soeurs, despojadas de casi toda connotación sexual en esa ansia de abrazar la virtud encarnada por la Virgen María, siempre censora y de mirada pétrea en los jardines de Lillian. Y escribíamos casi porque en efecto podemos hallar una frustrada relación lésbica dentro del anime, que no es sino la conjura metafórica contra el régimen falocéntrico establecido tanto en Japón como en el resto del mundo. La escuela para señoritas pasaría a ser, según nuestro punto de vista, un solaz de crecimiento femenino, donde ellas son «libres» para sentir y ansiar todo aquello que afuera de sus muros les está prohibido. Entonces, admitamos de consuno que la figura del hombre es una molestia al menos dentro de este universo y que el amor sublime entre féminas, ya sea lésbico o platónico, simboliza un tipo de paraíso al que aspiran millones de lectoras constreñidas bajo la moral del mundo contemporáneo.

\section{BIBLIOGRAFÍA}

ACKERMAN, Diane (2000). Una historia natural del amor. Madrid: Anagrama.

ButLER, Judith (2007). El género en disputa: El feminismo y la subversión de la identidad. Barcelona: Paidós.

Esteban, Mari Luz y TÁvora, Ana (2008). «El amor romántico y la subordinación social de las mujeres: revisiones y propuestas». Anuario de Psicología (39), 59-73. 
HAIRSTON, Marc (2006). «The Yin and Yang of Schoolgirls experiences: Maria sama ga miteru and Azumanga Daioh». Mechademia (1), 177-180.

Hermes, James (1991). «Gender and/in Media Consumption». En CurRAn, James y GUREVITCH, Michael (eds.), Mass Media and Society. Londres: Edward Arnold. 307-328.

Konno, Oyuki (1998) Maria-sama ga miteru. Tokio: Shueisha.

Miguez Santa Cruz, Antonio (2012). «De santos, kamis y hotokes: La religión japonesa a través de las relaciones jesuitas del siglo XVl». En SerRano MARTín, Eliseo (ed.), De la tierra al cielo: Líneas recientes de investigación en historia moderna, vol. 2, 207-222.

OGl, Fusami (2009). «Beyond Shoujo, Blending Gender». En HeER, Jeet y WorCESTER, Kenton (eds.), A Comics Studies Reader. Jackson: University Press of Mississippi, 244-251.

Platón (García Romero, Fernando, trad. 1989). El banquete. Madrid: Alianza.

Romero Leo, Jaime (2017) «El auge de la estética kawaii: origen y consecuencias». Kokoro: Revista para la difusión de la cultura japonesa (24), 1-2.

SwEnson, Allan (2002). Flowers of the Bible and how to grow them. New York: Citadel Press.

TomasI, Daniele (1993). «Los japoneses, el melodrama y el amor». Nosferatu: Revista de cine (11), 54-63.

YRJö, Hirn (1912). The sacred shrine: A study of poetry and art of the Catholic Church. London: Macmillan and Co. 



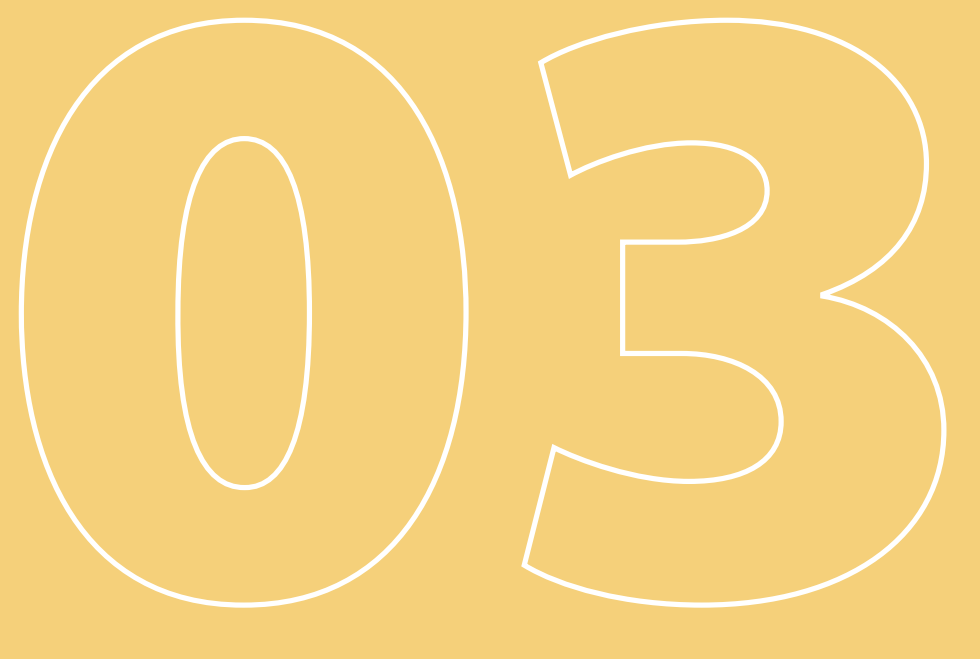

\section{"MACHOS, PROGRES Y}

\section{GALANES»: HOMBRES}

Y MOVIMIENTO FEMINISTA

\section{DURANTE LOS AÑOS}

\section{SETENTA Y OCHENTA}

«Machos, progres y galanes»: men and feminist

movement during the seventies and eighties

\section{CARLOS ADÁN GIL}

\section{Universidad de Zaragoza}

Fecha de recepción: 26 de junio de 2019 Fecha de aceptación: 10 de septiembre de 2019

\section{RESUMEN}

El artículo pretende sumergirse en los procesos de construcción de las masculinidades y la relación con el movimiento feminista de parte de la izquierda radical en España durante la Transición y los primeros años de la Democracia. Se trata de una contribución encaminada a cubrir un vacío historiográfico que amenaza con trasladar al presente un discurso sesgado en torno a los procesos de construcción identitaria y asimilación de valores igualitarios.

\section{Palabras clave}

Masculinidades, historia oral, izquierda revolucionaria, feminismo, identidad, género.

\section{ABSTRACT}

The article aims to immerse in the building processes of masculinities and its relationship with the feminist movement of the Radical Left in Spain during the Transition and the first years of Democracy. This article is a contribution aimed to cover a historiographic gap that threatens to bring into the present a biased discourse around the building processes of identity and the assimilation of egalitarian values.

\section{Keywords}

Masculinities, oral history, revolutionary left, feminism, identity, gender. 
El presente estudio tiene dos objetivos principales estrechamente relacionados entre sí: en primer lugar, pretende historizar el pasado de algunos hombres que se situaron, tanto a nivel personal como colectivo, del lado de sus compañeras feministas y, en paralelo, intenta analizar algunas de las causas que llevaron a que estos fueran minoritarios dentro del heterogéneo mundo de las izquierdas en la España de este periodo.' Tomados en conjunto, ambos objetivos dibujan el panorama de la relación del movimiento feminista con sus compañeros, con los que con frecuencia compartían luchas políticas, espacios e incluso proyectos de vida.

En el desarrollo de la investigación vamos a poner el foco, en primer lugar, en aquellos hombres que comenzaron a pensarse y plantearse sus roles de género de forma consciente, con una clara voluntad de cambio. Algunos de ellos llegaron incluso a formar grupos de reflexión y de trabajo con cierta permanencia en el tiempo, y a sentar las bases de lo que serían los estudios de género de los hombres y las masculinidades y del movimiento de hombres por la igualdad. Por otro lado, vamos a trabajar sobre aquellos militantes de partidos de izquierda que parecían vivir al margen de estos planteamientos, ignorando que su vida personal y los partidos políticos en los que militaban estaban cargados de significados de género; no eran conscientes, tal vez cegados por la coyuntura política y el centralismo democrático, de que una de las revoluciones más importantes que tenían pendiente estaba en sus relaciones de poder y el diálogo consigo mismos y sus cuerpos.

El presente trabajo no va a desarrollar otras masculinidades situadas en los márgenes, como las que evidencian personas con una orientación sexual no normativa o con un marcado transgénero. Los cuerpos y su dialéctica importan, y durante estos años va a desarrollarse un movimiento de liberación homosexual, formado por individuos que con frecuencia también militaban en partidos de izquierda, pero cuyas reivindicaciones, al igual que pasaba con las reivindicaciones feministas, no eran comprendidas y mucho menos consideradas prioritarias. Desde planteamientos libertarios también se desarrollaban formas de relacionarse no normativas. ${ }^{2}$ Estas posiciones, junto al «imaginario del 68», planeaban como telón de fondo de cambios en las relaciones de género que tenían lugar en algunas prácticas cotidianas, pero no se teorizaban y en ocasiones generaban tensiones y situaciones de crisis identitarias que llevaron al desarrollo de nuevas formas de expresar la masculinidad, aunque no siempre acarreaban un cambio en las relaciones de poder. ${ }^{3}$ El «macho ibérico» iba dejando paso, dentro de los círculos de la izquierda radical, a unas masculinidades más ancladas en la figura del «galán» o del «progre» que controla el discurso, el espacio público y la palabra. Unos y otros; aquellos más cercanos a las reivindicaciones feministas y con voluntad de cambio en lo personal y político, y sus compañeros, más

\section{INTRODUCCIÓN}

1. El título de la presente comunicación hace referencia directa a un curso que organizó el IPES (Instituto para la Promoción de Estudios Sociales) en Pamplona en 1985. El nombre del curso, «Machos, progres y galanes», sintetizaba muy bien las masculinidades prototípicas de ese momento, y en él participaron algunos de los protagonistas de este texto. Las aportaciones fueron de J. L. García, «Algunos mitos en relación con la sexualidad masculina»; Armand de Fluviá, «¿Existe una identidad homosexual?»; J. V. Marqués, «La masculinidad inhallable» y Rafael Castellano, «Desde la otra orilla».

2. Queda pendiente para futuras investigaciones trabajar las formas de convivencia y el desarrollo de las masculinidades en entornos más cercanos al anarquismo, en donde se hacía énfasis en la práctica cotidiana de la libertad y en la subversión de los valores establecidos; no obstante, también existieron desencuentros que llevaron a poner en marcha grupos de trabajo autónomos. Dos anécdotas que se citan en la obra de Laura Vicente Mujeres Libertarias de Zaragoza nos ponen sobre las coordenadas de unas relaciones muy similares a las que tenían lugar en otros entornos de la izquierda: la encuesta que mandó Mujeres Libertarias de Zaragoza sobre la presencia de mujeres en la organización de las federaciones locales de CNT, y la no participación de hombres en el grupo. Laura Vicente escribía respecto a la composición de Mujeres Libres/Libertarias, «aunque una parte importante de las mujeres defendían que fueran exclusivamente femeninos, se aprobó en la mayoría de los casos (así fue en el grupo de Zaragoza) que estuvieran abiertos a los hombres. El resultado final fue que ellos no aparecieron, o muy poco, por las reuniones y de ahí la esterilidad del debate» (Vicente, 2017: 64-65).

3. Los cambios en las prácticas cotidianas estaban centrados en el campo de la sexualidad, el amor libre, la vida en comunidad o cierta corresponsabilidad que en ningún caso llegaba a ser real. 
reacios o «miopes» ante esta perspectiva, estaban compartiendo espacios con mujeres feministas, y esto los marcó. ${ }^{4}$ Voy a intentar, por un lado, apuntar algunos rasgos de los primeros a través del análisis de testimonios y parte de la escasa producción escrita por ellos mismos en la época. Por otro lado, sobre los segundos, voy a trabajar principalmente a través de la historia oral y del análisis de sus historias de vida. ${ }^{5}$

Lo primero que llama la atención cuando nos acercamos al estudio de estos hombres y grupos de hombres «profeministas» o de trabajo personal en torno al género es la escasa conexión que parece haber entre ellos; el género es eso que nos constituye, establece límites de comportamiento, otorga privilegios, a veces incluso duele, y es de lo que un varón de este contexto es incapaz de hablar, tal vez víctima de ese «analfabetismo emocional» del que nos cuesta huir si no es a través de la ira o el enfado. Esta incapacidad para hablar de uno mismo, para cuestionarse, ayudó a que los grupos de reflexión no fueran muy numerosos, especialmente en una sociedad en la que las desviaciones de género no eran toleradas y, discursivamente, llegaban a suponer un problema mayor que la propia desviación sexual (Vélez-Pelligrini, 2011: 274). En ese contexto, ¿cómo hablar de uno mismo y no de política o deporte?, ¿cómo romper el silencio y «desnudarse» ante otros hombres?

Si los obstáculos que estaban encontrando estos hombres para expresarse y abrirse al resto de compañeros en pequeños grupos parecen evidentes, las dificultades que encontraron a la hora de significarse en el terreno de lo público para denunciar el patriarcado no fueron menores. En un homenaje al activista valenciano Josep Vicent Marqués, José Ángel Lozoya recordaba: «La denuncia del patriarcado la iniciaron algunas mujeres y muchos menos hombres. Unas y otros tuvieron que soportar la etiqueta de maricones y lesbianas con independencia de cuál fuera la orientación de su deseo sexual [...] mientras las feministas conectaban con las aspiraciones de las mujeres, los hombres por la igualdad se enfrentaban al rechazo del colectivo masculino, que los acusaba de hablar y escribir para caer bien a las mujeres. Algo que tampoco resultaba tarea fácil, porque un sector del movimiento feminista desconfiaba de cualquier hombre que defendiera sus argumentos». ${ }^{6}$ Este desprecio forma parte del juego de «premiar y castigar», utilizado para encauzar a aquellos individuos que se desvían de la norma, tanto a nivel discursivo como performativo, y en este juego las alusiones a la sexualidad estaban a la orden del día. En 1980, Joaquina Prades escribía en el periódico El País sobre las II Jornadas Sexológicas de Vitoria que se celebraron en 1979, en las que participó Josep Vicent. En palabras de Joaquina: «Cuando el sociólogo valenciano Josep Vicent Marqués
4. Además de la notable influencia que ejerce el feminismo en todos ellos, hay algunos rasgos que se derivan de la coyuntura que son comunes, mediatizando sus formas de acción y sus comportamientos. Estoy pensando en la obtención de la democracia como horizonte común, en las condiciones derivadas de la clandestinidad y en la necesidad de no significarse, con todo el componente simbólico-represivo que esto conllevaba.

\section{LA LUCHA ESTÁ TAMBIÉN EN NOSOTROS: HOMBRES
PROFEMINISTAS}

5. He encontrado algunas complicaciones metodológicas a la hora de trabajar sobre los primeros grupos de hombres, principalmente por la dificultad para dar con ellos. Se trataba de grupos de reflexión, cambiantes, de corta duración en el tiempo, con un marcado carácter introspectivo, y que, por norma general, no generaban documentación. Algunos, los menos, sí que están documentados, y otros van apareciendo poco a poco en algunas de las entrevistas que estoy realizando en el marco de mi tesis, pero todavía me encuentro lejos de poder hacer algo parecido a una «cartografía» de los mismos que me pueda llevar a valorar su «peso real». Respecto a militantes de partidos de izquierda que, si bien tenían contacto con el movimiento feminista, no hicieron de este su lucha, mi acercamiento ha sido a través de entrevistas en profundidad. Para desarrollar el presente texto, he utilizado una muestra de mis entrevistas a militantes de la izquierda radical. Una de las entrevistas fue algo diferente, al realizarla junto a su pareja, militante feminista. Creo que esta opción, aunque altere la dinámica metodológica del resto de las entrevistas y pueda llevar a mayores «deformaciones» del pasado, arrojó unos resultados muy fructíferos para la investigación.

6. Palabras pronunciadas en el acto de reconocimiento Hombre por la Igualdad 2007, promocionado por el Foro de hombres por la igualdad. Tuvo lugar en Sevilla el 20 de octubre de 2007. En la página Heterodoxia podemos encontrar una transcripción de parte del homenaje, que incluye las palabras de Josep Vicent y de José Ángel Lozoya, además de algunos vídeos del evento. Disponible en: $\underline{\text { https:// }}$ heterodoxia.wordpress.com 
intervino en las Jornadas Sexológicas del pasado año, sorprendió a propios y extraños con su furibundo ataque al machismo. Sus congéneres, posiblemente heridos en su virilidad, intentaron rápidamente descalificar tamaña osadía, "Marqués es homosexual", sentenciaron. Debieron pensar que, al no tratarse de un hombre de verdad, podía comprenderse su feroz crítica al género masculino» (Prades, 1980)

Marqués es, probablemente, el militante por la igualdad más prolífico y activo durante estos años. Entre 1978, momento en el que publica su artículo «Sobre la alienación del varón», y 1981, año en el que ve la luz la primera edición de su obra ¿Qué hace el poder en tu cama?, destaca su actividad en debates, seminarios y jornadas en las que denuncia activamente el patriarcado y la «miseria sexual» en la que, según decía, estábamos instalados los hombres.7 Estas dos obras destacan no solo por su contenido, sino por su acogida y difusión. El artículo «Sobre la alienación del varón» fue reconocido en 1978 con el premio de ensayo El Viejo Topo. En dicho artículo Marqués esboza, con su habitual estilo cómico, parte de la teoría que desarrollaría más a fondo durante la siguiente década, centrada en la crítica social y la denuncia del patriarcado y la opresión que también sufre el varón. ${ }^{8}$ Asimismo, su obra de 1981 ¿Qué hace el poder en tu cama?, recopilación de artículos y ponencias del autor durante los años anteriores, gozó de un gran éxito, con dos ediciones el año de su publicación con Ediciones 2001 y, debido a su demanda, una tercera edición en 1987, esta vez por parte de la editorial Icaria. El autor valenciano supo construir identidades más complejas, atendiendo también a la sexualidad o a la clase, consciente de que estas se conjugan ofreciéndonos distintos niveles de discriminación; si bien no teorizó sobre lo que posteriormente hemos denominado «interseccionalidad», sí que tuvo presente que las formas de dominación variaban en función de las características de los individuos, estableciéndose así jerarquías.

Medios como la revista El Viejo Topo o la editorial Icaria contribuyeron a dar voz a estos activistas. No obstante, se trata de unos años en los que no había todavía muchos medios en los que difundir estudios que aplicasen el género masculino como perspectiva de análisis; salvo contadas excepciones, estos se tenían que mover en los márgenes, haciéndose hueco en los espacios que les ofrecía la sexología, la medicina o los círculos feministas. ${ }^{9}$ En estos ambientes muchos activistas se empapaban de teoría feminista y «miraban de reojo» lo que estaban haciendo sus compañeras, y hubo hombres que, a imagen de algunos grupos feministas, ya fuese a causa de una tremenda empatía o interpelados por un cuerpo o unos roles que les pesaban, decidieron reunirse, compartir sentimientos y pensarse. ¿Por qué estos grupos no trascendieron en su momento? A las razones que se derivan del contexto político y de la creencia firme de sus compañeros de que su lucha no es prioritaria, y de que solo era importante en la medida en que permitía al partido ampliar sus bases, se unía su incapacidad para entender la vertiente identitaria del
7. En 2003, varios protagonistas del movimiento de Hombres por la igualdad volcaron algunos de los acontecimientos que consideraban importantes para el desarrollo de este movimiento en España en una cronología; en ella se recoge una referencia que hace Josep-Vicent Marqués a un artículo publicado en 1974 que inauguraría la reflexión sobre el varón. El nombre y autoría de dicho artículo todavía lo desconozco (Lozoya, 2003: 2).

8. El Viejo Topo es una revista de contenido político y cultural que sirvió de medio de expresión de muchas de las ideas de la izquierda del momento. Entre 1976 y 1982 llegó a publicar sesenta y nueve números, a los que habría que sumar ediciones monográficas. En 1993 se retomó su edición, que ha continuado hasta la actualidad.

9. Los agradecimientos que ofrece Marqués en su obra ¿Qué hace el poder en tu cama? son representativos del ambiente en el que se estaban debatiendo estas ideas; en ellos nos habla de las Jornadas Sexológicas de Vitoria, de cursillos de educación sexual, de la Semana de Psicología Gallega, de la coordinadora feminista de Pamplona, del Grupo de Mujeres del Ateneo de La Coruña, de los estudiantes de Medicina de la Autónoma de Barcelona o de varios grupos de sexología. Espacios que ejemplifican bien dónde se estaban desarrollando y debatiendo estas ideas. Considero importante poner en valor la influencia que han tenido estos campos en las principales preocupaciones teóricas de los estudios de los hombres y las masculinidades en España; así, no es difícil comprender el peso que tienen desde el inicio los trabajos relacionados con la medicina y la educación sexual y, con posterioridad, aquellos vinculados a la psicología, la sociología o la antropología, en detrimento de otros vinculados, por ejemplo, a la producción cultural, mucho más potentes en el ámbito anglosajón. 
género, y una decisión política de los integrantes de estos grupos de reflexión fue la de no trascender a la esfera pública, en la que los hombres siempre se han sentido tan cómodos, y quedarse en lo privado; en el trabajo personal. ${ }^{10}$

A pesar de esta decisión, encontramos algunos testimonios en artículos y revistas de la existencia y el funcionamiento de estos grupos. A partir de mediados de los ochenta, las referencias a los mismos son más frecuentes, en parte por la voluntad de dar a conocer su existencia y animar así a otros compañeros a reunirse y hablar, y también por su viraje hacia un trabajo personal que, en algunos casos, hace necesario marcar diferencias entre los grupos con un componente más político y aquellos con un desarrollo casi terapéutico, pero con anterioridad están prácticamente ausentes. En una edición extra de octubre de 1980, El Viejo Topo publicaba un número monográfico titulado Masculino, femenino, en el que participaban conocidas feministas de ese tiempo, junto a algunos hombres. ${ }^{11}$ El número, presentaba un artículo de Gerard Imbert Martí, «Los hombres sin palabra», y otro de Giles Bienvenu y Jean Michel Hirt, «Hombres al ralentí», extraído del número de la revista francesa Recherches titulado «Masculinités». En este número monográfico, además de artículos teóricos, se recogía el testimonio de dos participantes en un grupo de hombres de finales de los setenta, y se describían las características de sus integrantes, muy similares a las de sus compañeros del otro lado de los Pirineos: «Los componentes del grupo oscilaban entre los veinticinco y los treinta y cinco años, se situaban políticamente a la izquierda del PC, ninguno de ellos militaba en partidos, podían ser calificados en algún sentido de intelectuales y cuatro de ellos estaban o habían estado vinculados sentimentalmente con mujeres feministas». ${ }^{12}$

Al igual que en el citado ejemplo, en el que se había trabajado sobre «violencias», en España se estaban reuniendo los primeros grupos, generalmente empujados por compañeras feministas. ${ }^{13}$ Significativo de este empuje o de esta acción casi «reactiva» de algunos hombres ante la iniciativa de sus compañeras es un grupo que se crea en torno al 79 o el 80, al que denominaron «El Cardo». Juan, militante de un partido político de la izquierda radical, referencia un acontecimiento que pudo desembocar en su participación en este grupo. Al ser preguntado por la recepción de los planteamientos feministas en el seno del partido, por las dobles militancias y por los posibles espacios propios de sus compañeras, Juan me hablaba de «un momento de radicalización, en el sentido de lo que significaban los hombres respecto a las mujeres, o sea, nuestro alter ego, y plantearon que ellas tendrían que vivir separadas de nosotros, los hombres. Mi compañera se fue a vivir a un piso con mujeres y yo me quedé con mi hija».14

Sin embargo, encontramos otras vías por las que algunos militantes de partidos de la izquierda radical se acercaron al feminismo. Un caso curioso lo protagonizó Álvaro Guillén, que durante los años setenta militaba en el
10. Con frecuencia me he preguntado por el coste de oportunidad de esta decisión y cuáles habrían sido las dimensiones actuales del movimiento de haber tomado otra dirección desde sus inicios. Lo cierto es que el debate sobre focalizarse en el trabajo introspectivo o hacerlo en el trabajo de denuncia política e intervención en la esfera pública sigue hoy abierto. Podemos considerar los años noventa como años de cambio; tal vez empujados por la creciente denuncia social hacia la violencia machista (estoy pensando en casos tan mediáticos como el de Ana Orantes) o por los inicios de la implicación institucional en programas para hombres, estos grupos comenzaron a denunciar públicamente la violencia machista y el patriarcado.

11. Este número monográfico de 1980, con una tirada de 41000 ejemplares, es importante por su difusión, pero también como reflejo de que la problemática de género comenzaba a ganar visibilidad en España.

12. «Grupo de hombres», 1980.

13. En la ya citada cronología inconclusa del movimiento de hombres se referencia un grupo que se reunió durante los años setenta, en el que participaron activistas como Antonio Goyte, Albert García Hernández, Víctor Navarro y Julio A. Mañez, entre otros (Lozoya, 2003: 9).

14. Entrevista a Juan Ruiz (pseudónimo), bar El Callejón, Zaragoza, junio de 2018. Respecto al grupo de hombres «El Cardo», en él se intentó llevar a cabo un trabajo personal, pero no duró mucho, ya que se reunieron con una frecuencia trimestral a lo largo de un año. 
MCA (Movimiento Comunista de Aragón) en Teruel; un Teruel que parecía anclado en la década anterior y en donde desarrollar la actividad política era especialmente complejo, por el escaso número de militantes y por las dificultades que se planteaban a la hora de mantener el anonimato. Las características de esta ciudad hicieron que no se desarrollara un grupo de mujeres autónomo del MCA, y las lecturas que llegaban sobre feminismo a través del partido se acababan debatiendo de forma conjunta. Álvaro recuerda cómo estos debates le ayudaron a expresar mejor sus sentimientos y a posicionarse ante sus compañeros cuando reproducían mecánicas machistas: «Había que dar caña en las asambleas y llevarlo a la vida cotidiana, cuando alguien hacía algún comentario... y tú, así, también ibas aprendiendo». ${ }^{15}$

Unos y otros, los activistas que intentaban abrir espacio a las ideas igualitarias en el terreno de lo público y aquellos que llevaron su lucha a lo privado, mostraron tener una visión de cambio amplia, atendiendo también a otras formas de discriminación y creando entornos en los que se pudieran poner en práctica formas de relación menos autoritarias; entornos en los que «estar feminista». Esto no es extraño teniendo en cuenta su contexto: de alguna forma, la coyuntura los interpelaba y facilitaba que integrasen las diferentes luchas sociales en las que se veían inmersos, produciendo una visión muy rica, casi utópica, en un horizonte de expectativas amplio. ${ }^{16}$

La falta de implicación en la lucha contra el patriarcado de gran parte de la izquierda se puede explicar desde distintas perspectivas. Tal vez la que más influyó fue la de su propia posición de género: estos militantes, como hombres, gozaban de la comodidad de ser los beneficiarios de una posición de poder ventajosa en esa relación unívoca que se tiende a establecer con la otredad, y no sentir el peso específico del género puede llevar a reproducir inercias patriarcales y a ser «invisible a uno mismo». Otra perspectiva de análisis para explicar esta falta de interés es la que se desprende de la coyuntura: estaban condicionados por la prioridad política de la obtención de la democracia y la lucha contra el capitalismo. En 1978 Marqués escribía: «Una vez el mundo de los hombres hizo el capitalismo y el capitalismo siguió consagrando un mundo de varones, se hace difícil dar al varón lo que es del varón y al capitalismo lo que es del capitalismo, aunque hoy por hoy la izquierda parezca convencida de que el capitalismo tiene la culpa de todo» (Marqués, 1977: 13).

Inmersos en las dinámicas de partido, era difícil para ellos entender estas luchas como algo más que una extensión de su actividad. Nicolás Díaz,
15. Entrevista a Álvaro Guillén (pseudónimo), cedida por Sandra Blasco, Teruel, noviembre de 2018. No obstante, aunque en Teruel se produjeron debates en un ambiente mixto, la implicación masculina fue minoritaria; prueba de ello es que cuando Merche Gallizo fue a Teruel como militante del MCA y del Frente Feminista para dar a conocer las actividades del Frente en Zaragoza, en palabras de Álvaro Guillén, «en la presentación había unas 30 personas y el "único pantuflo" era él» (Blasco, 2019).

16. A finales de los años ochenta, muchos de estos hombres comprometidos con el cambio en las relaciones de género comienzan a abandonar la lucha desde un punto de vista holístico, de cambio del sistema, desmigajando y acotando sus reivindicaciones, parcelándolas en distintos frentes entre los que con frecuencia no se buscan puntos en común. En definitiva, se pierde gran parte del componente subversivo que tenía con anterioridad el movimiento, aunque se mantiene una denuncia activa de la violencia y se desarrolla un análisis crítico del componente identitario de género. Todavía está pendiente hacer un estudio serio sobre las consecuencias de esta tendencia, que tal vez acarrea un menor potencial deconstructivo; se trata de la fuerza de la ilusión y la utopía del cambio integral, frente al desencanto y un activismo más centrado en medidas concretas.

LA IZQUIERDA AUSENTE EN LAS REFLEXIONES DE GÉNERO 
militante de Larga Marcha hacia la Revolución Socialista, un partido que nació en Zaragoza, recordaba la función que se asumía que debían llevar a cabo las compañeras feministas: «Por supuesto que las mujeres en el movimiento feminista tienen que abrir paso al partido en el movimiento feminista, porque es un movimiento que se está abriendo y ahí hay que estar, ¿no? Pero quién dirige el movimiento feminista, pues el partido, y ¿el partido quién lo forma en la dirección? Pues el 80 o 90\% hombres... bueno, pues porque ha salido así...». ${ }^{17}$ Pere Serra, uno de los dirigentes del Partido del Trabajo en Aragón, recordaba como veían a la ADM (Asociación Democrática de la Mujer, la rama femenina del partido, más como movimiento en el que ganar posiciones políticas que para conseguir un cambio real: «Yo no puedo decirte más que, en mi vivencia pensada de aquel momento, la lucha que domina es la lucha por la democracia, y esa no lleva a un análisis directo e implícito del feminismo, sí en esos puntos más gordos que eran evidentes que son esclavitud. En realidad, estaríamos hablando de la esclavitud de la mujer en el movimiento primitivo, no tanto en las relaciones humanas». ${ }^{18}$ Juan Ruiz aseguraba: «Lo que te digo, apoyábamos la vivienda, apoyábamos todo [... La gente era muy muy muy de defensa de los currantes, la igualdad salarial y... iy sin embargo a las mujeres ni puto caso!». ${ }^{19}$ Respecto a las reivindicaciones del Movimiento de Liberación Homosexual, su postura era muy similar. Nicolás recuerda haber desarrollado cierto respeto, incluyendo este tema en el ámbito de lo personal y de la libertad, pero admite que se miraba con recelo y no se quería en sí. «También llega un momento que pasa como con el feminismo "bueno, pues los que estén en esa onda que se organicen en beneficio del partido". Es un ambiente en el que quedaría muy mal no estar... aunque el lenguaje seguía siendo muy agresivo contra esto...».20

Nicolás describe esta dinámica como «la pragmaticidad operativa política del marxismo leninismo», que «acababa pasando por encima de esa mixtura influenciada por el mayo del 68 y elementos pseudoanarquistas». Eusebia Cortés, militante de Larga Marcha, feminista y pareja de Nicolás, recuerda el centralismo democrático como un sistema que la apartó de una forma de vivir en la que se sentía más cómoda: «Yo no podía soportar el centralismo democrático... a mí me encantaba la contracultura. Vivíamos en grupo... éramos así. Pero en un momento dado, como estaba Franco y la estructura de partido, pues nada de contracultura, a casarse, a vestirse normal, porque si no la policía... [...] Y dentro de eso, las reivindicaciones de las mujeres pues caían también, porque lo importante era tirar la dictadura». ${ }^{21}$

A este aparato de partido cerrado y a las fuertes inercias que arrastraban, hay que añadir un espejismo que hacía todavía más complejo el diálogo entre las feministas y sus compañeros. Se trata de la firme creencia por parte de la mayoría de los militantes de que en sus entornos más cercanos,
17. Entrevista a Nicolás Díaz (pseudónimo), parque José Antonio Labordeta, Zaragoza, junio de 2018.

18. Entrevista a Pere Serra (pseudónimo), Yéqueda (Huesca), junio de 2018.

19. Entrevista a Juan Ruiz (pseudónimo), bar El Callejón, Zaragoza, junio de 2018.

20. Entrevista a Nicolás Díaz (pseudónimo), parque José Antonio Labordeta, Zaragoza, junio de 2018.

21. Entrevista a Eusebia Cortés (pseudónimo), parque José Antonio Labordeta, Zaragoza, junio de 2018. 
y en los propios partidos, ya se había instalado una suerte de igualdad entre sexos, y que, en todo caso, solo cabía apoyar a las mujeres en la obtención de algunos derechos en el terreno de lo político. Nicolás Díaz considera que «había un planteamiento de eso que se oye hoy también bastante, de que "la igualdad ya está","ya la tenemos entre nosotros"; luego, si yo soy más líder soy más líder...». Eusebia recuerda que era una inercia, pero que esta saltó en espacios privados con temas como el de la crianza, porque «había que cuidar a la criatura», recuerda, «como estábamos en un partido y él estaba en un nivel de partido más alto, pues siempre las cosas parecían más importantes. Entonces es cuando yo le dije que bueno, "aunque tú tengas una reunión de alto nivel del partido y yo me vaya a pasear, tengo derecho a ir a pasear", o sea, tuve que plantearlo así». Pere Serra también tenía una percepción similar en torno a la sensación de igualdad que flotaba en el ambiente entre muchos hombres. Sin embargo, entre las compañeras de militancia o de vida de estos activistas, ya empezaba a haber mujeres que «entraban un poco a contrapelo de lo que era una dinámica formalmente abierta pero operativamente muy patriarcal».22

Los hombres, aunque parecían conectar mejor con las reivindicaciones enfocadas a la obtención de derechos políticos, también fueron partícipes de avances importantes en el terreno de lo privado. Nicolás recuerda cómo entró a Larga Marcha por la Revolución Socialista después de haber participado en los comités de estudiantes durante sus años de carrera; y esos años fueron para él «los de las teorías comunitarias... yo creo que por influencia del mayo francés, y ahí era más el papel de la mujer... bueno, ahí estaba el tema, por ejemplo, del amor libre, la sinceridad entre la pareja, el tener relaciones múltiples en un momento determinado siempre que hubiera cariño verdadero y comunicación... jen fin! Todo eso era lo que movía un poquitín unas relaciones teóricamente igualitarias». Esta creencia en la normalidad instalada entre sus filas no solo complicaba una autocrítica de ellos mismos como sujetos opresores, sino que dificultaba la comprensión de la vertiente identitaria del género; vertiente que era invisible incluso para muchas mujeres, que no siempre supieron llevarla al campo de la teoría. Como afirmó Pere Serra ante la pregunta de si eran capaces de percibir el componente simbólico-identitario del movimiento: «los hombres no, y las mujeres sufriendo». ${ }^{23}$

$Y$ es que en este terreno, en el de los símbolos, los espacios, la palabra, las emociones, las inercias heredadas... es en donde más tuvieron que pelear las mujeres feministas con sus compañeros. Y ellos, poco a poco, fueron transitando de unas masculinidades a otras, aunque no siempre de forma consciente. Este tránsito, que muchas veces pasaba por la incorporación de elementos de «masculinidades subordinadas» o «no normativas», no hemos de entenderlo en términos lineales, ya que no siempre venía acompañado de una crítica a las relaciones de poder. La mayor parte de los militantes de la
22. Entrevista a Nicolás Díaz (pseudónimo), parque José Antonio Labordeta, Zaragoza, junio de 2018.

23. Entrevista a Pere Serra (pseudónimo), Yéqueda (Huesca), junio de 2018. 
izquierda radical percibía los modelos de masculinidad del franquismo, cuya caricatura estaría representada por el famoso «macho ibérico», como caducos y carentes de prestigio social, y entre ellos ganaba terreno un modelo mucho más acorde a su contexto personal: el del «progre» que controla la situación y domina la dialéctica. ${ }^{24} Y$ el éxito de este modelo entre muchos militantes de la izquierda radical no pasó inadvertido; su desarrollo constituyó una forma de anclaje identitario en un momento de transformación, e incluso de crisis de la masculinidad.

Gerard-Imbert Martí describía en 1980, con mucho acierto, este modelo en términos de relación de poder; según Martí el poder es también «el discurso del entendimiento, de aquel que "conoce lo suyo", es el metalenguaje del intelectual barbado, aquel que hace una profesión de su saber, que administra con toda tranquilidad de conciencia el territorio de su dominio. Es el lenguaje diplomático (enigmático, elíptico) de un buen número de intelectuales cansados y de vuelta de todo sin haber ido a ninguna parte; ex sesenta y ocho y lacanianos de buen tono que manejan su impotencia y saben dosificar sus silencios por miedo a caer sobre un terreno común al otro [...] lo que equivaldría al fin de su privilegio enunciador, a la muerte de su estrategia discursiva...» (Marti, 1980: 45). Pero «¿qué pasa cuando los hombres hartos de tener este lenguaje untuoso, codificado, eternamente repetido, cuando estos hombres deciden reunirse para decir otra cosa?» (Vandenesh, 1980: 50). Nuestros protagonistas, pese a ser los «dominadores de la palabra», presentaban un síntoma de su socialización que habría de pasarles factura en sus relaciones personales; se trata de su incapacidad para hablar de ellos mismos y trabajar el mundo de los sentimientos.

Muchos de estos militantes han acabado abriéndose a esta vertiente más identitaria del género; algunos, como Juan Ruiz, lo hicieron ya desde finales de los setenta, participando en grupos de reflexión como El Cardo, para otros, como Pere Serra, fue un proceso lento que, probablemente, comenzó también en los setenta, gracias a su implicación en los cuidados a raíz de su trabajo en un psiquiátrico y a un fuerte vínculo con las corrientes de la antipsiquiatría. Otros de los militantes de la izquierda radical se han abierto y han modificado sus masculinidades gracias a su implicación, ya en los años ochenta, en otros movimientos como el ecologismo o el pacifismo, y a los contactos con el MOC (Movimiento de Objeción de Conciencia) y sus formas de resistencia basadas en la confianza mutua y la no violencia. 25

Un caso muy ilustrativo es el de Nicolás Díaz, que sitúa su militancia en el Movimiento por la Paz y el Desarme, de marcado carácter proactivo, como un momento de ruptura de inercias nocivas y crecimiento personal. Nicolás recuerda: «Cuando llegaron las coordinadoras, siempre tocaba "a ver, ¿quién va a la coordinadora el próximo día?", y acabábamos yendo tres o cuatro tíos; un coche de tíos, y no... ahí sí que estaba ya el planteamiento de decir "a
24. Hago referencia a este modelo, común también entre militantes de izquierda de otros países, por ser uno de los más representativos del momento, pero entiendo la masculinidad como algo fluido y en constante cambio y, por tanto, como algo conformado por la subjetividad de cada individuo.

25. A partir de finales de los setenta se desarrollan diferentes movimientos que modifican las formas de relacionarse y de acción, cambiando los antiguos métodos de militancia: el movimiento antipsiquiátrico, el pacifismo y el ecologismo y, más adelante, el movimiento insumiso (con posterioridad el MOC). En la actualidad, muchos hombres cercanos al feminismo se han reencontrado con antiguos compañeros de militancia en estos movimientos sociales, junto a los que cuestionaban, sin saberlo, la cultura patriarcal: «Estoy convencido de que esa desobediencia a realizar el servicio militar fue un primer paso para aplicar, en nuestras propias vidas, la resistencia al mandato de las masculinidades hegemónicas tóxicas, contra las que habíamos empezado a luchar sin darnos cuenta» (Bacete, 2017: 203). 
ver, las mujeres, va, venga, ¿por qué no vais?" [...] sí que hubo un momento en el que se debate conscientemente en el colectivo "¿por qué no van las mujeres?"... y entonces piden ellas un espacio para hablarlo y se reúnen. Yo recuerdo, porque fue muy llamativo, que nos vinieron ya con una respuesta. [... . Llegan y dicen"que no, que hemos decidido que ya sabemos por qué no vamos y es que no nos gusta, no aceptamos el ambiente agresivo y competitivo que hay en las coordinadoras, y claro, mientras no cambiéis eso nosotras no vamos" [...] decían: no, no, mientras no nos cambiéis el entorno, nosotras ir allí para volver deprimidas y hechas polvo y tal, no vamos». ${ }^{26}$

Eusebia Cortés hace mucho énfasis en un punto: en el movimiento pacifista, al contrario de lo que había pasado en sus militancias anteriores, los métodos entraban. Recuerda que ahí era frecuente que marcasen liderazgo las mujeres. A veces se reunían por separado las mujeres y los hombres y «nosotras decíamos muchas cosas de nosotras mismas en la reunión, y ellos hablaban de temas exteriores a ellos, ¿no? Esa era un poco la cosa... . ${ }^{27}$ «Ellas, por ejemplo, tenían un énfasis temático en cuestiones identitarias muy fuerte, y hablaban continuamente de la relación, de la prioridad, del no sé qué, de la visibilidad, de todo esto, ¿no? Y a nosotros, que nos parecía bien todo eso, de alguna manera nos marcaban el liderazgo ellas, y en cuanto nos dejaban solos, pues estábamos arreglando el mundo (risas), de qué había que hacer las siguientes elecciones, de cómo habría que hacer no sé qué, y ya está... . ${ }^{28} \mathrm{~A}$ través de estas dinámicas, esa capacidad de análisis personal que tanto había dificultado los discursos de género en el terreno privado y esa supuesta «normalidad igualitaria» en la que se creían instalados buena parte de los militantes de la izquierda radical, se iba descomponiendo, hasta el punto de que poco a poco no solo fueron cambiando las relaciones con sus compañeras, sino también entre ellos. Esto se ejemplifica bien volviendo a la negativa de las mujeres del movimiento pacifista a ir a las reuniones de la coordinadora en Madrid si no cambiaban antes las formas de relacionarse. Nicolás reconoce: «Unos años después a nosotros ya no nos gustaba ir a Madrid tampoco [...] Ya estábamos en una línea en donde estábamos a gusto en las relaciones que habíamos sido capaces de desarrollar aquí». ${ }^{29}$

En la presente investigación hemos trabajado sobre testimonios y fuentes de época, con intención de afinar la visión que tenemos de un periodo de nuestro pasado reciente que, hoy en día, parece estar más vivo que nunca. Hablar de conclusiones es algo pretencioso si tenemos en cuenta que además de sacar a la luz a algunos grupos de hombres que se estaban formando desde los años setenta, hemos tratado de adentrarnos en el mundo subjetivo de las identidades y de la percepción personal sobre los

26. Entrevista a Nicolás Díaz (pseudónimo), parque José Antonio Labordeta, Zaragoza, junio de 2018. En este caso, los hombres del movimiento pacifista también acusaban una influencia europea, con partidos en donde las mujeres están en primera línea, como Los Verdes, con representantes como Petra Kelly. En la cadena humana que tuvo lugar en Zaragoza hacia la base militar (1983) se invita a los verdes y estos envían a Heidi, una mujer, lo que todavía choca con los esquemas que se arrastran de la etapa anterior.

27. Entrevista a Eusebia Cortés (pseudónimo), parque José Antonio Labordeta, Zaragoza, junio de 2018.

28. Entrevista a Nicolás Díaz (pseudónimo), parque José Antonio Labordeta, Zaragoza, junio de 2018.

29. Entrevista a Nicolás Díaz (pseudónimo), parque José Antonio Labordeta, Zaragoza, junio de 2018.

\section{CONCLUSIONES}


avances del feminismo. Tampoco hemos de olvidar, como se ha puesto de manifiesto al comienzo del texto, que hay un vacío historiográfico en torno a la relación de los componentes de los grupos de izquierda con el feminismo y cómo esta relación indujo cambios en sus masculinidades e influyó en el desarrollo de los distintos feminismos.

Como hemos visto, no fueron muy numerosos los activistas que se acercaban a las reivindicaciones feministas, pero entre ellos se encuentran los fundadores de los primeros grupos de hombres en España. El desarrollo de estos grupos de reflexión se produce en paralelo al crecimiento del movimiento feminista, e incluso podemos afirmar que la mayoría de ellos surgen como una reacción positiva a la crítica de los modelos de género y a un sistema patriarcal al que muchos relacionaban de forma unívoca con el sistema capitalista. En este contexto de efervescencia de los feminismos, los grupos de conciencia femenina y los debates en torno a las vías para cambiar el sistema, algunas feministas animaron a sus compañeros de militancia, a sus compañeros de vida y amigos, a crear grupos en los que se cuestionasen sus roles de género. ${ }^{30}$ Algunos hombres trascendieron los propios grupos, alzando su voz en el terreno público a través de medios de difusión en los márgenes, siendo por ello objeto de duras críticas.

Si durante los años setenta podemos hablar de los grupos de hombres como algo excepcional, esta excepcionalidad se rompe ligeramente en los ochenta cuando «se pasa de militancia a activismo»; cuando se modifican las formas de relación entre compañeros, dejando así hueco para que penetrasen algunas de las ideas que venía defendiendo el movimiento feminista, aunque desprovistas del componente de clase que las acompañaba una década antes.

Dentro del heterogéneo mundo de las izquierdas en la España de los años setenta y ochenta, lo más frecuente fue una posición pasiva e incluso reticente a las reivindicaciones que planteaban sus compañeras, tanto dentro del partido, como a través de grupos autónomos. Entre las causas que se desprenden de los testimonios que hemos recogido, podemos apuntar:

- Influencia del partido: Muchos de estos activistas formaban parte de una estructura de partido vertical, de centralismo democrático, en la que se priorizaba un determinado sujeto político y solo se abrían a otras reivindicaciones en la medida en la que les permitían generar hegemonía y ganar posiciones para el propio partido. Los espacios y los tiempos de trabajo no estaban concebidos para conciliar ni para compaginar la militancia con actividades asociadas al mundo femenino.

- Contexto político: La situación política hacía que la obtención de la democracia fuese el horizonte común a todos los grupos de izquierda de la época, desatendiendo en ocasiones las políticas de lo cotidiano. Además, la clandestinidad con frecuencia imponía ceñirse a la norma para
30. Algunas de estas ideas las desarrollé en la ponencia «Género y masculinidades. Identidades disidentes, rupturas comunitarias», expuesta en el I Congreso Internacional sobre Masculinidades e Igualdad, celebrado en Elche los días 4-6 de abril de 2019. En dicha ponencia se hacía referencia a cómo los grupos de hombres se estaban formando, en parte animados por compañeras feministas, y a los trasvases de militancia entre los nuevos movimientos sociales y los grupos de hombres igualitarios. 
conservar cierto grado de anonimato, dejando así de lado otras prácticas que pasaban por formas de convivencia y crianza en comunidad, amor libre o transgresiones estéticas.

— Concepción cerrada de lo político: Uno de los principales problemas que encontraron estos activistas cuando se enfrentaban a las propuestas que formulaban sus compañeras radicaba en su dificultad para situar lo político fuera de la estructura y el espacio público, haciendo complicado que pudiesen comprender en profundidad aquellas reivindicaciones que no estuviesen estrechamente relacionadas con la obtención de derechos concretos. Esta incomprensión hizo que con frecuencia se tomasen algunas de las cuestiones que debatían o proponían sus compañeras para mejorar la convivencia como reproches o ataques hacia su propia persona, rompiendo así los vínculos de confianza.

- Falsa percepción de que la igualdad ya estaba instalada entre ellos: Se trata de un «espejismo» recurrente en las entrevistas que he realizado, y es que entre muchos de los militantes de los partidos de la izquierda radical existía el convencimiento de que su entorno era tan diferente al de la época de sus padres que las desigualdades que seguían existiendo eran en esencia fruto de un sistema que las amparaba, pero que modificando el sistema a través de cambios legales y de una mayor incorporación de la mujer al mercado laboral desaparecerían. Esta percepción denota cierta falta de autocrítica y una gran dificultad para percibir que los cambios en la estructura también se pueden inferir a través de cambios en las relaciones de poder cotidianas, en las que ellos jugaban de forma inconsciente el papel de opresores.

— Tránsito entre modelos de masculinidad: Si bien es cierto que los hombres que tratamos en este apartado no se implicaron de forma activa en el movimiento feminista, la forma de expresar su masculinidad sí que cambió. Entre los componentes de los grupos de izquierda se desarrolló ampliamente el modelo del «intelectual» que dominaba la palabra y mantenía así cierto prestigio social.

En definitiva, la mayor parte de los hombres no se sentían vinculados a la lucha feminista, sea por incomprensión de muchas de sus reivindicaciones, por entender que el sujeto político que defendía dicha lucha los dejaba al margen o simplemente por miedo a los cambios en las relaciones de poder que sus propuestas pudiesen conllevar. En 1985, Ángel Lozoya escribía respecto a los hombres y los cambios que se iban produciendo de la mano del movimiento feminista: «Que la iniciativa de estos cambios no haya sido nuestra, plantea un doble problema: por un lado, nos hemos tenido que ir adaptando individualmente a una situación que no sabemos adónde nos lleva, a costa de una cierta pérdida de identidad, y a la vez, se trata de una adaptación a la que nos resistimos, por miedo a sus consecuencias» (Lozoya, 1985: 28). 


\section{BIBLIOGRAFÍA}

BACETE, Ritxar (2017). Nuevos hombres buenos: La masculinidad en la era del feminismo. Barcelona: Península.

BLAsCO LISA, Sandra (2019). La construcción de las subjetividades feministas en el tardofranquismo y la transición: El movimiento feminista en Aragón (1966-1986) [tesis doctoral]. Universidad de Zaragoza.

LozorA, José Ángel (1985). «El comportamiento masculino a debate (el hombre ante los avances de la mujer)». Sexpol: Revista de información sexológica (7). Disponible en: http://joaquimmontaner.net/cronologia/ los-80s/1985-2/\#

- et al. (2003). Cronología inconclusa del movimiento de hombres igualitarios en el estado español. Disponible en http://szil.info/es/system/files/ document/103-cronologia-inconclusa.pdf

MARQuÉs, Josep-Vicent (1978). «Sobre la alienación del varón». El Viejo Topo

(19), abril. Disponible en http://joaquimmontaner.net/cronologia/ timeline-post/sobre-la-alienacion-del-varon/

— (1981). ¿Qué hace el poder en tu cama? Barcelona: Ediciones 2001.

MARTI, Gerard-Imbert (1980) «Hacia una masculinidad de-liberada», El Viejo Topo, n.o extraordinario 10. Barcelona: Ediciones 2001.

Prades, Joaquina (1980). «Los modelos sexuales establecidos, sometidos a revisión en las jornadas de Vitoria». El País, 8 de abril. Disponible en: https:// elpais.com/diario/1980/04/08/sociedad/323992803_850215.html

S. a. (1980). «Grupo de hombres», El Viejo Topo, Extra n. ${ }^{10}$ (Masculino, femenino).

VAndENESH, Jean (1980). «Los hombres sin palabra». El Viejo Topo, Extra n.o 10. Vélez-Peluigrin, Laurentino (2011). Sujetos de un contra-discurso: Una historia de la producción teórica gay, lesbiana y queer en España. Barcelona: BeIlaterra.

ViCente, Laura (2017). Mujeres Libertarias de Zaragoza: El feminismo anarquista en la transición: Mallorca: Calumnia.

\section{ENTREVISTAS}

Entrevista a Álvaro Guillén (pseudónimo), cedida por Sandra Blasco, Teruel, noviembre de 2018.

Entrevista a Eusebia Cortés (pseudónimo), parque José Antonio Labordeta, Zaragoza, junio de 2018.

Entrevista a Juan Ruiz (pseudónimo), bar El Callejón, Zaragoza, junio de 2018.

Entrevista a Nicolás Díaz (pseudónimo), parque José Antonio Labordeta, Zaragoza, junio de 2018.

Entrevista a Pere Serra (pseudónimo), Yéqueda (Huesca), junio de 2018. 

off Filanderas with «Language, literature and coeducation», where she unraveled the details of time, effort and love that teachers, mostly women, dedicate to the inclusion of equality in educational life «usually in an invisible or invisible way by administrations» (2016: 74).

From the progressive implementation of gender policies, creation of national and regional laws regulating the incorporation of equality in the education system, regulations, pacts (including the recent approval of the State Pact on Sexist Violence), the inclusion of educational equality continues to be hampered by the idiosyncrasy of the educational system itself and the policies that govern it. This article is based on the analysis of this situation, as well as on the evaluation of the consequences of the absence of generalized equality in the education system.

\section{Key words}

Education, equality, inclusion, gender policies, teachers.

Numerosas jornadas y ponencias actuales, resultado de trabajos de investigación relacionados con la igualdad de género, sitúan en el punto de mira la enseñanza como camino hacia la erradicación de las violencias machistas y la incorporación de una igualdad real en los ámbitos de la sociedad actual. Se trata de una carrera de obstáculos, que comienza por los discursos documentados sobre propuestas de políticas de igualdad en el ámbito educativo, donde se legitiman objetivos que implican contradicciones permitiendo entrever relaciones de poder e ideologías implícitas (Pini, 2010: 108) que no solo no tienen nada que aportar a la consecución de una coeducación real y efectiva, sino que además dificultan el proceso.

El artículo desarrolla un análisis diacrónico de los procesos normativos que se han ido sucediendo en España con el objetivo de incorporar la igualdad de género en el sistema educativo nacional y autonómico, paralelamente a la revisión de los factores intrínsecos de la realidad de los centros educativos, con base en las investigaciones de diferentes autoras y autores. En el artículo se argumenta como la creación de normativas reguladoras de la incorporación de la igualdad de género en la vida escolar es real pero limitada por diversos factores. El argumento se expone en cuatro secciones: la primera trata el contexto de implementación de políticas de género en el ámbito educativo; la segunda, los ámbitos para la consecución de la igualdad real en la educación; la tercera recoge una muestra de los obstáculos que se oponen a la correcta implementación de la igualdad en los centros educativos y la última expone las conclusiones sobre la relación de la inexistencia de 
un sistema educativo igualitario y la perpetuación de la violencia de género desde las aulas.

Para el análisis del contexto de partida es preciso revisar nuestro reciente pasado desde el tránsito de la educación segregadora y sexista de Moyano a la instauración de la escuela mixta republicana, la recuperación de la segregación franquista y, con la llegada de la democracia, la actual escuela mixta.

Las políticas del gobierno de Zapatero dieron luz verde a numerosas iniciativas en pos de la igualdad hasta la entrada de políticas conservadoras que supusieron el gran retroceso de lo conseguido hasta el momento. En un intento por sumergir al sistema educativo español en la corriente neoliberalista dictaminada por el Banco Mundial y el Fondo Monetario Internacional (despejando el camino a la privatización de la enseñanza pública) y en pleno auge de las políticas de recortes, el ministro Wert, avalado por la LOMCE, retiró la asignatura de Educación para la ciudadanía del currículum a la vez que aumentaba la carga lectiva de la asignatura de Religión, incorporaba como alternativa la asignatura Valores culturales y sociales y protegía a los centros segregadores por sexo del retiro de conciertos, entre otras medidas; siendo advertido por el Consejo de Estado terminó proponiendo la inclusión de algunos de los contenidos de Educación para la ciudadanía en la asignatura Valores éticos (de naturaleza optativa) provocando que conocimientos básicos sobre la educación afectivo-sexual o la desigualdad de género quedaran relegados a un segundo plano a golpe de mazo, sin diálogo ni consenso con la comunidad educativa, pero con acuerdos con la Conferencia Episcopal (Pérez Mendoza, 2017).

El recientemente relevado gobierno de Rajoy, caracterizado por el respaldo de proyectos neoliberales, «apostando por unas políticas de igualdad más restrictivas de los derechos de las mujeres» (Lombardo y León, 2014: 32), y auspiciado por las políticas de austeridad procedentes de Europa, ha provocado la desarticulación de políticas específicas y la ausencia de medidas anticrisis para los países miembros de la UE, factor que puede desembocar en grandes regresiones en materia de igualdad (Idem), regresiones con gran incidencia en el ámbito social y, por lo tanto, en el ámbito educativo.

Dicha desarticulación de políticas específicas en materia de igualdad tiene su influencia sobre los diversos obstáculos estructurales que siguen dificultando o imposibilitando que mujeres y hombres ocupen los diferentes espacios sociales en condiciones de igualdad real (Venegas, 2010: 397) como mostraré a continuación en los diferentes ámbitos: normativo, económico, social y educativo.

\section{CONTEXTO DE IMPLEMENTACIÓN DE POLÍTICAS DE GÉNERO EN EL ÁMBITO EDUCATIVO}


El exceso de normas y regulaciones por parte de administraciones e instituciones provoca desajustes estructurales entre el entorno técnico (profesorado) y el entorno institucional que configuran las organizaciones escolares. ¿Esto qué quiere decir? Es una realidad que pone en evidencia cómo la burocracia característica del sistema educativo genera conflictos a nivel de participación del personal docente, sobre todo en relación a propuestas de introducción de innovaciones, y especialmente si van acompañadas de un sistema de incentivos desproporcionado (Fernández, 1995: 33-34): los claustros no muestran gran entusiasmo ante la idea de implementar programas que conlleven una carga extra de formación, coordinación, elaboración de nuevos materiales didácticos, revisión de los ya existentes, etc., recibiendo a cambio, en la mayoría de los casos, ${ }^{2}$ como máximo una o dos horas de liberación para poder dedicar a las nuevas tareas, a pesar del convencimiento o la comprensión (encontramos también diferentes grados de compromiso) de la necesidad de la inclusión de la igualdad en sus centros.

Según el informe sobre la calidad de la gobernanza ${ }^{3}$ del sistema educativo español de 2017 (López, García y Expósito, 2017: 84), se califica la calidad de la misma con un 1,6 en una escala del 0 al 4; como conclusiones, proponen una serie de recomendaciones relacionadas con la responsabilidad, formación y preparación de responsables políticos, cooperación entre instituciones, así como la profesionalización de las administraciones educativas, con la finalidad de conseguir una gobernanza más competente.

Como muestra de esta evidencia basta recordar como la totalidad de la comunidad educativa, respaldada por una mayoría parlamentaria, mostró su firme oposición al mantenimiento de la LOMCE, ley que en la actualidad se encuentra en proceso de desactivación, pero mantiene vivas grandes secuelas materializadas en el derroche de recursos y energías de la mano de reformas y contrarreformas que siguen sin reflejar las necesidades curriculares de una sociedad actual repleta de desigualdades (Idem).

A continuación, se muestra una presentación de los diferentes ámbitos de influencia que condicionan la consecución de la igualdad real y efectiva en los espacios educativos.

\section{Ámbito normativo}

La Ley Orgánica de medidas de protección Integral contra la Violencia de Género, de 29 de diciembre de 2004, recoge en su apartado II: «La violencia de género se enfoca por la Ley de un modo integral y multidisciplinar, empezando por el proceso de socialización y educación. La conquista de la igualdad y el respeto a la dignidad humana y la libertad de las personas tienen que ser un objetivo prioritario en todos los niveles de socialización». ${ }^{4}$

\begin{abstract}
2. El departamento de Educación del Gobierno Vasco ha activado la convocatoria de Proyectos de actuación en el ámbito de la coeducación y la prevención de la violencia de género 2018-2021 con la asignación de crédito horario correspondiente a la jornada de medio profesor o profesora (nueve horas semanales) que podrá ser disfrutada en cualquiera de los tres cursos del proyecto, para los proyectos de Educación Primaria y para los proyectos de Educación Secundaria, tres horas de crédito horario semanal durante cada uno de los tres cursos a los que hace referencia esta convocatoria. (Instrucciones por la que se convoca a los centros públicos de Educación Primaria y Educación Secundaria de la CAPV, para solicitar la realización de proyectos de actuación que les permita abordar la coeducación y la prevención de la violencia de género para los cursos 2018-2019, 2019-2020 y 2020-2021. Disponible en:www.berritzeguneak.net/legeria/1/2018/ bidelaguna 2018-2019 c.pdf).
\end{abstract}

3. «El concepto de gobernanza proviene del mundo anglosajón y se refiere a las tradiciones e instituciones que ejercen la autoridad en una esfera pública determinada». (Martínez Celorio, 2017: 7)

4. Ley Orgánica 1/2004, de 28 de diciembre, de Medidas de Protección Integral contra la Violencia de Género. Publicado en BOE 313 de 29 de diciembre de 2004. 
El Capítulo I de la misma ley desarrolla las medidas a implementar en el ámbito educativo, estableciendo la incorporación de la educación para la igualdad de género, o modelo coeducativo, en todos los niveles del sistema educativo: infantil, primaria, secundaria, bachillerato y formación profesional.

En cuanto a las leyes educativas encontramos el precedente en la Ley Orgánica 8/1985, de 3 de julio, reguladora del derecho a la educación, modificada por la LOE, al incorporar competencias de los órganos de gobierno de los centros docentes relacionadas con «la convivencia en los centros, la protección contra la violencia de género, la igualdad efectiva entre hombres y mujeres y el respeto a los derechos y las libertades fundamentales».

La Ley Orgánica 8/2013 de mejora de la calidad educativa, ${ }^{5}$ más conocida como LOMCE, recoge el artículo 1 apartado I) de la LO 1/2006, de 3 de mayo, de Educación (LOE), incorporando «el desarrollo de la igualdad de derechos y oportunidades y el fomento de la igualdad efectiva entre hombres y mujeres, así como la prevención de la violencia de género» y, de modo transversal, en el título preliminar: «promoción de la igualdad de oportunidades, la prevención de la violencia de género y la resolución pacífica de conflictos».

Como podemos ver, la LOMCE, retomando las iniciativas de la LOE y la LOGSE, regula aspectos organizativos específicos de los centros escolares, pretendiendo la incorporación de la coeducación en las políticas educativas. Macarena Serrano (2017), analiza el progreso de la LOMCE respecto de la LOE en materia de igualdad:

\section{Igualdad: de la LOMCE a la LOE}

\section{Principios:}

Artículo 1. I. «El desarrollo, en la escuela, de los valores que fomenten la igualdad efectiva entre hombres y mujeres». Igual que la LOE, pero la LOMCE añade: «Así como la prevención de la violencia de género».

\section{Fines:}

Se abunda en la igualdad de los hombres y mujeres en uno de los fines del sistema educativo, pero este permanece intacto en la LOMCE respecto de la LOE:

Artículo 2. 1. b. «La educación en el respeto de los derechos y libertades fundamentales, en la igualdad de derechos y oportunidades entre hombres y mujeres y en la igualdad de trato y no discriminación de las personas con discapacidad».

\section{En la Educación Primaria:}

Artículo 17. d. «Conocer, comprender y respetar las diferentes culturas y las diferencias entre las personas, la igualdad de derechos y oportunidades de hombres y mujeres y la no discriminación de personas con discapacidad».
5. De acuerdo con el documento «El tratamiento de la violencia de género en el sistema educativo de acuerdo con la ley orgánica 8/2013 de mejora de la calidad educativa y sus normas de desarrollo». Disponible en http://www.violenciagenero. msssi.gob.es/laDelegacion/nforma/pdfs/ VG_Sistema_Educativo.pdf 
Artículo 17. m. «Desarrollar sus capacidades afectivas en todos los ámbitos de la personalidad y en sus relaciones con los demás, así como una actitud contraria a la violencia, a los prejuicios de cualquier tipo y a los estereotipos sexistas».

\section{En la ESO:}

Artículo 23. c. «Valorar y respetar la diferencia de sexos y la igualdad de derechos y oportunidades entre ellos. Rechazar los estereotipos que supongan discriminación entre hombres y mujeres».

\section{En el Bachillerato:}

Artículo 33. c. «Fomentar la igualdad efectiva de derechos y oportunidades entre hombres y mujeres, analizar y valorar críticamente las desigualdades existentes e impulsar la igualdad real y la no discriminación de las personas con discapacidad».

\section{En Formación Profesional:}

Artículo 40. d. «Aprender por sí mismos y trabajar en equipo, así como formarse en la prevención de conflictos y en la resolución pacífica de los mismos en todos los ámbitos de la vida personal, familiar y social, con especial atención a la prevención de la violencia de género».

Artículo 40. e. «Fomentar la igualdad efectiva de oportunidades entre hombres y mujeres, así como de las personas con discapacidad, para acceder a una formación que permita todo tipo de opciones profesionales y el ejercicio de las mismas».

\section{En los programas de formación permanente del profesorado:}

Este artículo se mantiene sin cambios en la LOMCE y en la LOE:

Artículo 102.2. «Los programas de formación permanente deberán contemplar la adecuación de los conocimientos y métodos a la evolución de las ciencias y de las didácticas específicas, así como todos aquellos aspectos de coordinación, orientación, tutoría, atención educativa a la diversidad y organización encaminados a mejorar la calidad de la enseñanza y el funcionamiento de los centros. Asimismo, deberán incluir formación específica en materia de igualdad en los términos establecidos en el artículo 7 de la Ley Orgánica 1/2004, de 28 de diciembre, de Medidas de Protección Integral contra la Violencia de Género».

\section{El Consejo Escolar:}

Artículo 126. 2 «Designará una persona que impulse medidas educativas que fomenten la igualdad real y efectiva entre hombres y mujeres». Lo anterior proviene ya de la LOE. 
Artículo 127. g. «Proponer medidas e iniciativas que favorezcan la convivencia en el centro, la igualdad entre hombres y mujeres». Hasta aquí igual que la LOE, pero la LOMCE añade: «La igualdad de trato y la no discriminación por las causas a las que se refiere el artículo 84. 3 de la presente Ley Orgánica» (que son condiciones de nacimiento, sexo, religión, opinión o cualquier otra circunstancia personal o social), «la resolución pacífica de conflictos y la prevención de la violencia de género».

\section{Funciones de la inspección educativa:}

El artículo 151. e se mantiene sin cambios en la LOMCE respecto de la LOE: «Velar por el cumplimiento y aplicación de los principios y valores recogidos en esta Ley, incluidos los destinados a fomentar la igualdad real entre hombres y mujeres».

\section{Libros de texto y demás materiales curriculares:}

Finalmente, en la Disposición adicional cuarta, punto 2, se lee: «La edición y adopción de los libros de texto y demás materiales [...] deberán reflejar y fomentar el respeto a los principios, valores, libertades, derechos y deberes constitucionales, así como a los principios y valores recogidos en la presente Ley y en la Ley Orgánica 1/2004, de 28 de diciembre, de Medidas de Protección Integral contra la Violencia de Género, a los que ha de ajustarse toda la actividad educativa».

Cada comunidad autónoma integra en sus decretos curriculares el abordaje de la igualdad y la violencia de género establecido en la LOMCE encontrándonos con diferentes desarrollos de los mismos a nivel curricular. En el currículum de las Islas Baleares, comunidad en la que llevo desarrollando mi labor profesional como docente desde el año 2005, la incorporación de la igualdad en la enseñanza obligatoria está reflejada de la siguiente manera:

- En primaria: Decreto 28/2016, de 20 de mayo, por el que se modifica el Decreto 32/2014, de 18 de julio, por el que se establece el currículum de la educación primaria en las Islas Baleares:

- Artículo 2: Se modifican los apartados 8, 9 y 14 del artículo 4 del Decreto 32/2014 y se añade un nuevo apartado: 14. «Desarrollar las capacidades emocionales y afectivas en todos los ámbitos de la personalidad en las relaciones con los demás, así como una actitud contraria a la violencia, a los prejuicios de cualquier tipo y a los estereotipos relacionados con la diversidad sexual y de género».

- En secundaria: Decreto 34/2015, de 15 de mayo, por el que se establece el currículum de la educación secundaria obligatoria en las Islas Baleares (BOIB 73, de 16 de mayo de 2015): 
- Artículo 13: Elementos transversales. 2. Se debe fomentar el desarrollo de los valores que promuevan la igualdad efectiva entre hombres y mujeres y la prevención de la violencia de género, y de los valores inherentes al principio de igualdad de trato y de no discriminación por cualquier condición o circunstancia personal o social. Se deben evitar los comportamientos y los contenidos sexistas y los estereotipos que supongan discriminación.

- Artículo 29: Programaciones docentes. 4. La prevención de la violencia de género, de la violencia terrorista y de cualquier forma de violencia, racismo o xenofobia, incluido el estudio de cualquier crimen contra la humanidad, debe incluirse en alguna programación docente de la etapa.

- Artículo 31: Materiales curriculares. 2. Corresponde a los centros educativos, en el marco de su autonomía pedagógica, elegir, en su caso, los materiales curriculares, siempre que se adapten al rigor científico adecuado a la edad de los alumnos y al currículum establecido por el Gobierno de las Islas Baleares mediante este Decreto. Los materiales deben reflejar y fomentar el respeto a los principios, valores, libertades, derechos y deberes constitucionales y estatutarios, así como los principios y valores recogidos en la Ley Orgánica 1/2004, de 28 de diciembre, de Medidas de Protección Integral ante la Violencia de Género, a los que debe ajustarse toda la actividad educativa. La Consejería de Educación, Cultura y Universidades velará por que en los materiales educativos se eliminen los estereotipos sexistas o discriminatorios y para que fomenten la igualdad entre mujeres y hombres.

Dos protocolos, aprobados en el 2006, favorecen la igualdad de los colectivos con mayor riesgo:

a) el Protocolo de prevención, detección e intervención del acoso escolar de las Islas Baleares, ${ }^{6}$

b) el Protocolo de detección, comunicación y actuaciones para alumnos transexuales y transgénero en los centros educativos de las Islas Baleares, ${ }^{7}$ a pesar de la inexistencia de un protocolo específico para el tratamiento de la violencia de género ejercida en el ámbito educativo en el ámbito territorial de las Islas Baleares, ${ }^{8}$ a diferencia de otras comunidades, como Andalucía, donde está en vigor desde el $2011 .{ }^{9}$

Entre las leyes de incorporación más reciente encontramos la Ley 11/2016, de 28 de julio, de lgualdad de Mujeres y Hombres, ${ }^{10}$ que apuesta por la coeducación en el artículo 26 de sus disposiciones generales tanto a nivel de políticas públicas educativas, como de competencias de la administración educativa de las Islas Baleares, en relación a la consecución de modelos educativos igualitarios, prevención de conductas violentas (especialmente
6. Disponible en: $\underline{\text { http://www. }}$ caib.es/sites/convivexit/ca/ normativa i protocols/archivopub. do? ctrl=MCRST8146ZI218139\&id=218139

7. Disponible en: http://www. caib.es/sites/convivexit/ca/

normativa i protocols/archivopub. do? ctrl=MCRST $8146 Z$ Z $224650 \& i d=224650$

8. Existe un protocolo en estado inoperativo, el Protocolo interinstitucional de detección, prevención y atención de la violencia machista y en casos de ataques sexuales de las Islas Baleares, que en el punto 7.3.5. hace referencia al Ámbito educativo. Disponible en: $\underline{\text { http://www. }}$ poderjudicial.es/stfls/TRIBUNALES\%20 SUPERIORES\%20DE\%20JUSTICIA TSJ\%20Baleares/PROTOCOLOS\%20Y\%20 CONVENIOS/FICHEROS/20091223\%20 Protocolo\%20violencia\%20contra\%20 la\%20mujer.pdf

9. Consejería de Educación, Orden de 20 de junio de 2011 (BOJA 132, de 7 de julio).

10. Disponible en: https://www.boe.es/ buscar/pdf/2016/BOE-A-2016-7994consolidado.pdf 
la violencia machista) en todos los niveles educativos, puesta en marcha de proyectos coeducativos, presencia de personas responsables de coeducación en todos los centros, formación permanente del profesorado en la materia y revisión de materiales didácticos. Así mismo, la Ley 8/2016, de 30 de mayo, para garantizar los derechos de lesbianas, gais, trans, bisexuales, intersexuales y para erradicar la LGTBI fobia," ${ }^{11}$ afecta a todo el sistema educativo indicando que «en el contenido de los materiales escolares, en las actividades deportivas escolares y en las de ocio infantil y juvenil, en los recursos formativos o en la formación de madres y padres, se tenga en cuenta la diversidad afectiva y sexual y se evite cualquier tipo de discriminación, y que se disponga de medidas de prevención y actuación contra el acoso de que puedan ser objeto las personas LGTBI en el ámbito escolar».

El Pacto Reaccionem recoge en un documento los compromisos del Gobierno de las Islas Baleares contra las violencias machistas. La línea estratégica 1, de promoción de la igualdad y prevención de las violencias machistas en la infancia y en la juventud, cuenta dentro de sus objetivos con la incorporación de la coeducación en el sistema educativo de las Islas Baleares, así como la prevención de las violencias machistas en todas las etapas educativas y la sensibilización sobre las mismas.

\section{Ámbito económico}

Las dificultades en cuanto a financiación provenientes de los recortes en materia de políticas de igualdad ${ }^{12}$ son justificadas por el gobierno conservador mediante argumentos repetitivos como son la crisis económica y la mala administración del gobierno anterior. ${ }^{13}$ La falta de financiación se suma más frecuentemente de lo deseado a una falta de sensibilización de la administración sobre la necesidad de aplicar la perspectiva de género a cualquier política educativa, dada la naturaleza de «espacio feminizado» (Ballarín, 2004: 42) del sector educativo.

El recientemente aprobado Pacto de Estado contra las violencias machistas sigue en espera de ejecución, y a pesar de que el nuevo gobierno socialista prometiera una dotación económica de 200 millones de euros en la partida de 2018 (cifra bastante ajustada teniendo en cuenta la dimensión de las políticas diseñadas), el anteproyecto de Presupuestos Generales del Estado $^{14}$ del pasado mes de marzo ha reducido sustancialmente esta cifra, manteniendo la línea de políticas de austeridad del gobierno anterior que obstaculizaron a nivel de la administración central, autonómica y local el cumplimiento de la Ley Integral 1/2004. ${ }^{15}$

También cabe destacar la relevancia de la continuidad de subvenciones públicas a centros educativos que promueven prácticas discriminatorias entre niños y niñas desde que el pasado mes de abril, el Tribunal Constitucional rechazara el recurso del PSOE contra la LOMCE, avalando dichas
11. Disponible en: https://www.boe.es/ buscar/pdf/2016/BOE-A-2016-6310consolidado.pdf

12. Sindicatos como UGT han señalado que durante la legislatura 2012-2016, el recorte en materia de igualdad de género en los Presupuestos Generales del Estado ha sido del 20,9\%, alcanzando el 47,6\% respecto del presupuesto de 2009. Concretamente, la partida presupuestaria destinada a la lucha contra la violencia de género, entre los años 2009 (último año tomado como referencia antes de comenzar los recortes) y 2014 observó una reducción del $23 \%$, pasando de 28,3 a 21,2 millones de euros. Fuente: Tribuna Feminista, 25 de noviembre de 2016.

13. El País, 24 de noviembre de 2012.

14. Disponible en: https://www.boe.es/ diario boe/txt.php?id=BOE-A-2018-9027

15. El Diario.es, 16 de mayo de 2018. 
subvenciones a las escuelas que segregan por sexo a su alumnado, así como segregan por sexo en los itinerarios académicos. ${ }^{16}$

\section{Ámbito social}

Bajo un contexto social de partida como es el que caracteriza a la estructura social patriarcal española, y en base a la definición de patriarcado como

sistema ideológico que ordena y clasifica el mundo de forma desigual entre hombres y mujeres bajo los principios de jerarquía, subordinación, otroriedad y opacidad, los cuales están presentes en todas las estructuras organizativas de la sociedad [...] que impide que otros modelos de género, cultura, clase y etnia lleguen a ser significativos en las escuelas (Blat, 1994: 130),

no podemos pasar por alto la evidencia de la influencia de dicha organización social en sus instituciones educativas.

Cabe recordar la relevancia de las investigaciones feministas, de las cuales un amplio repertorio de medidas, políticas y pactos para la promoción de la igualdad concretadas en políticas educativas de igualdad desde el ámbito gubernamental ha tomado como referencia dichas investigaciones, sus evidencias empíricas y formulaciones teóricas que las desarrollan (Venegas, 2010: 396).

Respecto a la violencia de género entre las jóvenes nos encontramos con altos porcentajes de violencia machista, tal como se evidencia en la Macroencuesta de violencia 2015, ${ }^{17}$ porcentajes que se muestran más adelante en el apartado de las conclusiones.

\section{Ámbito educativo}

Las políticas educativas siguen dirigiéndose a un «colectivo asexuado» (Ballarín, 2004: 42), sin tener en cuenta la feminización generalizada de la profesión docente (mostrada en el cuadro inferior), a pesar del progresivo aumento de la incorporación masculina a la misma.

La investigación social feminista sitúa una de las dimensiones de la desigualdad de género en la escuela en el análisis de la presencia/ausencia de mujeres, mostrando las siguientes evidencias cuantitativas (Venegas, 2010: 394-395):

\section{a) En el alumnado}

- Incremento de la escolarización de las niñas

- Mayor analfabetismo, abandono y deserción entre niñas

- Diferenciación por especialidades en secundaria y universidad (aunque a igual nivel de matriculación)
16. Huffpost, 10 de abril de 2018.

17. Disponible en: $\underline{\text { http://www. }}$. violenciagenero.iqualdad.mpr.gob.es/ violenciaEnCifras/estudios/colecciones/ pdf/Libro_22_Macroencuesta2015.pdf 


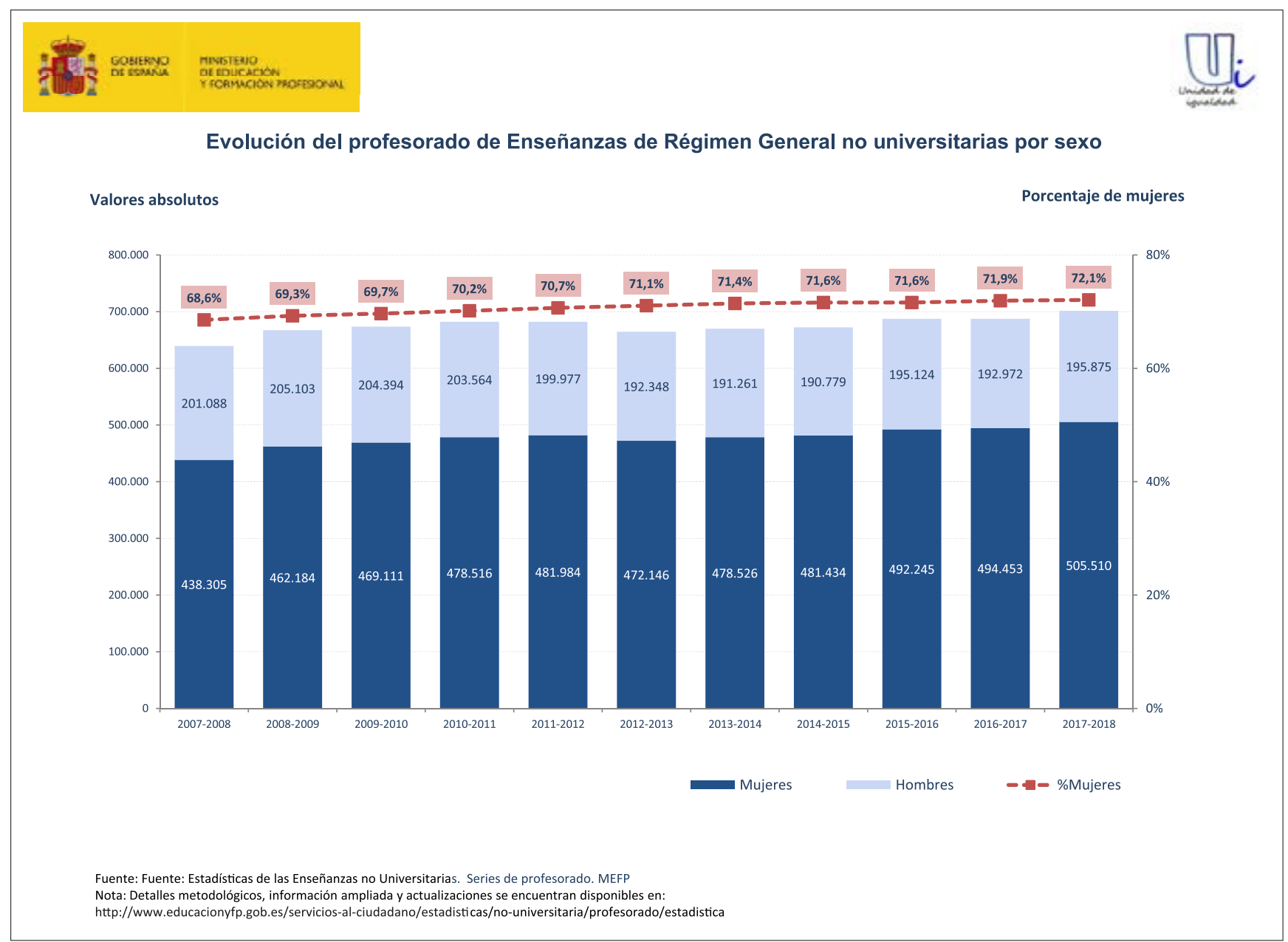

Evolución del profesorado de Enseñanzas de Régimen General no universitarias por sexo ${ }^{18}$

\section{b) En el profesorado}

\section{- Feminización de la docencia}

- Condiciones laborales, de estatus, prestigio y responsabilidad inferiores para las mujeres

\section{c) Cargos directivos}

- Más hombres en puestos de responsabilidad

- Percepción de jerarquización sexista desde el alumnado

Poniendo el foco de atención en la experiencia de los niños y las niñas a su paso por las aulas escolares, encontramos otras dos dimensiones vinculadas a la pervivencia de las desigualdades de género. La primera de ellas analiza el código de género existente en los centros escolares, observando la influencia de una cultura escolar dominada por el arquetipo viril, así como las diferencias existentes entre la desigual preparación de los niños y las niñas en cuanto a la transmisión de identidades «a través de los mensajes, valores y conductas de masculinidad/feminidad» (Ibidem: 395).

La segunda dimensión indaga, por un lado, cómo los estereotipos sexistas son transmitidos en las aulas desde la interacción entre alumnado

18. Estadística de las Enseñanzas no universitarias. Series de profesorado. MECD. 
y profesorado durante los procesos de enseñanza-aprendizaje, observando cómo los espacios (pasillos, patios, aulas) muestran una dominación masculina en contraposición a la invisibilidad femenina y se observan diferencias en cuanto a la cantidad, frecuencia, duración y naturaleza de las interacciones de los niños y de las niñas durante los procesos de aprendizaje.

Por otro lado, la presencia de estereotipos sexistas en la actividad docente se encuentra representada por los libros de texto y materiales didácticos, cuya renovación se ve dificultada por intereses económicos provenientes de las editoriales.

El pedagogo Paulo Freire (1976) definía la educación verdadera como «praxis, reflexión y acción del hombre sobre el mundo para transformarlo». La reflexión que añado a dicha definición es que la transformación que necesita nuestro mundo si parte únicamente del hombre difícilmente logrará su objetivo.

Una redefinición de la educación con la finalidad de no excluir en los procesos de enseñanza-aprendizaje a nadie, de dotar a cada persona, independientemente de su género, de las herramientas para la transformación, sería el inicio del camino hacia la igualdad. Desde este punto de partida, «entendemos por coeducación el desarrollo integral de todo el alumnado, tanto de las chicas como de los chicos, prestando especial atención al conocimiento del otro sexo y al enriquecimiento mutuo de ambos» (Cabeza, 2010: 39).

Encontrándonos en la actualidad, por un lado, con la presencia de resistencias por parte de pedagogos y legisladores, entre otros, a la escuela mixta y a la coeducación, sin conciencia sobre «la necesidad de introducir indicadores de calidad interna vinculados a esta perspectiva» (Flecha, 2014: 57), tanto en el diseño de los programas formativos como en el desarrollo y ejecución de los mismos; y por otro lado, entre los obstáculos que también entorpecen el desarrollo de las propuestas coeducativas dentro de los centros educativos en base a la investigación social feminista (Venegas, 2010: 394-395) destaca la reproducción de pautas sexistas visible en:

a) la persistencia de un colectivo docente feminizado acompañado de una «distribución estereotipada de las profesoras por los diferentes niveles y ramas del sistema educativo» (Anguita y Torrego, 2009: 19).

b) la incidencia del patriarcado a través de los procesos de socialización e identificación de género según la diferente orientación académica y profesional que reciben las alumnas y los alumnos, entre otros aspectos: el lenguaje empleado en la enseñanza en los centros educativos caracterizado por la forma, el discurso, la definición y categorización de un lenguaje sexista; el androcentrismo presente en el currículum a través de una concepción patriarcal de

OBSTÁCULOS

ESTRUCTURALES

DE OPOSICIÓN

A LA CORRECTA

IMPLEMENTACIÓN DE

LA IGUALDAD EN LOS CENTROS EDUCATIVOS 
la sociedad y del conocimiento, sobre todo científico, así como mediante la invisibilidad de los saberes y haceres de las mujeres, provocando una falta de identificación por parte de las niñas y jóvenes, por la falta de referentes.

c) el código de género en los centros escolares.

d) la presencia de estereotipos sexistas en las aulas.

Diez años después del análisis y las conclusiones a las que llegó el Instituto de la Mujer ${ }^{19}$ sobre las diferencias educativas basadas en el género, los contenidos sexistas continúan presentes y la formación en igualdad sigue dependiendo de la voluntad de los centros. Gran parte de las comunidades autónomas disponen de programas, proyectos e iniciativas que se llevan a cabo respaldadas por equipos directivos con mayor o menor interés y profesorado con grandes dosis de tenacidad y amor al arte o total indiferencia; no hay que olvidar que los centros que no estén interesados pueden renunciar a la coeducación y a la igualdad en las aulas, ya que su aplicación solo es recomendable.

Una única comunidad autónoma cuenta con normativa de obligado cumplimiento para todos sus centros educativos financiados con fondos públicos, Andalucía, donde ya van por el II Plan Estratégico de Igualdad de Género en Educación (2016-2021). La financiación destaca como factor clave y, siendo unas cuantas más las comunidades que llevan décadas emprendiendo tareas y realizando esfuerzos a favor de la igualdad real entre hombres y mujeres desde todos los ámbitos, hay que tener en cuenta la disminución de presupuesto que se aplicó en todas las comunidades autónomas y a todos los niveles de gobierno en el periodo 2009-2013, con la excepción de Andalucía, donde el presupuesto destinado a las políticas de género aumentó un 15,5\% (Lombardo y León, 2014: 28).

Una cultura androcéntrica junto a sus códigos de género destaca como el gran obstáculo que impide el avance de la igualdad real y efectiva en la educación a pesar de que «en nuestro país, los aspectos más visibles sobre esta desigualdad están en recesión, pero no así otros elementos pertenecientes al currículum oculto» (Anguita y Torrego, 2009: 19).

Como recogen Anguita y Torrego en su investigación «Género, educación y formación del profesorado. Retos y posibilidades», el currículum oculto está compuesto por elementos sutiles y difíciles de detectar, estudiados por diversos autores y autoras; elementos como las discriminaciones en el trato a las alumnas frente a los alumnos (Simón, 2000 y 2008), los procesos de relación estereotipados en función del sexo dominados por la sobrevaloración y aceptación acrítica de la cultura masculina tradicional (Rodríguez y García, 2009; Sánchez e Iglesias, 2008), así como la idea cosificada desde la escuela
19. Red2Red Consultores S. L. (2008). Guía de coeducación síntesis sobre la educación para la iqualdad de oportunidades entre mujeres y hombres: Observatorio para la igualdad de oportunidades (Observatorio 9). Madrid: Instituto de la Mujer.

\section{CONCLUSIONES} SOBRE LA RELACIÓN ENTRE LA AUSENCIA DE IGUALDAD EN EL SISTEMA EDUCATIVO $Y$ LA PERPETUACIÓN DE LA VIOLENCIA DE GÉNERO DESDE LAS AULAS 
de la complementariedad de los sexos y el fomento y la permisividad ante un estricto comportamiento sexual estereotipado (Ballarín, 2008: 170-171).

Otro elemento vinculado al currículum oculto es el hecho de que conocimientos como las aportaciones de las mujeres a la creación de las civilizaciones y sus saberes, la educación afectivo-sexual, la cultura del cuidado y de la corresponsabilidad, conocimientos que han pertenecido al mundo de lo privado y no logran tener categoría de conocimientos relevantes para toda la humanidad ni para la formación de nuestros niños y niñas (Ballarín, 2008: 182), continúan excluidos del currículum oficial de la enseñanza, así como el abordaje de las violencias machistas, al seguirse considerando un problema privado (Valls et al., 2009).

Las numerosas iniciativas coeducativas llevadas a cabo por el profesorado (hombres y mujeres), están sufriendo la falta de apoyo, difusión y continuidad, al igual que sucede con políticas institucionales vinculadas a la formación permanente del profesorado, tanto por las administraciones educativas como por los institutos de la mujer estatal y autonómicos (Díaz de Greñu, 2010).

En cuanto a la relación entre la ausencia de una adecuada educación en igualdad con la perpetuación de la violencia contra las mujeres (originada desde la estructura social patriarcal) en la escuela, es interesante destacar la situación de percepción de violencia de género entre el alumnado.

La Macroencuesta de violencia $2015^{20}$ ha evidenciado altos porcentajes de violencia machista entre las jóvenes. Una de cada cuatro mujeres (25\%) de entre dieciséis y diecisiete años aseguró haber padecido actitudes machistas en los últimos doce meses, frente al 9,6\% de la media general.

El Centro de Investigaciones Sociológicas (CIS) realizó el estudio Percepción de la violencia de género en la adolescencia y la juventud ${ }_{1}^{21}$ encargado en 2015 por la Delegación del Gobierno para la Violencia de Género y dirigido a la población residente en España de quince a veintinueve años, con el objetivo de recoger información relacionada con sus opiniones y actitudes sobre la violencia de género y las medidas que se adoptan para combatirla.

Estas son algunas de las conclusiones del estudio:22

a) Percepción sobre la desigualdad de género de la adolescencia y la juventud

- Cuando se compara la población adolescente y joven (15-29) con el conjunto de la población, se observa que tanto los hombres como las mujeres de este grupo de edad perciben en menor medida que el resto de grupos de edad que existan desigualdades de género.

b) Tolerancia frente a la violencia

- Aunque las diferencias son pequeñas, los jóvenes de quince a veintinueve años son algo más tolerantes que el conjunto de la población con la violencia de control.
20. Disponible en: http://www. violenciagenero.igualdad.mpr.gob.es/ violenciaEnCifras/estudios/colecciones/ pdf/Libro 22 Macroencuesta2015.pdf

21. Disponible en: http://www. violenciagenero.igualdad.mpr. gob.es/violenciaEnCifras/estudios/ investigaciones/2015/pdf/Libro20 Percepcion Social VG .pdf

22. Tomado del material didáctico del curso La atención profesional a las víctimas de violencia de género, edición de junio de 2018, organizado por el Institut Balear de la Dona, en el marco del Proyecto Ariadna. 
- No todas las formas de violencia de género suscitan el mismo rechazo ni todos los comportamientos que constituyen maltrato son identificados como tales:

— La violencia física y sexual es rechazada por el $97 \%$ de la juventud y la adolescencia.

- El 93\% de jóvenes de 15 a 29 años consideran totalmente inaceptable la violencia verbal.

- El $67 \%$ considera inaceptable la violencia de control. Es decir, uno de cada tres jóvenes de quince a veintinueve años (33\%) considera inevitable o aceptable en algunas circunstancias «controlar los horarios de la pareja», «impedir a la pareja que vea a su familia o amistades», «no permitir que la pareja trabaje o estudie» o «decirle las cosas que puede o no puede hacer».

- El $67 \%$ de los hombres y el $72 \%$ de las mujeres de quince a veintinueve años considera que las amenazas verbales son inaceptables y deben ser siempre castigadas por la ley. Las y los jóvenes de 20 a 24 años (73\%) y de veinticinco a veintinueve (71\%) suscriben esta afirmación en mayor medida que las y los que tienen entre quince y diecisiete años (63\%).

c) Estereotipos frente a víctimas y agresores

- El $40 \%$ de las y los jóvenes de quince a veintinueve años tienden a exculpar al agresor al considerar que «los agresores suelen tener alguna enfermedad mental», y el $38 \%$ considera que hay más agresores entre los extranjeros que entre los españoles.

- El grupo que valoran como más vulnerable es el de las mujeres discapacitadas (62\%), seguidas de las menores de edad (56\%) y las mujeres extranjeras (52\%).

d) Conocimiento de casos de violencia en el entorno cercano de jóvenes y adolescentes

- El 29\% de las personas jóvenes y adolescentes afirma conocer alguna víctima de violencia de género en su contexto más próximo.

e) Reacción frente a un caso de violencia de género

- El 58\% de adolescentes y jóvenes afirma que llamaría a la policía en el supuesto de presenciar o conocer algún caso de malos tratos hacia una mujer. Un $23 \%$ se enfrentaría al agresor y un 14\% llamaría la atención de otras personas.

- Las mujeres jóvenes llamarían a la policía (65\%) o intentarían captar la atención de otras personas (17\%) con más frecuencia que los hombres de estas edades (52\% llamarían a la policía, $11 \%$ intentarían captar la atención de otras personas). En cambio, los hombres se enfrentarían al agresor (32\%) en mayor medida que las mujeres $(12 \%)$. 
f) Motivos por los que piensan que las víctimas no denuncian a su agresor

- El $80 \%$ de la adolescencia y la juventud opina que una de las principales causas para no denunciar es el miedo, el $40 \%$ piensa que no se denuncia por las y los hijos, un $25 \%$ cree que las víctimas no denuncian su situación por vergüenza y un $15 \%$ porque la víctima depende económicamente de su agresor.

Las estadísticas oficiales no ofrecen un tratamiento adecuado de la incidencia de la violencia de género entre las y los menores, aunque algunas cifras pueden servir de referencia:23

— En el 2016 se incoaron un 2,4\% más de casos de violencia de género, 28281 en 2016 frente a las 27624 de 2015. Entre las mujeres menores de dieciocho años, en el año 2015 se produjo un aumento del 10,6\%, constituyendo el segundo de los grupos de edad que experimentó el aumento más significativo (pasando de 576 en 2014 a 637 en 2015). El año 2016 ha presentado un descenso en mujeres menores de dieciocho años, pasando de 638 a 569 según el Balance anual del Registro de Violencia Doméstica y de Género del Instituto Nacional de Estadística.

_ En Baleares, durante el año 2016 se dieron un total de 853 casos de violencia de género con medidas cautelares u orden de protección. 16 de ellos fueron de mujeres menores de dieciocho años (1,8\%) y 116 de mujeres de dieciocho a veinticuatro años (13,6\%) según la Estadística de Violencia Doméstica y Violencia de Género, asuntos incoados, año 2016 del INE.

- A nivel nacional, fueron un total de 28201 hombres denunciados por violencia de género, correspondiendo un 5,9\% a los menores de dieciocho años, franja en la que se dio un mayor incremento en relación a años anteriores, acompañada de hombres de más de setenta y cinco (12,9\%). 107 menores agresores fueron denunciados a lo largo de 2016, frente a los 101 del año 2015 y los 90 del año 2014, datos que corroboran el incremento de denunciados por violencia de género.

- El informe anual de 2015 de la Fundación ANAR (organización sin ánimo de lucro para la promoción y defensa de los derechos de niñas, niños y adolescentes que cuenta con un número de teléfono de atención a menores, el 9002020 10) muestra cómo el número de llamadas en España se ha multiplicado por diez desde 2009; de enero a diciembre de 2016 recibieron un total de 2729 llamadas telefónicas motivadas por la violencia de género, evidenciando un aumento en relación a los seis años anteriores. Según datos publicados en el informe de la Fundación ANAR, el 12,8\% de los casos eran niñas de entre trece y catorce años que sufren violencia física, psicológica y sexual, sin ser conscientes de ser víctimas de violencia de género.

— El Ministerio de Sanidad contabilizó de enero a septiembre de 2015 nueve menores víctimas mortales por violencia de género, el año en que la
23. Tomado del material didáctico del curso La atención profesional a las víctimas de violencia de género, edición de junio de 2018, organizado por el Institut Balear de la Dona. 
nueva Ley de la Infancia y la adolescencia que reconoce de forma explícita por primera vez como víctimas a los menores expuestos a violencia de género, entró en vigor. En 2016 contabilizó a nivel nacional una víctima mortal menor, en 2017, ocho menores y hasta el 23 de abril de 2018, una víctima mortal menor. Cuarenta y cuatro menores han sido asesinados en los últimos diez años por sus progenitores paternos, veintiséis de los cuales en el transcurso del cumplimiento del régimen de visitas. Cabe destacar que en el año 2015 cincuenta menores quedaron huérfanos por la violencia de género. ${ }^{24}$

El estudio de Save the Children de febrero de 2011 En la violencia de género no hay una sola víctima estimaba que 800000 menores sufrían las consecuencias en España. Según otro estudio de junio de 2015 de la organización, Violencia contra la Infancia: Hacia una Estrategia Integral, desde que se contabilizaron oficialmente los niños y niñas víctimas en el marco de la violencia de género en 2013, hasta mayo de 2015, doce niñas y niños habían sido asesinados y cien habían quedado huérfanos.

Como conclusión cabe destacar la evidencia de retrocesos relacionados con el resurgimiento de conductas de dependencia en relaciones asimétricas de desigualdad no percibidas como tales (Flecha, 2014: 58) en las jóvenes españolas, basada en numerosos estudios sobre violencia en las estrechas relaciones entre los procesos de igualdad y la prevención del sexismo y la violencia machista (Díaz Aguado, 2011; Ferrer y Bosch, 2004, 2008 y 2013), tal como explica Simón (2009):

Con el objetivo de diseñar proyectos de intervención encaminados a prevenir la violencia de género temprana, la que se produce en la adolescencia y primera juventud, se impulsaron estudios de seguimiento de las concepciones del profesorado y del alumnado respecto a los estereotipos de género. Los resultados apuntaban la urgencia de revisar los estereotipos de género y la continuidad de las identidades sexuales que reproducían los modelos de masculinidad y la feminidad que podían influir de forma directa en las conductas de violencia hacia las mujeres (Grañeras et al., 2007). Porque si bien las jóvenes a las que empezaba a afectar de manera clara eran herederas afortunadas de una evolución protagonizada por sus madres y abuelas en un periodo de tiempo relativamente corto, los cambios, quizás más exteriores que profundos, habían impregnado escasamente dimensiones mentales, afectivas y emocionales imprescindibles para una autoestima protectora.

La Declaración sobre la eliminación de la violencia contra la mujer ${ }^{25}$ de la Asamblea General de Naciones Unidas de 1993 especificaba como una de las formas de violencia aquella perpetrada o tolerada por el Estado. Actualmente está empíricamente evidenciado cómo el Estado
24. Disponible en: http://www. violenciagenero.igualdad.mpr.gob.es/ violenciaEnCifras/

25. Disponible en: https://www.ohchr. org/sp/professionalinterest/pages/ violenceagainstwomen.aspx 
puede ser también un agente que comete formas de violencia de género institucionalizada, no solo porque a través de sus agentes se realicen actos de violencias físicas, psicológicas o sexuales, sino también por la responsabilidad que tiene el Estado y sus agentes en la prevención, sanción y erradicación de dichas violencias contra las mujeres (Bodelón, 2014: 132-133).

Vuelvo a las primeras líneas donde indicaba cómo la educación se sitúa en el punto de mira respecto a la eliminación de la violencia de género y la incorporación de una igualdad real en todos los ámbitos de la sociedad actual, al evidenciar que «la coeducación sigue siendo totalmente necesaria, todavía es una asignatura pendiente de la educación española y es probablemente más urgente que nunca implantarla» (Subirats, 2017: 26). Concluyo el artículo con la enumeración de diez indicadores de buenas prácticas para la consecución de la equidad de género en la educación (Rebollo et al., 2012: 149):

1. La inclusión de la perspectiva de género en las políticas de igualdad del ámbito educativo debe hacerse real y efectiva.

2. El reconocimiento y respeto hacia los méritos de la labor coeducativa debe venir acompañado de la asignación de crédito horario proporcionado al tiempo real de dedicación a dicha labor.

3. Al margen de la existencia de recursos coeducativos en los centros, prácticas, estrategias, propósitos e incorporación de la figura de agentes de igualdad, es necesaria la integración de la coeducación en los proyectos educativos de centro y el respaldo real de los equipos directivos.

4. La perdurabilidad de las prácticas coeducativas en los centros escolares está condicionada no solo por la implicación de equipos directivos, sino también de los equipos docentes, del personal administrativo, no docente, las familias, la policía, la o el tutor, etc.

5. La promoción e integración de los proyectos o programas en las comunidades educativas se consigue mediante la necesaria coordinación de actuaciones a nivel local, con el apoyo de administraciones e instituciones (ayuntamientos, centros de formación del profesorado, casa de juventud, casa de la cultura, etc.).

6. Lograr objetivos a largo plazo supone la implicación progresiva de todas y todos sus agentes, la integración de nuevo personal en la comunidad educativa y la necesidad de realización de procesos conjuntos de reflexión.

7. Son proyectos que implican cambios en las formas que el profesorado y el personal de la administración pública tiene de organizarse y trabajar, generando la aparición de nuevas dinámicas de interacción en la comunidad educativa y nuevos significados de las acciones educativas y comunitarias. 
8. Se hace evidente la importancia de la estabilidad de las plantillas docentes.

9. La sostenibilidad de los proyectos se basa en la coordinación entre niveles y ciclos educativos y la creación de redes de intercambio de experiencias e iniciativas entre los centros educativos de los municipios.

10. La meta que se debe alcanzar pasa por el trabajo coordinado de toda la comunidad.

\section{BIBLIOGRAFÍA}

Anguita Martínez, Rocío y Torrego Egido, Luis (2009). «Género, educación y formación del profesorado: Retos y posibilidades». Revista Interuniversitaria de Formación del Profesorado (64: 1), 17-26.

Ballarín Domingo, Pilar (2004). «Género y políticas educativas». XXI Revista de Educación (6), 35-42.

BLAT GIMENO, Amparo (1994). «Informe sobre la igualdad de oportunidades educativas entre los sexos». Revista Iberoamericana de Educación (6), 123-146.

Bodelón, Encarna (2014). «Violencia institucional y violencia de género». Anales de la Cátedra Francisco Suárez (48), 131-155.

Bosch, Esperanza, Ferrer, Victoria A. y Alzamora, Aina (2006). El laberinto patriarcal: Reflexiones teórico-prácticas sobre la violencia contra las mujeres. Barcelona: Anthropos Editorial.

Cabeza Leiva, Ana (2010). «Importancia de la coeducación en los centros educativos». Pedagogía Magna (8), 39-45.

Díaz-Aguado, María José (2011). Igualdad y prevención de la violencia de género en la adolescencia. Madrid: Ministerio de Sanidad, Política Social e Igualdad.

Díaz de Greñu, Sofía (2010). La educación en el respeto a la diferencia a través de la enseñanza de la Historia [tesis doctoral inédita]. Universidad de Valladolid.

Fernández HerRería, Alfonso (1995). «Violencia estructural y currículo orientado a la educación para la paz». Revista Interuniversitaria de Formación para el Profesorado (22), 21-38.

FerReR, Victoria y Bosch, Esperanza. (2004). «Violencia contra las mujeres». En Barbera, E.; Martínez, I. y Bonilla, A. (coords.), Psicología y género. Madrid: Pearson, 241-270.

- (2008). «Los/as profesionales de la educación ante la violencia contra las mujeres en la pareja: formación y percepción del problema en alumnado universitario». Revista electrónica interuniversitaria de formación del profesorado, 11-3. 
— (2013). «Del amor romántico a la violencia de género: para una coeducación emocional en la agenda educativa». Profesorado: Revista de currículum y formación del profesorado (17: 1), 105-122.

FleCha García, Consuelo (2014). «Desequilibrios de género en educación en la España Contemporánea: causas, indicadores y consecuencias». ÁREAS Revista Internacional de Ciencias Sociales (33), 49-60.

FreIRE, Paulo (1976). La educación como práctica de la libertad. Buenos Aires: Siglo XXI.

Grañeras Pastrana, Montserrat et al. (2007). «La prevención de la violencia contra las mujeres desde la educación: Investigaciones y actuaciones educativas públicas y privadas». Revista de educación (342), 289-212.

LEón, Margarita y Lombardo, Emanuela (2014). «Políticas de igualdad de género y sociales en España: origen, desarrollo y desmantelamiento en un contexto de crisis económica». Investigaciones Feministas (5), 13-35. Disponible en: $\underline{\text { http://dx.doi.org/10.5209/rev INFE.2014.v5.47986 }}$

López Rupérez, Francisco, García García, Isabel y Expósito CaSAs, Eva (2017). La calidad de la gobernanza del sistema educativo español: Un estudio empírico. Madrid: Universidad Camilo José Cela.

Lledó CunilL, Eulàlia (2016). «Lengua, literatura y coeducación». Filanderas. Revista Interdisciplinar de Estudios Feministas (1), 61-76. Disponible en: https://papiro.unizar.es/ojs/index.php/filanderas/article/view/1505

Martínez Celorio, Xavier (2017). Innovación y equidad educativa. Barcelona: Editorial Octaedro, 7.

Pérez Mendoza, Sofía (2017). «La educación en igualdad, la gran ausente en los colegios españoles». El diario.es, 8 de marzo. Disponible en: https://lab. eldiario.es/diadelamujer/educacion/

PINI, Mónica (2010). «Análisis crítico del discurso: Políticas educativas en España». RASE Revista de la Asociación de Sociología de la Educación (3: 1), 105-127. Disponible en: https://ojs.uv.es/index.php/RASE/article/ view/8630

Rebollo CatalÁn, M. a Ángeles et al. (2012). "La equidad de género en educación: análisis y descripción de buenas prácticas educativas». Revista de Educación (358), 129-152.

SerRano, Macarena (2017). "La igualdad de hombres y mujeres vigente en educación». Revista digital UNIR, Universidad Internacional de La Rioja. Disponible en: https://www.unir.net/educacion/revista/ noticias/la-igualdad-de-hombres-y-mujeres-vigente-en-educacion/549201771570/

Simón Rodríguez, M. a Elena (2000). «Tiempos y espacios para la coeducación». En Santos, Miguel A. (coord.), El harén pedagógico (33-51). Barcelona: Graó. 
- (2009). Hijas de la igualdad. Herederas de injusticias. Madrid: Narcea.

SuBIRATS, Marina (2017). Coeducació, aposta per la llibertat. Barcelona: Editorial Octaedro.

VenEGAS, Mar (2010). «La igualdad de género en la escuela». RASE Revista de la Asociación de Sociología de la Educación (3: 3), 388-402. Disponible en: https://ojs.uv.es/index.php/RASE/article/view/8720/8263 

El 26 de abril de 2017, cinco meses después de que Donald Trump se hiciera con la presidencia de los Estados Unidos, la serie de televisión basada en El cuento de la criada de Margaret Atwood se estrenó en todo el mundo. Desde que ganó las elecciones en noviembre de 2016, Donal Trump ha sido un presidente que ha demostrado sin ningún pudor su desdén por los derechos de la mujer. Una de sus primeras órdenes, en su primer día de oficio, fue restablecer «the Global Gag Rule», una ley de los tiempos de Reagan que deniega fondos públicos para cualquier ONG internacional que proporcione ayuda para abortar a chicas sin recursos. Su vicepresidente Mike Pence ya demostró su carácter [ultra] conservador en 2013 cuando dijo: «Creo que el matrimonio es la unión entre un hombre y una mujer y es la única institución que merece la pena defender en nuestro estado y nación. Durante miles de años, el matrimonio ha servido como el pegamento que aglutina juntas a familias y sociedades y así tiene que ser siempre» (traducción propia, Cook y Scheneider, 2016). Conservador radical, en su discurso sobre el estado de la nación del 2016 Pence mostró mucho más interés en proteger los derechos religiosos que los de los colectivos LGTB. Quizá es por eso que Rebecca Mead, columnista del New Yorker, ve tantos paralelismos y coincidencias entre los Estados Unidos bajo la presidencia de Trump y la república de Gilead en la novela que llega a llamar a Margaret Atwood «la profeta de la distopía» (traducción propia, Mead, 2017). Aprovechando en su campaña de promoción y haciendo suyo el descontento de los sectores feministas, Atwood, que colabora en el guion de la serie, llegó a afirmar: «No estamos haciendo ficción, estamos haciendo un documental [ya que] [...] nunca la democracia en América ha sido tan desafiada» (traducción propia, Mead, 2017).

La primera adaptación audiovisual de El cuento de la criada fue la película del mismo nombre dirigida por Walter Schlondorff, de 1990. Etiquetada antes de ser rodada como un producto «feminista», muchas actrices famosas no quisieron verse marcadas con el «estigma» de ser asociadas con una película que se preveía radical. Finalmente, la película pudo grabarse con Natasha Richardson en el papel protagonista de la criada, Defred, Faye Dunaway como la esposa y Robert Duvall como el comandante Fred. La película, que en su cartel promocional evocaba engañosamente un thriller erótico, pasó sin pena ni gloria hasta ser rescatada del olvido por el estreno de la serie de Hulu en el 2017. A diferencia de la versión de 1990, la serie El cuento de la criada, distribuida a través de una plataforma de televisión online de pago, se ha convertido en un éxito de audiencia desde su estreno y ha contribuido a la recuperación de una novela publicada hace más de tres décadas. Aunque El cuento de la criada se ha reimprimido periódicamente y es la obra más vendida de Atwood, no ha sido hasta el año 2017 cuando, catapultada por el estreno de la serie, ha alcanzado un innegable impacto mundial.

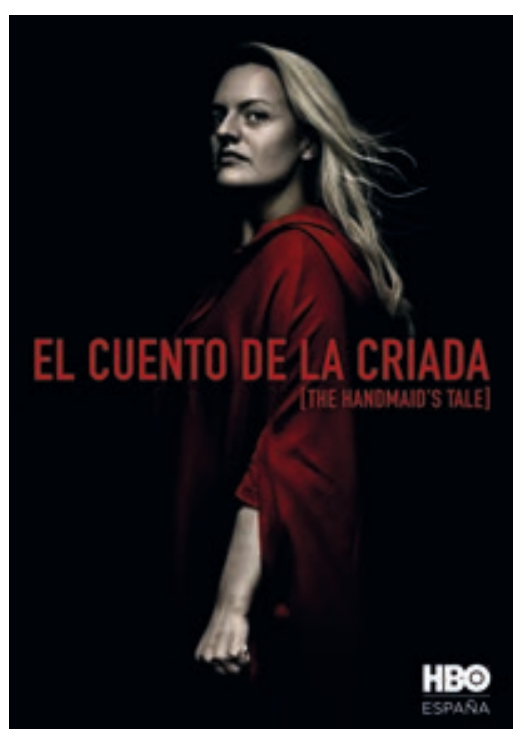


Barbara Kay, columnista del canadiense National Post, niega rotundamente que haya alguna relación fundamentada entre Gilead y los problemas sociales de la sociedad occidental actual, afirmando que más de treinta años después de la publicación de la novela de Atwood no existe ni rastro en ningún país democrático de un programa ni remotamente parecido al de las criadas en Gilead. Sin embargo, existen muchas coincidencias inquietantes entre la vida que llevan las criadas de la serie en Gilead y la realidad de las madres subrogadas de nuestros días: «Contratadas, externas y fuera de la vista [...] separadas de sus propias familias, incluidos sus hijos, durante el embarazo y obligadas a estar en dormitorios constantemente monitorizadas e incapaces de marcharse cuando les apetece» (Chaterjee, 2017).

La sociedad de El cuento de la criada sufre una epidemia de esterilidad, algo que oficialmente solo afecta a las mujeres porque todo problema relacionado con la procreación es por ley culpa de la mujer, nunca por causa del hombre. Es el pensamiento más genuinamente patriarcal el que lleva a los comandantes en Gilead a perseguir la conservación de sus propios genes a través de las handmaids. En un mundo en el que los bebés sanos se han convertido en un producto de lujo por su escasez, los poderosos se arrogan con el derecho exclusivo a su posesión. El papel de las criadas es asumido y aceptado en Gilead con sobrecogedora naturalidad por el resto de la ciudadanía, al igual que pasa con las madres subrogadas o vientres de alquiler en nuestra sociedad actual. Las a menudo pésimas condiciones de vida que sufren las madres subrogadas del siglo xxı son ignoradas al igual que sucede en la novela con la situación de las criadas. Una de las principales objeciones que se puede hacer en contra de la gestación subrogada es que no solo se cosifica el cuerpo de la mujer, al igual que sucede en la prostitución, sino que el tener un bebé genéticamente relacionado con los futuros padres se convierte en «tendencia» $\mathrm{y}$ «producto de lujo» para personas con posibles. La gestación subrogada es un negocio que mueve millones de dólares solamente en los EE. UU. y ha transformado la India y otros países del tercer mundo en «proveedores de úteros» (Pardies, 2016). Algunos hacen una interpretación emancipatoria de la gestación subrogada como un derecho más de la mujer a disponer de su propio cuerpo y una decisión libre de todas las partes involucradas en el contrato. También se habla de una supuesta recompensa psicológica, además de la económica, para la madre que presta su vientre y ayuda a otros seres humanos a tener sus propios hijos, esto es, todo el mundo sale ganando. Sin embargo, no es una relación igualitaria entre todas las partes. A modo de ejemplo, en el distrito norteamericano de Columbia, la nueva ley de subrogación de abril de 2017 prevé evaluaciones de la salud mental y física de la madre de alquiler, pero no de los futuros padres (Crockin, 2017). Es más, en 2106 el caso del «baby Gammy» ocupó las primeras planas de los periódicos. Nacido por gestación subrogada con síndrome de Down, fue 
rechazado por la pareja australiana que encargó su concepción, pero que sin embargo sí acogió a su hermana gemela Pipah. El caso se reveló todavía más complicado cuando la madre de alquiler supo que el padre que había pagado por la gestación era un agresor sexual (Lahl, 2017). La madre de alquiler, el útero con piernas, es compañera de infortunios de la handmaid y expulsada de un proceso de maternidad en el que su cuerpo pierde todos los derechos. La desposesión de su cuerpo llega hasta el punto de no tener poder de decisión sobre él, ni siquiera si abortar o no una vez que se inicia el embarazo; es el caso de una madre embarazada con tres embriones a la que le fue denegada la posibilidad de llevar adelante el embarazo, ya que el futuro padre no quería más de dos y un acuerdo de setenta y cinco páginas incluía una cláusula de «reducción selectiva» (Crockin, 2017). Como Block se pregunta, si la gestación subrogada elimina los derechos de maternidad, si el pensamiento es «este no es mi bebé, no es mi semilla, yo no soy la madre, ¿puede ser la conclusión final que este no es mi cuerpo?». ¿Puede ser la madre subrogada compañera de las criadas en una vuelta a la biología de Aristóteles, desposeídas de su cuerpo y meras vasijas para la semilla del hombre?

Sin embargo, la historia, los personajes y las circunstancias que se narran en la novela no son idénticos a su última adaptación audiovisual. Atwood, entrevistada por Dockterman, dice: «Partimos de ahora, no de 1984 [...] y al igual que ahora hay teléfonos móviles en la serie, también hemos tenido que actualizar otras cosas». Las numerosas y significativas diferencias entre novela y serie, las más evidentes relativas a la caracterización, pueden indicar que la sociedad norteamericana ha experimentado cambios sustanciales a lo largo de las últimas tres décadas. Sin embargo, ese supuesto estaría contradiciendo la reclamada atemporalidad de la historia de la doncella, ya que los cambios introducidos demostrarían que la sociedad del siglo XXI está lejos de la de los años ochenta.

Todos los grupos tradicionalmente marginados, mujeres, homosexuales y no blancos, que se habían esforzado por adquirir visibilidad en los años sesenta estaban de nuevo en riesgo de exclusión en los conservadores años ochenta bajo la presidencia de Ronald Reagan. Las crisis medioambientales, las marchas por los derechos de la mujer y las protestas en contra del racismo eran los temas calientes en la vanguardia del malestar social norteamericano que se reflejan en la novela. En la novela, la teocrática república de Gilead — misógina, racista y homófoba- no tolera ningún tipo de diferencia. Cualquier ciudadano fuera de la norma ya sea disidente político, no heterosexual o no blanco es eliminado. Gilead ejerce violencia y represión sobre toda la diversidad que se saliera del ideal conservador en los ochenta. Sin embargo, ese fuerte compromiso con las minorías sociales y el carácter reivindicativo de la novela apenas es discernible en la primera temporada de la serie. A pesar de que la serie 


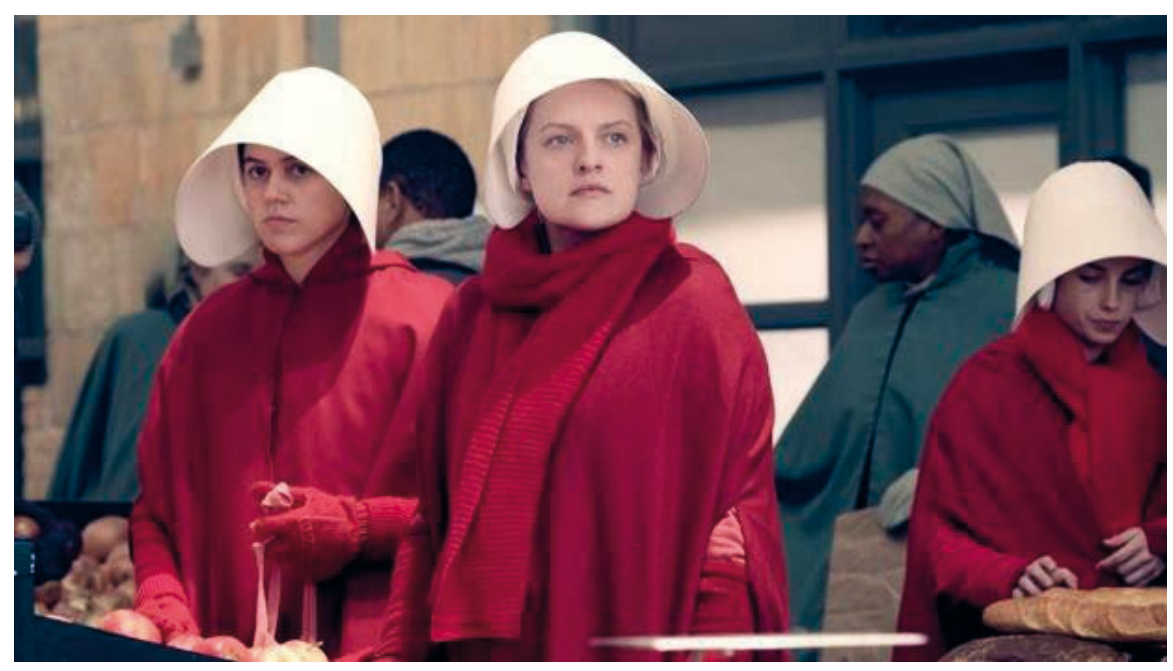

se autodefine en su promoción como un producto feminista y desde que empezó su promoción ha habido marchas y protestas en Estados Unidos con mujeres con el vestido rojo y el gorro blanco de las criadas, la madre de Defred, una activista radical de la segunda ola del feminismo, ha sido totalmente borrada del guion. Asuntos problemáticos como el racismo o la segunda ola feminista no son asuntos centrales en el guion de la serie, mientras que el problema de la polución y la degradación medioambiental —origen de la epidemia de infertilidad - es tan sutil que resulta apenas reconocible. La serie es tan imprecisa acerca del origen de la crisis física y política que origina la república de Gilead que no queda muy claro cuáles son los peligros sobre los que nos alerta y advierte. Los mensajes antirracistas, antihomofóbicos, ecologistas y el cuestionamiento de la naturaleza prescriptiva del feminismo de los sesenta desaparecen al contextualizar la serie en el siglo XXI, un escenario distinto de la sociedad de los ochenta, muy a pesar de la campaña de promoción de la serie en la que defendían su carácter «documental». A pesar de los paralelismos ideológicos entre la era Reagan y el gobierno de Trump, las circunstancias sociales han cambiado y por esa razón la serie introduce personajes de distintas razas y hay una mayor presencia del colectivo LGTB. En ese sentido, la serie, que se dirige a una audiencia mucho mayor que la de la novela, se convierte en un producto más políticamente correcto, pero menos comprometido y en mi opinión más difícil de comprender y de creer. La serie combina una estética muy atractiva, hermosos espacios verdes, impresionantes mansiones y modernos hospitales perfectamente equipados, con una violencia represiva creciente, mucho mayor que la de la novela. Sin embargo, no hay ni un signo de deterioro medioambiental, desechos nucleares o incluso contaminación, que en la novela eran muy significativos. No hay recordatorio o explicación de por qué o cómo los cuerpos de los habitantes de Gilead han sido infectados y esterilizados por la degradación de su entorno. El caso es 
que, a pesar de las similitudes políticas, no estamos ya en 1980, estamos en una época diferente en la que El cuento de la criada puede ser considerado atractivo, terrible, impresionante pero no lo suficientemente conectado con nuestro presente social o político. Sin embargo, la serie, a pesar de no mantener intacta la complejidad de la novela, es una exitosa evolución de la misma, capaz de adaptarse y sobrevivir porque mantiene aún vivo uno de los más importantes mensajes de la obra original: no podemos rendirnos ni tolerar ningún recorte en los derechos civiles ni humanos en favor de ninguna pretendida seguridad, privilegio o ideología.

\section{BIBLIOGRAFÍA}

Atwood, Margaret (1996). The Handmaid's Tale. Londres: Vintage Books.

BLock, Jennifer (2009). «The other side of surrogacy. What gestational surrogate really go through». Babble, 13 de abril. Disponible en: https:// web.archive.org/web/20140121122300/www.babble.com/pregnan-

cy/gestational-surrogacy-how-to-be-a-surrogate-mother/

Bouson, Brooks, John (2010). Critical Insights: The Handmaid's Tale. Massachusetts: Salem Press.

ChaterueE, Ayesha (2017). «The Handmaid's Tale and Modern-Day Surrogacy». The Hastings Center, 13 de julio. Disponible en: http://www.thehastingscenter.org/handmaids-tale-modern-day-surrogacy/

Cook, Tony y SCHnelder, Chelsea (2016). «What we know about Gov. Mike Pence's position on gay rights over the years.» IndyStar. US Today Network, 13 de enero. Disponible en: http://www.indystar.com/story/ news/politics/2016/01/04/what-we-know-gov-mike-pences-position-gay-rights/78257192/

CROCKIN, Susan L. (2017). «D. C. enacts surrogacy legislation replacing former prohibition on compensated surrogacy». Society for Assisted Reproductive Technology, 18 de abril.

DockTeRman, Eliana (2017). «Margaret Atwood and Elisabeth Moss on the urgency of The Handmaid's Tale». Time Entertainment, 7 de septiembre. Disponible en: http://time.com/4734904/margaret-atwood-elisabeth-moss-handmaids-tale/

KAY, Barbara (2017). «The problem with Handmaid's Tale is that it's not a believable dystopia. It's sci-fiction». National Post, 2 de mayo. Disponible en: http://nationalpost.com/opinion/barbara-kay-the-problem-withhandmaids-tale-is-that-its-not-a-believable-dystopia-its-sci-fi

LAHL, Jennifer (2017). «The Handmaid's Tale'shows exploited surrogacy as fiction, but it's happening in our world today». Verily, 26 de abril. Disponible 
en: https://verilymag.com/2017/04/the-handmaids-tale-hulu-surrogacy-exploitation

MeAd, Rebeca (2017). «The prophet of dystopia.» New Yorker, 17 de abril. Disponible en: https://www.newyorker.com/magazine/2017/04/17/margaret-atwood-the-prophet-of-dystopia

MıLleR, Bruce (prod.) (2017). The Handmaid's Tale, primera temporada. Hulu TV.

PARDIES, Ariel (2016). «How commercial surrogacy became a massive international business». Vice, 14 de enero. Disponible en: https://www. vice.com/en us/article/exq7nz/how-commercial-surrogacy-became-a-massive-international-business

SCHLÖNDORFF, Volker (dir.) (1990). The Handmaid's Tale. Metro-Goldwyn-Mayer. 



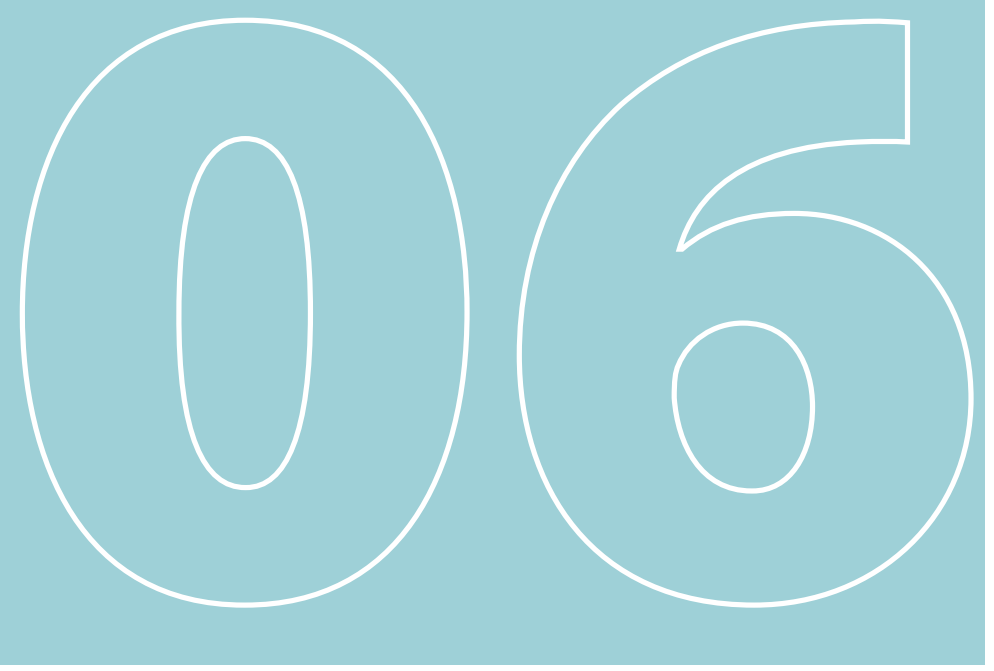

\section{LO QUE MÁS ME GUSTA}

\section{SON LOS MONSTRUOS}

Emil Ferris

Reservoir Books, 2017

Traducción de Montse Meneses Vilar

\section{MARA GONZÁLEZ}

Universidad Complutense de Madrid
Hice que los mortales dejaran de pensar en la muerte antes de tiempo.

Esquilo, Prometeo, 9

En todas las casas americanas hay un desván o un sótano, un ala prohibida o una puerta cerrada. El género del terror ofrece innumerables ejemplos de secretos y misterios temibles que aguardan más allá de los umbrales. A veces no se trata solamente de un lugar peligroso; a veces encierra un tiempo, un recuerdo, la verdad sobre nosotros mismos. Otras veces es un poder externo, autoridades ideológicas o eclesiásticas que nos obligan a enterrar ciertos asuntos, a eliminarlos de la historia de la humanidad. A estos secretos obligados a meterse en el sótano se los conoce como tabúes y parten del miedo del ser humano por nombrar algo, por darle notoriedad o reconocer su existencia. Se tiene miedo, por ejemplo, a pronunciar un nombre, a descubrir las barbaridades que acontecían durante el exterminio nazi, a hablar de las putas, etc. Quizá temamos revelar el tipo de monstruo que llevamos dentro.

Al silenciarse, el horror a ser mencionado de nuevo va ocultando aún más esos tabúes, despreciándolos. Por eso, resultado de un proceso metonímico, el cuarto oscuro y cerrado se convierte en lo desconocido, aquello que no puede decirse, que no se concibe más que en las pesadillas o en el inconsciente. Las 
cerraduras son incomprensibles y suscitan muchas preguntas: ¿Qué esconden, quién se esconde? ¿Quién pone cerraduras al caso de Anka Silverberg, la vecina de Karen, nuestra protagonista?

El libro primero de Lo que más me gusta son los monstruos (2017) —un cuaderno de ilusiones, anotaciones y descubrimientos - se sitúa en la década de los sesenta, los años de la Guerra Fría, las revoluciones contraculturales y las manifestaciones pro derechos civiles. Era un periodo proclive a cuestionar las bases del pensamiento. Emil Ferris aprovecha ese contexto para hacer particular esa grandilocuencia pasajera y anteponer las ocupaciones de tantos personajes inadaptados que, por fin, cuentan su historia. Se habla de la injusta subordinación de las clases bajas a la rudeza social y, en el caso de las mujeres, a la explotación sexual. De hecho, la prostitución es el corazón de esta abigarrada novela gráfica reconocida como la mejor del año pasado en los premios Eisner.

Karen Reyes, su autora en la ficción y alter ego de Emil Ferris, nos adentra en un mosaico de personajes y temas antes despreciados o demonizados. Lo hace para recuperar la verdad sobre aquellos y demostrar que las apariencias engañan. Por ejemplo, en lo que respecta a la prostitución, Ferris sugiere que la sociedad ha asesinado a Medusa y después ha usado su sangre para curar su mala conciencia. Es decir, que bajo el estereotipo de la mujer sensual con poderes de atracción irremisibles que parece un monstruo de pecado y vicio en realidad se encuentra una niña anciana, débil y cuya vida no vale nada, de acuerdo con el desprecio dirigido al colectivo de las prostitutas o trabajadoras sexuales.

La joven narradora de la historia, Karen Reyes, siente fascinación por su vecina Anka Silverberg. Quiere ser la fuerza sensible que busque todas esas claves/llaves para reabrir la guarida del monstruo y descubrirnos cómo y por qué murió de verdad su vecina: personaje difícil de encasillar y de comprender. Por un lado, el cómic nos ofrece el relato de la fatal existencia de Anka —nacida en Berlín y dejada en manos de una madre irresponsable y torturada - ; por el otro, la mirada idealizada de la joven detective destaca la personalidad y el carisma de la alemana. A pesar de que a una mujer se le aconseja no ser curiosa, no cuchichear; Karen Reyes lo es y está dispuesta a descubrir la verdad, ese monstruo que debe salir a la luz y devorar con sus mandíbulas a la población de Chicago y del mundo entero.

Durante su aventura investigadora, Karen explorará esos mundos que la sociedad conoce separados por el binomio de realidad y ficción. Emil Ferris une estos dos universos como a una pareja de enamorados, Karen los confunde entre sí, como lo hacen Anka y Deeze. De hecho, la recuperación de lo mitológico es uno de los grandes logros de la novela. Una de las enfermedades de esta sociedad y de aquellos demasiado absorbidos por la dinámica individualista y racional es que se convierten en aquello que Charles Chaplin 
describía en Candilejas (1952) como un enorme y peligroso monstruo sin cabeza. Pero «no son sus trabajos de cocinero, enfermera o granjero lo que les convierte en masa, jno!, sino el hecho de que la mayoría solo cree en aquello que puede ver, oler, saborear, tocar, oír, o comprar». (18) Para los personajes de esta historia, los mitos que se descubren en cuadros y novelas son los amigos más leales del mundo. Entienden que en estos se encuentre el misterio, el fuego de la creatividad que Prometeo robó a los dioses para dárselo a los mortales. Son como esa vela encendida en mitad de la noche que describe la anciana Sonja para consolarse ante las dificultades de la vida. Por eso visitan los museos con frecuencia, para descubrir no solo que los monstruos son inspiradores, sino que toda criatura nacida de la ficción y los sueños supera con creces a los humanos. A Karen le parece ver a Anka retratada en las Magdalenas penitentes y en cuadros del romanticismo y concibe la recuperación de la amistad del monstruo como si fuera una pequeña Mary Shelley que se apiada de los outsiders. Los monstruos le ayudan a entender mejor las cosas porque, además de ser despreciados y combatir constantemente el estigma de ser temibles y malvados, carecen de género y tienen el poder de autoconstruirse, lo cual es un hito en el desarrollo afectivo. No son como ese personaje tan patético, el Sr. Chugg, el ventrílocuo, que tiene muñecos vestidos de humanoides sin nada interesante que decir.

A veces la forma no solo acompaña al contenido, sino que se pone a su servicio. La virtud del preciosismo que se despliega en las páginas de Lo que más me gusta son los monstruos es su particular manera de cuestionar el género y el lenguaje del cómic al tiempo que captura la magia del sketch, del boceto vital que a veces es perfecto en detalles y técnica y otras no lo es tanto. Entonces parece un dibujo caótico que se mueve al ritmo de las ideas, en cuyas páginas se multiplican los mensajes con flechas, los textos en diferentes sentidos y la superposición de imágenes, como en un cuaderno de estudio, de exploración y autoconocimiento. Me parece que, al dibujarlas, Ferris acaricie el alma de las personas como quien acaricia a un gato describiendo el movimiento de su pelo, desde la raíz hasta fuera. No se me ocurre mejor manera de constatar todo aquello que la joven narradora empieza a comprender sobre el mundo que le rodea, su posicionamiento y ese interés por recuperar las caras de mujeres olvidadas.

La técnica del dibujo estilográfico actúa como la aguja de un tatuador, taladrando la superficie del papel para dar la sensación de fortaleza y dinamismo. La misma fuerza que tienen los otros dos personajes nucleares: Diego Zapata Reyes (Deeze) hermano de Karen y fuente de inspiración —Deeze dibuja constantemente- y Marvela Reyes, su madre. Son mestizos, de raza irlandesa, americana y mexicana. Su mestizaje forma parte de un complot por parte de la autora contra el convencionalismo, igual que los personajes tratan de escapar el determinismo genérico y desempeñar papeles más complejos;
1. Las páginas del cómic no están indicadas, imagino que por algún motivo estético, así que las he contado manualmente. 
véase la bellísima interpretación del cuadro de San Jorge matando al dragón de Bernat Martorell y el paralelismo con las tres personas que cohabitan en Deeze. El libro nos descubrirá hasta qué punto el trío de Reyes está implicado en el caso de Anka, aunque la transformación existencial definitiva no tenga lugar y, por lo tanto, dejemos a Karen en medio de una persecución milenaria en búsqueda de la inmortalidad más ruidosa de todo Chicago. 
Campoamor, Mercedes Fórmica), la ambigüedad autorial (María Martínez Sierra) o la especialización en actividades literarias consideradas secundarias como la literatura infantil (Elena Fortún, Concha Méndez), el periodismo (Magda Donato, M. ${ }^{a}$ Luz Morales) y la traducción (Elisabeth Mulder, M. a Luz Morales). En el rescate de estas escritoras hay que destacar la labor pionera de la crítica feminista (Breve historia feminista de la literatura española, 19932000), la actividad continuada de grupos de investigación como el grupo LOEP (2007) de la Universidad Complutense o el Seminario Permanente sobre Literatura y Mujer (2008) de la UNED.

En esta primera aproximación a las ediciones de mujeres escritoras de la editorial Renacimiento haré una reseña de los libros de María de la O Lejárraga (Martínez Sierra) y Cecilia G. de Guilarte publicados por la citada editorial.

De María Lejárraga han salido a la luz tres títulos con la firma de María Martínez Sierra, que es la que pone al frente de su libro La mujer española ante la República (1931) y de los que publica tras la muerte de su esposo Gregorio Martínez Sierra en 1947. Los anteriores, excepto el primero (Cuentos breves, 1899), firmado con su nombre de soltera, María Lejárraga, llevan una firma literaria que abarca a dos artistas, María y Gregorio, bajo el nombre del esposo.

Renacimiento ha editado el libro de memorias Una mujer por caminos de España (1952, ed. 2019), y dos volúmenes de teatro: Tragedia de la perra vida y otras diversiones: Teatro del exilio 1939-1974 (ed. 2009) y Viajes de una gota de agua (1954, ed. 2018); la primera pertenece a la colección Biblioteca de la Memoria y las otras dos a la Biblioteca del Exilio y a la colección Fábula de Literatura Infantil respectivamente.

Una mujer por caminos de España es una excelente edición de uno de los dos relatos memorialísticos de su autora; el otro es Gregorio y yo (medio siglo de colaboración) (1953); ambos se publicaron tras la muerte de su esposo, Gregorio Martínez Sierra, y constituyen un conjunto unitario. El primero de ellos lo anota magníficamente Juan Aguilera Sastre, uno de los mejores conocedores de la vida y la obra de María, que ha publicado al menos una decena de trabajos sobre ella y varias ediciones de sus textos, como las tres que voy a comentar. En este texto María da cuenta de sus andanzas por España para predicar la buena nueva socialista, en particular durante la campaña electoral de 1933, en la provincia de Granada, en la que resultó elegida diputada, pero no solo y no con todo detalle: «Seleccionó momentos y vivencias de entre sus recuerdos para contar la verdad, "su verdad", sobre un momento de la historia de España que vivió apasionadamente como protagonista privilegiada» (Aguilera, 2019: 77)

El primer y el último capítulo anclan el libro en el presente, mientras que los quince centrales se retrotraen al pasado republicano de la propagandista; el primero es un diálogo entre «La propagandista y su conciencia» y el
Maria Martinez Sierra

TRAGEDIA DE LA PERRA VIDA $Y$ OTRAS DIVERSIONES TEATRO DEL EXIL.IO |

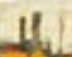

BHeHoitca oth IxHL 
último una autobiografía de infancia y juventud, «Una infancia feliz y llena de curiosidad»; este es quizás el único texto estrictamente autobiográfico de la autora, que no reconoce como autobiografías ni Una mujer por caminos de España ni Gregorio y yo y fue escrito por exigencias de la editorial estadounidense que inicialmente iba a publicar el libro.

El volumen viene precedido de una larga introducción en la que Aguilera resume varios de los trabajos ya realizados sobre la autora y añade datos nuevos, como el poco conocido sobre la militancia política de María en el PSOE en sus años de exilio; insiste en la importancia de la República en su biografía y profundiza en el asociacionismo, fundamental en su compromiso y en su proyección pública. Pero además, explica cómo llegó el libro a adquirir la estructura con la que hoy lo conocemos: desde su génesis (en parte ya analizada por Alba Blanco), pasando por el título y el orden de los capítulos (que no son los que les había asignado inicialmente), hasta la comprobación de que varios de ellos son artículos publicados previamente en la prensa o capítulos estrechamente relacionados con sus artículos periodísticos.

El texto de María se reproduce tal cual, con sus escasísimas notas, y Aguilera añade un extenso aparato de notas complementario en el que documenta y aclara casi cualquier aspecto de la vida, el compromiso político y otras facetas del personaje en cuestión, con el apoyo de una amplia documentación periodística, deshaciendo errores, precisando datos; como colofón de una edición tan esmerada se añaden al conjunto dos apéndices: el primero que ofrece una serie de artículos de propaganda publicados por la autora en la prensa, y el segundo sobre los numerosos actos electorales en que participó entre 1931 y 1936.

Con todo ello, Juan Aguilera hace una aportación fundamental a la bibliografía de María Martínez Sierra tanto en su aspecto textual como en lo relativo a la oratoria y al trabajo periodístico de la autora; y es que la profesión de fe socialista de María se expresa verbalmente por estos dos cauces, de modo que su figura pública resulta enormemente coherente. Edición tanto más necesaria por cuanto la única próxima en el tiempo es la de la Editorial Castalia (Biblioteca de Escritoras) en 1989.

Tragedia de la perra vida y otras diversiones, al igual que Viajes de una gota de agua, han sido editados al alimón por Juan Aguilera e Isabel Lizárraga. La colaboración de ambos en la investigación literaria ha sido hasta el momento muy fructífera, como lo testimonia el imprescindible volumen De Madrid a Ginebra: El feminismo español y el VIII Congreso de la Alianza Internacional para el Sufragio de la Mujer (1920) publicado en 2010, así como varios otros trabajos sobre literatura española del siglo xx, entre ellos algunos dedicados a María Martínez Sierra.

Tragedia de la perra vida es un volumen facticio en el que se recoge el libro titulado Fiesta en el Olimpo y otras diversiones menos olímpicas (1960) y

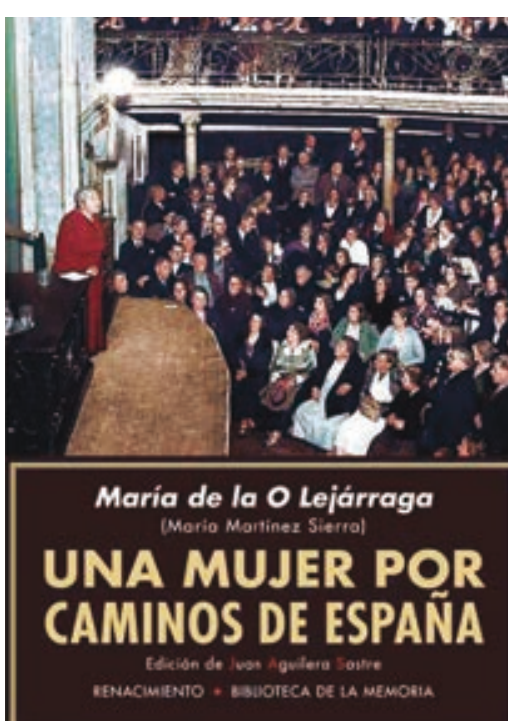


otras piezas inéditas o solo publicadas antes en la prensa argentina. El citado libro no había vuelto a reeditarse sino en parte (cinco piezas) en 1996 por Eduardo Pérez-Rasilla con el título de Teatro escogido en la editorial de la ADE.

El volumen se articula en tres partes: «Teatro», «Televisión sin pantalla» y «Otras diversiones»; solo la segunda se reproduce tal cual con respecto al original de 1960, mientras que las otras dos incluyen textos que no estaban en el mismo. «Teatro» incluye obras largas y libretos para ballet; «Televisión sin pantalla» $y$ «Otras diversiones» son «una especie de antología de piezas breves», teatrales y narrativas, escenas o estampas tomadas al azar del espectáculo de la vida y con una importante impronta visual, muy diversas en formato, lenguaje y temas.

El teatro fue la vocación fundamental de María durante los años en que colaboró con su esposo Gregorio Martínez Sierra, ya que si era ella quien escribía, él era el empresario que llevaba a la escena las piezas fruto de su pluma. Con la muerte de Gregorio y el exilio, su vocación teatral siguió viva pero le fue imposible a María llegar a estrenar sus obras en Buenos Aires; de ahí que el teatro que escribió en el exilio nunca fuera representado.

Juan Aguilera e Isabel Lizárraga, teniendo en cuenta los papeles del Archivo Lejárraga, hacen una impecable reconstrucción del libro editado en 1960, de los que se deduce que se publicó sin seguir el plan previsto por la autora, ya que esta hubo de plegarse a las exigencias del editor: cambio de título y de estructura y exclusión de varias piezas. Ambos investigadores contextualizan con todo rigor las obras nuevas que incluyen en el volumen, apuntan hacia la clave de lectura autobiográfica y consideran la mejor de estas obras Tragedia de la perra vida (Fiesta en el Olimpo), que era además la más querida por María.

Viajes de una gota de agua recoge tres piezas de teatro infantil: Viajes de una gota de agua, Merlín y Viviana y En busca de una peluca; esta colección no había vuelto a ser editada desde 1954, por lo que su reedición es una buena noticia. El trabajo de presentación del volumen que hacen Aguilera y Lizárraga es espléndido; el prólogo dibuja el entorno argentino de María, en el que vivió los veintitrés últimos años de su vida, y pretende reconstruir el aspecto anímico y sentimental de la autora durante esa época. Todo ello sin caer en sentimentalismos fáciles ni en afirmaciones aleatorias porque los editores, que conocen muy bien la obra de Martínez Sierra, utilizan la correspondencia particular de la autora (que se conserva en varios archivos, entre otros en el archivo familiar) para reconstruir el proceso y las circunstancias que rodearon la escritura de los textos que integran el volumen.

Con estas obritas regresa María a la temática infantil de su primer libro (Cuentos breves), si bien con un tono diferente y mayor altura literaria, pero con la misma impronta pedagógica manifiesta en varios textos de la autora, vinculada a su profesión de maestra; aspecto este último que 
ha sido estudiado por Isabel Lizárraga (María Lejárraga, pedagoga: «Cuentos breves» y otros textos, 2004). La edición de Renacimiento reproduce también las ilustraciones de la de 1954 realizadas por el dibujante argentino Armando Páez Torres.

Las tres piezas que constituyen Viajes de una gota de agua son muy diferentes. Viajes de una gota de agua es un relato dramatizado de estructura eminentemente dialogada pero con un carácter más narrativo que teatral (es una crónica) y con un buen número de canciones; es una alegoría de la vida en tono infantil y de propósito pedagógico. Merlín y Viviana es una fábula de animales, un texto de inspiración americana que su autora concibió como guion cinematográfico para una película de Walt Disney, sueño que no llegó a realizarse. En busca de una peluca es una comedia de magia basada en una farsa francesa, protagonizada por hadas, animales y fantoches.

Por otra parte, Cecilia G. de Guilarte fue novelista y dramaturga, periodista y profesora universitaria; trabajó como corresponsal de guerra para la prensa anarquista durante la guerra civil en los Frentes del Norte (Guillermo TaberniIlas y Julen Lezamiz, Cecilia G. de Guilarte: reporter de la CNT, 2007), experiencia que la afectó profundamente y determinó su evolución hacia un humanismo cristiano y socialista basado en el amor al prójimo, que marcará en adelante su vida y su producción literaria. Fue, al igual que Martínez Sierra, una de las exiliadas que salió de España en 1939, con destino a Francia primero y a México después; en este último país residirá hasta su vuelta a España en 1964. Con todo, sigue siendo una figura bastante desconocida a la que se ha empezado a prestar atención en las dos últimas décadas

En Renacimiento se han editado dos títulos suyos: una autobiografía periodística publicada bajo el título de Un barco cargado de... (2012) por Mónica Jato Brizueta, y la novela autobiográfica inédita Los nudos del quipu (2015), por Manuel Aznar Soler. Ambos pertenecen a la colección Biblioteca del Exilio y cuentan con la garantía de los investigadores que las avalan: Mónica Jato y Manuel Aznar, que han dedicado buena parte de su tarea investigadora al exilio literario español de 1939, que cuenta ya con una abundantísima bibliografía.

Un barco cargado de... está compuesto por treinta y un artículos publicados en La Voz de España de San Sebastián, con este título, entre enero y marzo de 1972, que habían sido recogidos parcialmente en la colección del mismo título publicada por la Editorial Saturrarán en 2001; quince de ellos son inéditos, ya que no pudieron ser publicados por intervención de la censura. El conjunto constituye un relato autobiográfico sobre esa experiencia fronteriza que es el exilio, donde se pone de manifiesto la naturaleza política de este; la memoria es el punto de apoyo de este relato testimonial (testimonio colectivo) ya desde el lúdico epígrafe que lo encabeza; es un relato autobiográfico, pero también un relato de viaje, al que se incorporan algunas
Cecilia G. de Guilarte

LOS NUDOS DEL QUIPU

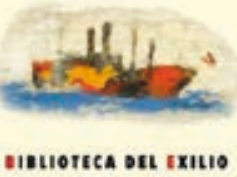


técnicas novelísticas; esta escritura fragmentaria, híbrida y fronteriza se halla ligada a la lucha por la supervivencia cultural, con la que Guilarte intenta restablecer la comunicación con el público español y proporcionar una versión de la Guerra Civil y el exilio diferente de la ofrecida por la historiografía franquista. La excelente introducción de Mónica Jato, así como las notas a los artículos, muy bien documentados, proporcionan las claves necesarias para aproximarse a los diversos aspectos de la dolorosa experiencia del exilio que se dan cita en estas páginas.

La novela Los nudos del quipu presenta el aliciente de su novedad, ya que es un texto hasta ahora inédito, que constituye la tercera parte de la «Trilogía sobre el exilio» de Guilarte; las dos primeras, publicadas en 1969 y 1975, respectivamente, son Cualquiera que os dé muerte y La soledad y sus ríos. La edición de este inédito, como la de otros del mismo periodo histórico publicados por Renacimiento, ha sido posible gracias a la generosidad de los herederos de la escritora, que consideran fundamental difundir el legado cultural del que son depositarios.

Los nudos del quipu, cuya redacción debió terminarse en junio de 1968, viene precedida por una breve introducción de Manuel Aznar, que sitúa el relato en su contexto histórico y literario. Es una novela sobre el exilio republicano español, con muchos aspectos autobiográficos, en la que el ambiente mexicano está muy bien reflejado, sobre todo por la excelente asimilación de las peculiaridades lingüísticas del español hablado en México.

Ambas escritoras, aunque nacidas en fechas y periodos históricos distintos y distantes (María en 1874 y Cecilia en 1915) realizan aportaciones de primer orden a la literatura de «La Otra Edad de Plata»; son mujeres modernas. María desde la inmensa labor teatral que realizó junto con Gregorio, la de escritora de cuentos, novelas y poesías, de libretos para obras musicales o de guiones cinematográficos, y también desde la reflexión feminista en libros como La mujer moderna, Cartas a las mujeres de España o La mujer española ante la República, además de su labor como periodista y conferenciante. Cecilia con sus novelas y cuentos, sus obras teatrales y ensayos biográficos y con su trabajo periodístico. Ambas formaron parte del inmenso colectivo de escritores españoles que hubieron de exiliarse tras la Guerra Civil, y a ambas el exilio les fue muy rentable desde el punto de vista literario, ya que en él produjeron algunas de sus mejores obras: para María fue la ocasión de recuperar públicamente su identidad como escritora con la firma de María Martínez Sierra; para Cecilia supuso la madurez en el oficio de escribir.

\section{Cecilia G. de Guilarte}

\section{UN BARCO CARGADO DE...}



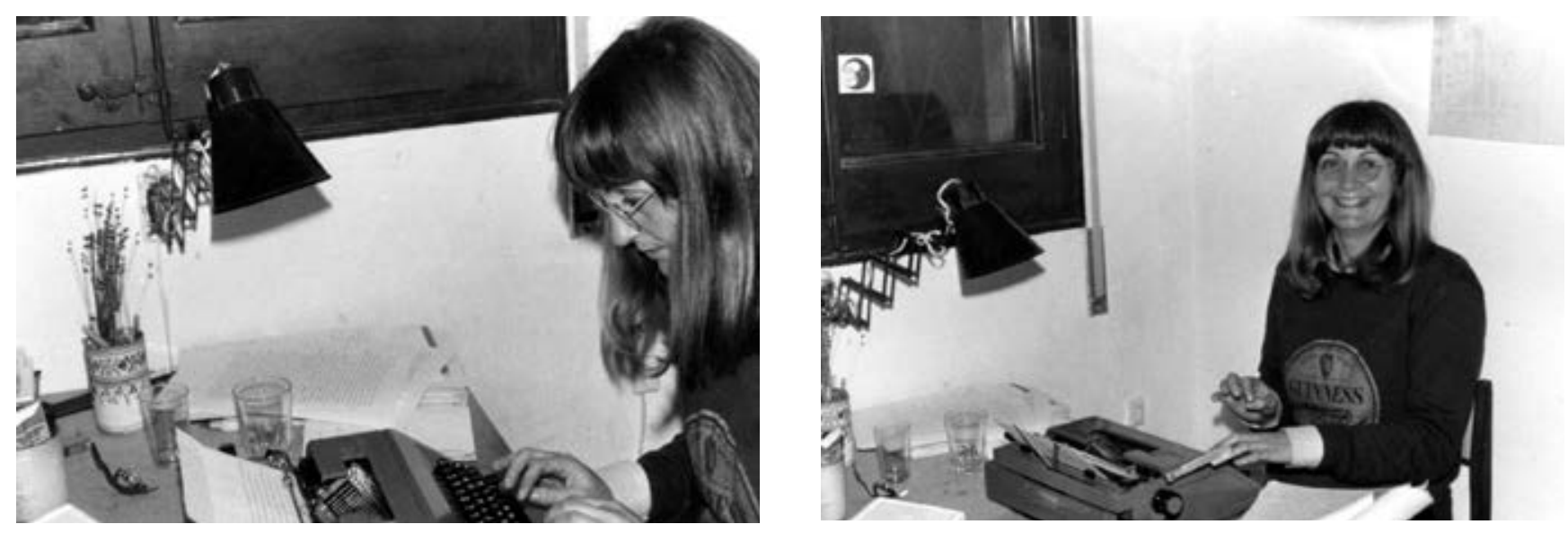

Mary Nash redactando la tesis doctoral en su máquina Olivetti, c. 1974.

las mujeres y del género, editado por Teresa M. ${ }^{\text {a Ortega }}$ López, Ana Aguado Higón y Elena Hernández Sandoica (Cátedra, 2019), resultado del homenaje que se le rindió en la Universidad de Granada en 2017.

Lo que puedo ofrecer es tan solo un fragmento del diálogo que mantuvimos, en el que hablamos, entre otras cosas, de nuestros alumnos y alumnas, de feminismo actual, de lo individual y lo colectivo, de la memoria y desmemoria del feminismo. Y acabamos elogiando el último libro de Siri Hustvedt, de la cual ambas nos descubrimos como admiradoras de su finura, sutileza y sensibilidad. Cuando transcribí la entrevista, mi mente se empeñaba en practicar la irrefrenable operación de extraer el sentido de este relato, una especie de mensaje profundo en él o de lectura entre líneas. En las palabras de la profesora Nash había apertura, heterodoxia y dinamismo, además de mucha pasión por la historia y de una profunda conciencia de la memoria del feminismo, de la necesidad de pensar históricamente como un eje de la ciudadanía activa.

Naciste en Limerick (Irlanda) en 1947. ¿Qué te atrajo de España y de Cataluña y cómo recuerdas el contexto que encontraste entonces, el de los últimos años del franquismo con las movilizaciones contra la dictadura como telón de fondo?

Había estudiado en la Universidad de Cork, en el sur de Irlanda, la carrera de Historia y Francés, Literatura y Lengua francesa. Tengo la impresión de que en una
Irlanda que, pese a ser una democracia, era casi nacionalcatólica y donde el lugar de las mujeres era casarse, callarse y tener hijos, se me envió a la universidad, como a la mayoría de las chicas de la época, para encontrar un buen novio y casarme. A mí me interesaba la Historia, pero no tenía claro lo que quería hacer una vez licenciada. Encontré un anuncio en el departamento de Francés sobre un Instituto de Estudios europeos en Turín e hice la solicitud para una beca de posgrado allí, lo que me cambió absolutamente la vida. Mi ruta hubiera sido Irlanda, Gran Bretaña o los Estados Unidos, pero, en cambio, me encontré con Italia, el Mediterráneo y acabé en Barcelona, algo muy atípico para una chica irlandesa de mi generación.

El proyecto en Turín, donde tuve maestros como Albert Soboul y Witold Kula, se basaba en la idea de que jóvenes de la Guerra Fría, estudiantes de países como Francia, Irlanda, España y la URSS y su órbita, viviesen juntos para poder establecer relaciones de convivencia y paz. Después de aquello, me vine a Barcelona. Quería ver mundo, ir más a la aventura, no quería volver a esa vida preasignada para mí. Empecé a dar clases de inglés para ganarme la vida, pero no me convalidaron mis estudios, así que empecé otra vez como estudiante en la Universidad de Barcelona. Fue una experiencia magnífica: aprendía castellano en el aula, en el contexto final del franquismo, con el movimiento estudiantil a tope, la universidad cerrada, los grises, la policía y esa sensación de que podíamos cambiar el mundo. 
Como ya llevaba cierto bagaje como historiadora, opté por hacer trabajo de archivo, para estudiar aspectos sobre la Guerra Civil y la Segunda República, ya que había leído a Gabriel Jackson, Hugh Thomas y Noam Chomsky sobre el anarquismo, en inglés todo ello porque no se habían traducido. Iba mucho al Archivo Municipal, a la Casa de l'Ardiaca, donde ya me iban conociendo como joven investigadora. Gracias a Montse Condomines (siempre digo que habría que hacer un monumento a las archiveras y bibliotecarias), que había guardado en un lugar secreto del archivo, en el «Infierno», la documentación sobre ese periodo, encontré la de Mujeres Libres, la organización anarquista. Hice uno de mis trabajos sobre ello, mientras que el otro lo realicé sobre las revueltas de 1835, donde también estaban las obreras del textil en Barcelona. El Dr. Emili Giralt me dio matrícula de honor en ambos, pero quiso que hiciera la tesis sobre las revueltas de 1835 , obviamente.

Yo, que había leído a Simone de Beauvoir, a Betty Friedan y a alguna novelista irlandesa en cuyas obras veía reflejadas mis inquietudes, y que tenía la intuición de que faltaba algo en esa historia que nos estaban contando, que había una negación total de cualquier contribución de las mujeres a la historia (también por parte de los historiadores progresistas de la época), comprendí que estas mujeres habían sido no solo olvidadas, sino denigradas. Así que le dije al Dr. Giralt que ni hablar, que yo quería hacer la tesis sobre esas mujeres estupendas y fuertes que había encontrado, y, finalmente, le convencí. Primero hice la tesina y luego la tesis, que presenté en 1977, sobre las mujeres en la izquierda durante la Segunda República y la Guerra Civil.

Cuando explicaba la investigación, se reían de mí. Era joven, minifaldera, con poca credibilidad, y me dijeron en varias ocasiones que lo había inventado, que era imposible que existiera una organización de ese tipo. Esto tiene que ver con la amnesia histórica del franquismo, pero, aún más, con la actitud de los historiadores progresistas (marxistas de su época), para quienes las mujeres no tenían ninguna impor- tancia y, por lo tanto, no podían haberse organizado, creado políticas públicas al respecto ni luchado por sus derechos. Era toda una discusión frente al mundo cerrado androcéntrico que no admitía a las mujeres como sujeto histórico. Eso también me llevó a querer compartir esta información, por lo que propuse crear una asignatura de Historia de las mujeres, que empezó a hacerse en 1974, todavía bajo el franquismo. En aquel momento no existía ni el nombre de Historia de las mujeres; creo recordar que la denominé Feminismos, Mujeres y algo más. Se burlaban de mí, claro. Sin embargo, Giralt, un hombre liberal, que no entendía nada pero que dejaba hacer, me dijo años después: «Ahora empiezo a entender lo que usted hacía, por mis hijas».

¿Y no pudiste apoyarte o establecer relaciones con los incipientes grupos feministas?

En 1976, antes de las Jornadas Catalanas de la Mujer, organicé mesas redondas para hablar sobre mujeres con mis estudiantes, cada dos semanas en el Paraninfo durante el último semestre. ¡Hablar sobre mujeres en público! En un momento en el que lo importante era ganar a Franco y en el que cualquier asunto relacionado con las mujeres era considerado un impedimento a la lucha de clases y a la revolución social. Esta era la actitud de aquellos progresistas. Invité a gente que conocía, a través de contactos personales, porque yo formaba parte de uno de esos grupos que se reunían en las casas para hablar de temas que nos preocupaban (después los llamaríamos «de autoconciencia») y que fueron absolutamente decisivos al crear una conciencia feminista. Era el momento de convertir lo personal en lo político. Lo cierto es que fue una experiencia extraordinaria: mi primer libro, Mujeres Libres: España 1936-1939 (Tusquets, 1975), al que tengo mucho cariño, se convirtió en un pequeño best-seller de la época, porque el movimiento feminista, que entonces estaba creciendo, encontró en él una genealogía de mujeres. Así, el mito de la ausencia total de mujeres en la Segunda República, y en general en la historia, se venía abajo. 
¿Cómo fue tu integración en Cataluña? ¿Crees que proceder de un país como Irlanda te ha influido? ¿Y en tu mirada analítica?

De entrada, yo me casé con un catalán aún bajo el franquismo, así que, según la legislación española, tenía que adaptar mi nacionalidad a la del marido y, debido a la irlandesa, perdí la originaria. Así fue como me convertí en española en el año 1970, lo que también me facilitó poder seguir mi carrera académica en Historia (a diferencia de otras extranjeras ubicadas aquí, que normalmente seguían el camino de la Filología Inglesa), convertirme en funcionaria y acabar siendo catedrática, que, como extranjera, no podía haberlo hecho en su momento.

A la vez, yo siempre he tenido facilidad para las lenguas. Me era muy fácil pasar del francés al catalán, al italiano y al castellano, acostumbrada como estaba al bilingüismo, al haber realizado los estudios en gaélico y no en inglés. Además, yo tenía ganas de aprender catalán, lo hice de manera autodidacta. Recuerdo que, cuando se empezaba a reclamar el derecho de hablar catalán bajo el franquismo, me tomaban a mí como ejemplo de originaria de un país en el que se podían hablar otras lenguas.

Otra cuestión es haber sido siempre consciente de que Irlanda fue colonia inglesa, de manera que la idea de la otredad, la alteridad, el colonialismo, el poscolonialismo, la diversidad cultural, y todo ello en relación con el género, eran temas cuya conexión resurgió en la década de los noventa ya que estaban, de alguna manera, en mis raíces culturales. También es cierto que había más empatía hacia mí por el hecho de ser irlandesa y no inglesa: me sentía muy acogida en los setenta, como estudiante, muy guiri, muy forastera; me conocían como la minifaldera de Barcelona.

Por otro lado, mi mirada fue distinta hacia cuestiones como la jerarquía. Irlanda era un país muy jerárquico, nosotros como estudiantes aún vestíamos toga. Pero mi relación con el Dr. Giralt era, en cambio, de «bueno, hablemos y negociemos», algo que me parecía muy normal entonces. En España, los códigos eran muchísimo más rígidos y quizás esta mirada des- de fuera me dio una percepción, una convicción, que facilitó ciertas cosas. Aunque parte de mi historia fue un intento de integración tan grande que tuve que repensarme otra vez. Siempre cito a mi querido Edward Said: yo vine como outsider, quise ser insider y acabé in-between, porque, te guste o no te guste, la gente te ubica con esta mirada de alteridad. Aunque eso también ha sido muy beneficioso en mi vida.

Fuiste una de las impulsoras, en las décadas de los setenta y los ochenta, de la Historia de las mujeres en la universidad española y participaste activamente en su institucionalización a través de la creación del Centro de Investigación Histórica de la Mujer (CIHM) en 1982, del impulso de la revista Arenal, que en 2013 cumplió 25 años, y de la Asociación Española de Investigación Histórica de las Mujeres (1991). ¿Cómo recuerdas y valoras este proceso?

Una historiadora puede trabajar sola, dar una asignatura optativa de Historia de las mujeres, pero yo tenía muy claro que había que crear organismos, asociaciones, redes (académicas en este caso) para facilitar la labor de conocimiento, difusión y reconocimiento. Quizás porque durante los primeros años fue un trabajo muy solitario y rechazado, cuya viabilidad y credibilidad eran cuestionadas, por lo que tenía claro que se tenían que crear sistemas para trabajar de manera colectiva y darlo a conocer.

La primera iniciativa fue la creación del CIHM, dentro del Centre d'Estudis Històrics Internacionals (CEHI). Se lo planteé al Dr. Giralt y lo estuvimos discutiendo durante largo tiempo, hasta que me dio el visto bueno para crear una sección con nuestros despachos. Lo que hice fue intentar reunir, dentro de la órbita de la Universidad de Barcelona y cercanías, a las pocas personas que se dedicaban a la Historia de las mujeres. Siempre he tenido una visión liberal, es decir, abierta a la incorporación de maneras de trabajar diferentes de la mía, porque creo que es desde iniciativas plurales y diversas como avanzamos. Estaba centrado en la Historia, pero con cierta apertura disciplinaria, 
aspecto este que he ido desarrollando, sobre todo, a nivel teórico y en los equipos de investigación que he llevado a posteriori. Todos los trabajos que se hacían se daban a conocer, además, a través de congresos y seminarios.

En aquellos años asumí también, por responsabilidad, la propuesta del Ministerio de Educación de crear un posgrado de formación en educación no sexista, el primero en España, allá por 1991. Me pareció una iniciativa importante porque venían dos profesoras de cada provincia de España para introducir y reforzar una metodología y un pensamiento no sexista en educación secundaria. Quizás me quedaba un poco lejano, pero opté por ello; más tarde creó problemas entre algunas personas del CIHD, que no veían la necesidad o el interés en hacerlo. Fue duro, pero fue una experiencia interesante.

Creamos, además, manuales y textos no sexistas en Lengua, en Historia y en todo el ámbito de la docencia impartida en secundaria. Eso, hoy en día, se reclama como gran novedad: inventamos cada vez la rueda y es muy frustrante. Ayer escuché en una entrevista a una mujer hablando, como un descubrimiento, sobre el tema del color rosa para las niñas y del condicionamiento sexista, cuando todo eso ya lo habíamos tratado en esta programación que hicimos en los noventa. Creo que hay que mejorar partiendo de lo que ya se ha hecho, no empezar desde cero, porque debemos reconocer la genealogía. Es un problema inmenso de reconocimiento de la labor investigadora.

Dentro de esta preocupación por crear tejido académico, otra etapa sería la creación de la AEIHM. Conocía a historiadoras que estaban en la Federación Internacional y había participado en congresos, de modo que surgió la posibilidad de crear, aquí en España, una asociación. Lo hice contando con gente de diversas universidades españolas, para formar primero la comisión y luego la asociación. Da gran satisfacción ver lo potente que es hoy en día, pero cuando la iniciamos éramos muy pocas. Fue un paso importante para sentir que no estás sola y poder discutir lo que investigas con gente que te puede entender y aportar. A partir de los

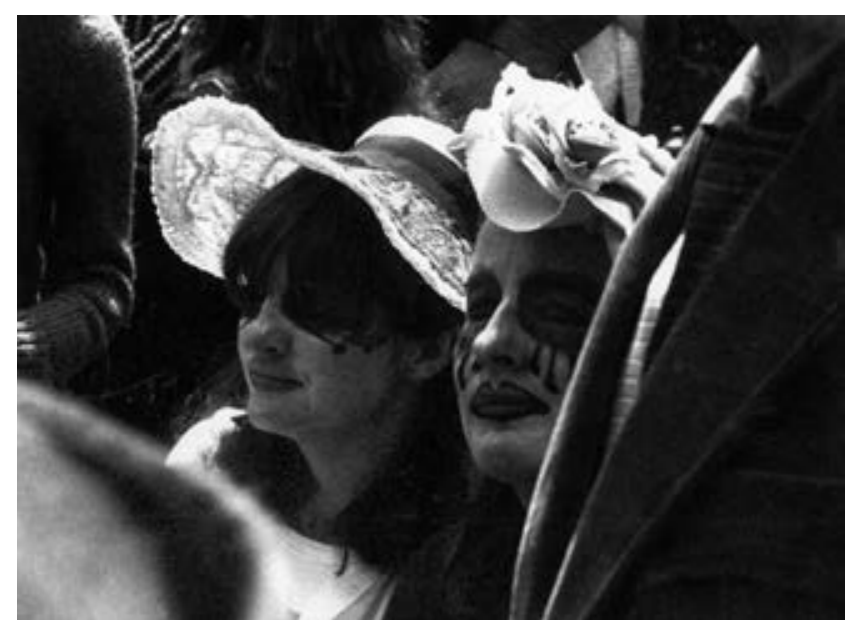

Mary Nash con la antropóloga Verena Stolke disfrazadas de sufragistas en una manifestación feminista en Barcelona, c. 1975.

debates, surgió también, inicialmente en Barcelona, el tema de crear una revista. Porque había investigación y era necesario publicar, aunque en la mayoría de las revistas había cierta oposición. En Historia Social me llamaron para formar parte del Consejo Editorial. Allí sí había una sensibilidad que permitía la transversalidad; es decir, reconocer que tenían que llegar las aportaciones, las obras y las investigaciones no solamente a las revistas de mujeres, para conseguir así que ningún historiador negara su existencia. Ha habido estrategias diversas y una de ellas es Arenal, una revista excelente, con colaboradoras que siguen desde el inicio y otras renovadas. Mirando atrás, a los proyectos, grupos y seminarios que han ido saliendo, se ve que hemos conseguido mucho, aunque a veces nos parezca poco.

Si este esfuerzo colectivo ha dado sus frutos, ¿cómo evalúas la situación actual de la Historia de las mujeres?

El esfuerzo colectivo es lo que permite avanzar de manera más rápida. Es importante la capacidad de reinventarnos, de empezar a manejar otros instrumentos analíticos, de no estancarnos. Si miramos hacia atrás, vemos que lo primero fue contar, describir, conocer los nombres de las mujeres. Sin embargo, ahora la historia de las mujeres tiene un bagaje analítico fuerte, nutrido de las aportaciones de otras disciplinas cercanas, 
que nos ha permitido no solo ver la contribución de las mujeres, sino profundizar en la revisión de nuestro conocimiento general de la historia. A mí, por ejemplo, siempre me ha interesado el tema de las representaciones y los discursos, cuestiones que tienen que ver con Foucault, la capilaridad del poder y cómo se crean sus mecanismos, sobre todo respecto a las mujeres y los imaginarios colectivos, que son mecanismos culturales. Inicialmente, estábamos inmersas en una historia más social, que sigue ahí y que se está recuperando, pero, a la vez, creo que intentar descifrar los mecanismos culturales que llevan a la discriminación y a la opresión, o las propias dificultades en la transformación hacia la igualdad, permite entender procesos que se estancan o no llegan a su término.

En los últimos tiempos, el tema de la construcción de las subjetividades también ha sido muy importante para entender de forma más elaborada y compleja, sobre todo en el contexto de una sociedad que crea una cultura del blanco y negro, de frases de Twitter. Para mí, que siempre me han fascinado los intersticios y los in-between para entender las fronteras de la interacción, todo eso se pierde. En cambio, veo que hay cierta recuperación de una visión social, marxista, cuyo énfasis me sorprende porque parece el descubrimiento de algo nuevo. Lo social y lo cultural siempre han formado parte del tipo de historia que me ha interesado.

En sus orígenes, la Historia fue una de las principales disciplinas que participó en la configuración de una crítica al androcentrismo, al sexismo y también en el proyecto de visibilización (y revalorización) de las vidas de las mujeres y de su protagonismo social e histórico. ¿Qué papel crees que sigue teniendo la Historia en el conocimiento feminista actual?

La Historia lo que hace es dar presencia a una existencia negada, dado que no había genealogía respecto a otras mujeres y su labor emprendida. Claro, si no existe, no hay referencias, por eso tomé mucho cariño en su momento a la idea de que, si no se nombra un colectivo, no existe. Nombrar e incluir es decisivo,

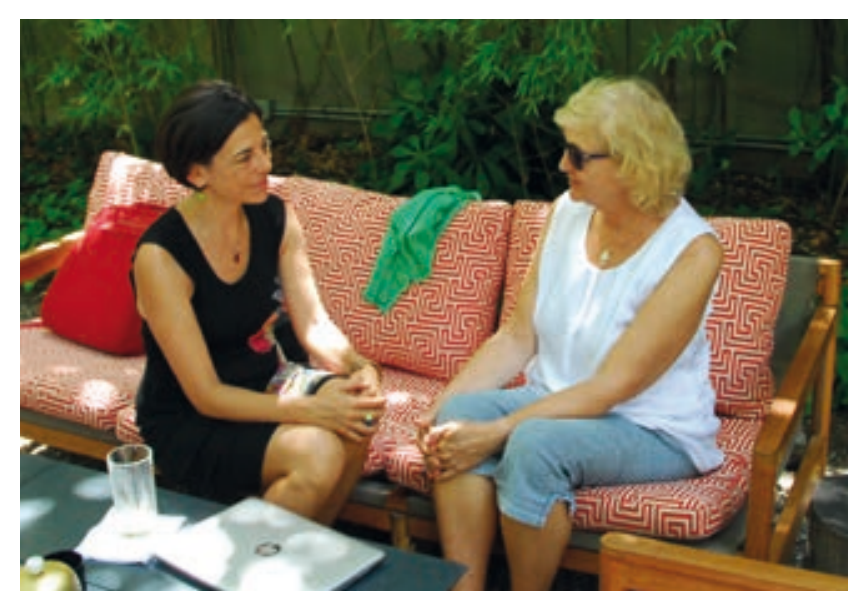

además, porque sin políticas de reconocimiento, como propone Nancy Fraser, se dificulta la igualdad, que es lo que hay que intentar lograr en la historiografía.

Con respecto al feminismo, creo que la Historia también ha sido clave. Por una parte, estoy pensando en Mujeres Libres, ese pequeño librito que marcó un antes y un después al crear un proceso de identificación con mujeres del pasado, de quienes no sabíamos nada y quienes de alguna manera son modelos a seguir. En aquel caso, el referente era la Guerra Civil, con mujeres revolucionarias a las que también identificábamos como feministas luchadoras. Así es como descubres una manera totalmente distinta de ver la historia. Por eso creo que fue crucial para el feminismo, porque no se empieza desde cero, sino que existe una legitimidad anterior, todo un proceso de lucha, una ligazón, estrategias diferentes, experiencias vividas... No venimos de la nada. Lo terrible es pensar que sí, que se inventa todo de nuevo.

Por otra parte, conocer los feminismos anteriores es primordial. Pienso en tres ejemplos que me parecen paradigmáticos. El primero es la adquisición de derechos políticos para las mujeres que ha tenido lugar desde la Transición: los políticos de la oposición franquista jamás habían pensado en ello hasta que el feminismo les emplazó a crear una cultura política en clave feminista.

El segundo ejemplo tiene que ver con el conocimiento de los límites. Una de las grandes victorias feministas durante la Transición fue que toda la experiencia 
de las mujeres que se hacía desde los pequeños contextos, como era el caso de DAIA (Mujeres por el Autoconocimiento y la Anticoncepción), fue incorporado a las políticas públicas, lo que ayudó a crear los primeros centros de planificación familiar. Este reconocimiento del derecho de las mujeres sobre sus cuerpos fue un avance extraordinario viniendo del franquismo. Sin embargo, algunas de ellas no lo vieron del todo bien, porque la filosofía de empoderamiento de las mujeres sobre su propio cuerpo y la ética feminista se perdían en el momento en el que pasaban a ser políticas de salud pública. Los profesionales de la sanidad, que tienen la técnica o los conocimientos médicos, no transmiten los valores feministas, de modo que por un lado se gana, pero, por otro, también se pierde. En ese momento, lo que se plantea en el centro del debate es cómo transmitir el empoderamiento de las mujeres sobre su cuerpo.

El tercer ejemplo es el de la violencia machista. El movimiento del \#MeToo actual ya estaba funcionando en los años setenta: era el «yo también soy adúltera», junto a esa idea de sororidad. Yo misma estuve en las manifestaciones sobre adulterio con mi bebé en brazos. Pero hay un factor que no estaba funcionando en los setenta, el de los nuevos sistemas de comunicación. En la actualidad existen otras plataformas, así que las condiciones son distintas. Aunque la lección parece un poco pedante («el contexto es diferente, pero hay elementos comunes»), hay que transmitirla, porque si no es como si nunca hubiera habido reacción colectiva de las mujeres frente a los abusos o la discriminación. Claro que la hubo, pero se olvida. No sé siquiera si los estudiantes actuales de Historia lo conocen. ¿Cómo lo transmitimos sin simplificarlo? Porque la complejidad no vende. ¿Cómo hacer la historia más atractiva y comprender su valor, en una sociedad que lee pocos libros? Incluso entre las jóvenes feministas, a nivel intergeneracional, la comunicación es fundamental.

\section{¿Y los jóvenes, los chicos?}

El de la cuestión de las nuevas masculinidades es un tema que da esperanzas. Hay jóvenes estudiantes que vienen a mis clases (no todos, pero sí un núcleo muy importante) que están deconstruyendo la masculinidad y que tienen una visión feminista. Nosotras hemos hecho un esfuerzo enorme de deconstruir-reconstruir, de debatir y de abrir nuestros horizontes, pero si ellos no cambian, ¿cómo transformas los mecanismos de dominación? Es imposible. La identificación y la no tolerancia de la violencia machista son claves. Me acuerdo cuando se contaban chistes verdes y yo, al poner mala cara, era la estrecha. En este sentido, actualmente hay que reconocer y agradecer el impacto de ciertas figuras, tanto aquí como a nivel internacional, a un nivel que como historiadoras nosotras no tendremos nunca. Eso está bien, porque deviene un debate popular. Pensemos en que este año llevamos ya 36 asesinadas (es solo la punta del iceberg, porque hablamos de los casos extremos), pero, si miramos a los años setenta, el secretismo, la obligación del silencio y el «iaguanta, mujer!» se han roto. Por eso se espera que otros niveles también se puedan romper y haya tolerancia cero en cualquier manifestación de violencia y abusos respecto a las mujeres.

Y, sin embargo, al mismo tiempo, bien sea por las redes sociales o por la transmisión en las familias, todavía hay una educación muy machista. Hay cierta contradicción entre los comportamientos entre adolescentes y jóvenes basados en relaciones de control y jerarquía, por una parte, y la oferta de unos imaginarios femeninos que remiten a la autonomía, la fortaleza, etc., por otra.

Claro, el control del vestido, del ambiente, del cuerpo. Y la tecnología, totalmente diferente, tenemos que dominarla para dar las respuestas de manera impactante. Yo puedo escribir un libro, pero cada generación tiene que reaccionar desde los instrumentos a su disposición. En este sentido, las representaciones explican muchas cosas en el sistema de discriminación: si no hay contra-modelos, es difícil para las chicas y chicos jóvenes re-imaginar, teniendo en cuenta que para ellos hay menos oferta, porque siguen el modelo de masculinidad hegemónica tradicional. Yo explico, en parte, el grado de asesinatos de violencia machista por 
la construcción identitaria de la masculinidad tradicional sobre la sexualidad, la virilidad y ser el breadwinner, el «ganador de pan». Ahora, con la precariedad laboral, todo este sistema de creación de una identidad fuerte se ha deshecho. Las mujeres han ido ascendiendo, han cuestionado la maternidad como eje central y otras muchísimas cosas a lo largo de estas décadas; pero los hombres, no. Y creo que no hemos entrado mucho en este aspecto de construcción de imaginarios (dibujos, series, cómics...), pero tiene que haber un movimiento de hombres que lo haga. Y a nivel académico, lo mismo.

\section{En un librito de reciente aparición (Feminism} for the $99 \%$. A manifesto. Verso Books, 2019), Cinzia Arruzza, Tithi Bhattacharya y Nancy Fraser aluden a la huelga del 8 de marzo de 2018 en España como un ejemplo de «dos visiones del feminismo». Tú has tratado este tema de la diversidad del 102 feminismo en tu artículo de referencia («Experiencia y aprendizaje: la formación histórica de los feminismos en España», Historia Social n. ${ }^{\circ} 20,1994$ ) y en tu colaboración en el libro coordinado por Ángela Cenarro y Régine Illion (Feminismos. Contribuciones desde la historia, PUZ, 2014). También tu línea de investigación (Grup de Recerca Consolidat Multiculturalisme i Gènere), que se ha visto plasmada, entre otras muchas contribuciones, en el magnífico Mujeres en el mundo: Historia, retos y movimientos (Alianza Editorial, 2004), nos invita a reflexionar sobre otros feminismos en el pasado y en el presente.

Un gran aprendizaje es hablar del feminismo en plural. Creo que reconocer que hay caminos diversos entre los feminismos es absolutamente decisivo. A veces, porque es más fácil tener una sola ruta, una agenda, pero nuestro mundo no funciona así, ni en el pasado ni en la actualidad. Y, quizás, volviendo a mis raíces, este fue uno de los asuntos que me hizo pensar en términos de las que se han identificado como las «otras», porque yo también me encontraba en esta situación: soy de aquí, pero no soy de aquí; hay una mirada que te interpreta y te interpela como «la otra».
A partir de aquí partió mi interés en abarcar no solo los movimientos de mujeres a nivel europeo, en el contexto más cercano, sino también a nivel más global. Me iba encontrando con mujeres que podían definirse como feministas, pero que no encajaban, lo que me llevó a hacer otras lecturas. Me parecía sumamente interesante y me hacía pensar cómo, en momentos determinados, hay ciertas coincidencias, mientras que, en otros, son muchas las diferencias. Esta era la dificultad que teníamos aquí en los noventa, pues la recepción de mi artículo en Historia Social sobre los feminismos históricos fue muy dura y polémica.

También mi interés por la historia de la India y el debate poscolonial, así como la ocasión de ser profesora visitante en universidades de Estados Unidos y tener contacto con historiadoras de la India, me abrieron todo un mundo. Está claro que hay muchas formas de interpelar al patriarcado y que ha habido formas muy sistemáticas de imposición de modelos anglocéntricos y eurocéntricos, desde Occidente, de entender el feminismo. Y que han sido, en términos de Foucault, manifestaciones de poder. Yo lo he vivido, por ejemplo, en un congreso en Berlín en los años noventa. Una compañera turca, con quien había coincidido en el Consejo de Europa, y yo presentamos un análisis de la situación del profesorado universitario y la educación en nuestros respectivos países fundamentado con muchas estadísticas. Sin embargo, las profesoras de los países del Norte de Europa cuestionaron nuestros datos y la fiabilidad de estos ya que mostraron una situación mejor que en sus países, que consideraban más avanzados. En mi experiencia en el CE (que fue muy interesante, porque había mujeres de Turquía, de Grecia y de los países de la ex órbita soviética), recuerdo los debates que manteníamos sobre transiciones de dictadura a democracia, las maneras tan diferentes que hay, y la imposición de cánones del Norte sobre el Sur y el Este en estos debates. Así, en 1993 celebramos en Barcelona un congreso que debatía precisamente estas transiciones, desde la perspectiva de los países mediterráneos y ex soviéticos, y que logró un diálogo más fructífero que con los países del norte de Europa. 
Fue otra lección para entender el reconocimiento de la diversidad, de las posibilidades que tienen las mujeres y de cómo operan a partir de sus contextos, aunque no encajen con nuestros propios valores. En este caso ellas reclamaban la vuelta al hogar de las mujeres obligadas por el régimen soviético a un trabajo asalariado, mientras nosotras, que salíamos de las dictaduras de Franco y de Salazar, reivindicábamos lo contrario.

En cuanto a Mujeres en el mundo, libro que está ligado a mi propia docencia, se publicó a principios de los 2000, tras esos años noventa en los que España estaba recibiendo las grandes oleadas migratorias. Por aquel entonces, me interesaba toda la situación de las mujeres migradas y el debate en torno a la diversidad, el reconocimiento, la mirada de superioridad-alteridad, los sistemas alterizantes respecto a los colectivos de personas. En Barcelona lo tenía presente en la calle, pero quería salir del imaginario victimista. Me interesaba ir a las respuestas de las mujeres en el mundo árabe, a la validez o a la declaración que hacía Leila Ahmed de que las mujeres occidentales no renegaron de su cultura para avanzar en sus derechos. Entonces, ¿cómo podemos pedir a las otras culturas, que definimos como «otras» de entrada, que asuman una cultura que no es suya y abandonen la propia?

Para ir cerrando nuestra conversación, quiero reflexionar sobre el presente. El término patriarcado (ahora «heteropatriarcado») ha experimentado una reactivación en el movimiento feminista más reciente, que también ha impactado sobre el ámbito académico (en Gender \& History de 2016 se publicó un dosier que invitaba a re-pensar las posibilidades del concepto patriarcado para los análisis de la Historia Moderna). ¿Qué piensas de este concepto como categoría analítica, en el ámbito de la Historia?

Es un tema que surge y resurge. Yo he tenido problemas siempre que se define el patriarcado o heteropatriarcado, porque ¿hasta qué punto lo no-hetero no es patriarcal? Parece estar liberando a los

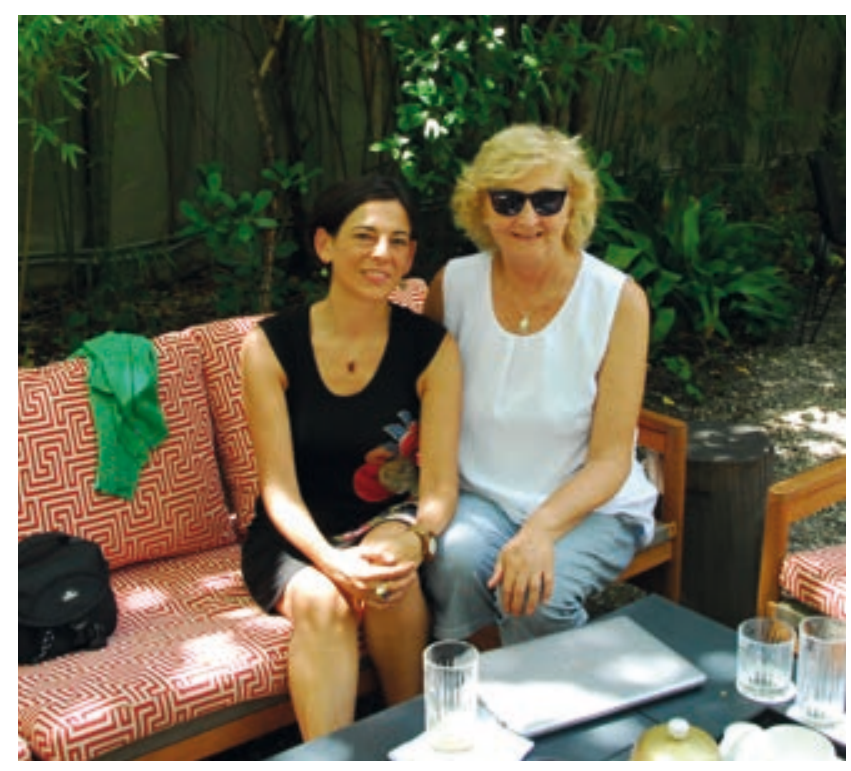

Inmaculada Blasco y Mary Nash durante la entrevista.

no-heteros de ese sistema. También está el tema de las fuentes: cómo accedemos a lo no-hetero. A mí, como historiadora, me interesa la forma en la que se va creando y construyendo el patriarcado en contextos distintos, no como algo fijo. No lo utilizo mucho como concepto, prefiero sistemas de género, pero entiendo que al decir patriarcado la gente comprende, en el imaginario actual, de qué estás hablando. Es una simplificación, pero es genial para explicar una serie de cosas. Sin embargo, si quieres entrar en el ámbito de las complejidades, de las zonas grises y de la transformación histórica, entonces falla, en mi opinión.

Todo tu trabajo muestra un espíritu abierto y cuestionador, ciertamente. Me parece muy rico para construir miradas críticas-autocríticas.

Me he revisado, no ha sido fácil. He sido bastante inquieta intelectualmente, me resulta muy estimulante leer desde otras disciplinas o conocer otras maneras de interpretar la Historia. Es esto lo que me mantiene en el camino, a mí, que soy una apasionada de la Historia. Algo, por cierto, que no acabo de entender: tengo setenta y dos años y sigo tan apasionada. 

IN MEMORIAM.

CONCEPCIÓN TOMÁS AZNAR

ZSE PUEDE EVALUAR LA

\section{PERSPECTIVA DE GÉNERO}

\section{EN LOS PROYECTOS DE}

\section{INVESTIGACIÓN?}

Can the gender perspective be assessed in research projects?

*Este artículo fue publicado originalmente en Gaceta Sanitaria, 2011, 25(2), 146-150. DOI: 10.1016/j.gaceta.2010.09.023.

Nuestro agradecimiento a Carlos Álvarez-Dardet, director de Gaceta Sanitaria.

\section{RESUMEN}

\section{Objetivo}

La perspectiva de género es un enfoque teórico procedente de las teorías feministas, cuyo eje principal es el análisis de las desigualdades de género, y su incorporación es crucial para promover la equidad en salud. El objetivo de nuestra investigación fue elaborar un protocolo/cuestionario para evaluar si la perspectiva de género está presente en un proyecto de investigación, y con ello paliar la carencia de instrumentos de evaluación.

\section{Método}

Se aplicó un diseño cualitativo con dos técnicas: grupo de discusión y encuentro grupal de expertas. El grupo de discusión realizó un análisis dialéctico de los conceptos base sobre investigación y género, e integró los resultados del discurso producido en el encuentro grupal de expertas. La elaboración del protocolo se organizó en torno a las preguntas relevantes a formularse en cada una de las etapas de un proyecto de investigación.

\section{Resultados}

El protocolo elaborado consta de 15 cuestiones: 4 en la introducción, 2 en objetivos e hipótesis, 3 en metodología, 3 en finalidad del estudio y 3 para ser aplicadas a lo largo del proyecto de investigación.

\section{Conclusiones}

Este protocolo es una herramienta que posibilita identificar aquellos proyectos que incluyan la 
perspectiva de género, y su utilización dará una mayor calidad a la investigación y ayudará a reducir las inequidades por cuestiones de género.

\title{
Palabras clave
}

Perspectiva de género, investigación, evaluación, salud de la mujer.

\begin{abstract}
Objective

Gender perspective is a theoretical approach that developed from feminist theories and whose main focus is the analysis of gender inequalities. Integration of this perspective is central to promoting equity in health. The aim of our study was to devise a protocol/questionnaire to assess whether gender is present in research projects and thus help to fill the gap in assessment tools.
\end{abstract}

\section{Methods}

We used a qualitative design with two techniques: group discussion and expert group meetings. The discussion group conducted a dialectical analysis of the basic concepts in research and gender and integrated the results of the discourse produced in the expert group meeting. The drafting of the protocol was organized around the pertinent questions that should be asked at each stage of a research project.

\section{Results}

The protocol consists of 15 questions: four in the introduction section, two in goals and hypotheses, three in methodology, three in purpose of the study and three to be implemented throughout the research project.

\section{Conclusions}

The protocol identifies projects that include a gender perspective. Use of this protocol will improve the quality of research and will help to reduce gender inequities.

\section{Keywords}

Gender perspective, research, evaluation, women's health.

\section{INTRODUCCIÓN}

La investigación en salud con perspectiva de género se ha trabajado desde diferentes ámbitos y profesiones, y su aplicación es un requisito de buenas prácticas (Rohlfs, Borrell, Artazcoz, et al., 2007: ii20-ii25). Diferentes iniciativas legislativas avalan la pertinencia de la incorporación de la perspectiva de género, tanto en el ámbito estatal como en la Unión Europea (Ley 30/2003; Ley Orgánica 3/2007; Council of Europe, 2008; Pérez, 2007: 367-370). 
En los últimos años se ha realizado un gran esfuerzo para incorporar la perspectiva de género en la investigación y el desarrollo de programas de salud, con el fin de identificar y evidenciar situaciones de discriminación y desigualdades, reflexionar sobre sus causas y actuar para transformarlas. Esta es la aportación específica de la perspectiva de género, que es crucial para promover la equidad (Un-Instraw, 2007).

La perspectiva de género es un enfoque teórico procedente de las teorías feministas, cuyo eje principal es el análisis de las desigualdades de género (Velasco, 2008; Harding, 1988). Algunas de sus categorías centrales son: socialización y roles de género, división sexual del trabajo, relaciones de poder o sistema de dominación-subordinación entre sexos. Es necesario reflexionar sobre el hecho de que los roles de género no existen como realidades estables, sino como expresiones que se establecen como un continuo, y que hay que tener en cuenta en la investigación en salud. Los determinantes de género, como la etnia, el estatus socioeconómico, la orientación sexual y otros factores, sitúan a mujeres y hombres de forma diferente en el contexto social y en las relaciones que se establecen entre ellos, dando lugar a diferencias definidas por un acceso desigual a la salud (Canadian Institutes, 2006).

El análisis de género en salud a menudo evidencia que la salud de las mujeres está en situación de desventaja, y que los riesgos y problemas de salud de mujeres y hombres son resultado de la construcción social de los roles a los que ambos están expuestos (Organización Mundial de la Salud, 2002). Lo específico de hombres y mujeres en términos de salud y enfermedad solo se pone de manifiesto si se realiza el análisis separado por sexos y se indaga en las causas de estas diferencias (Velasco, 2008; García Calvente, 2010; Ruiz-Cantero, Vives Cases, Artazcoz et al., 2007; Ruiz-Cantero, 2001).

Detectar carencias en la aplicación de una perspectiva de género en los proyectos de investigación, darlas a conocer y plantear formación, ayudaría a mejorar la salud y disminuir la inequidad, y esta finalidad está en sintonía con el Plan de Calidad del Sistema Nacional de Salud, que señala en su cuarta estrategia la necesidad de «promover el conocimiento sobre las desigualdades de género en salud y fortalecer el enfoque de género en las políticas de salud y en la formación continuada del personal de salud» (Ruiz-Cantero, 2007; Ministerio de Sanidad y Consumo, 2007).

Los estados miembros y la Organización Mundial de la Salud (OMS) deberán incluir la perspectiva de género como uno de los criterios para la financiación de cualquier investigación relevante. Esto conlleva establecer directrices y programas de formación sobre género y salud dirigidos a las personas que investigan y a quienes evalúan las propuestas de investigación (Ruiz-Cantero, Papí Gálvez, 2007).

En la actualidad se dispone de guías para la investigación con perspectiva de género (García Calvente, 2010; Ruiz-Cantero, Papí Gálvez, 2007; 
García Calvente, 2005; WHO, 2001), pero no existe una herramienta que permita evaluar si los proyectos de investigación la incluyen, lo que constituye una clara debilidad del proceso de evaluación de la calidad de los proyectos. El objetivo de nuestra investigación es elaborar un protocolo/cuestionario que permita evaluar si la perspectiva de género se encuentra presente en un proyecto de investigación, y con ello paliar la carencia de instrumentos de evaluación. La utilización de este protocolo en la evaluación de los proyectos de investigación contribuirá a sedimentar una metodología de investigación, que sitúe al género como una categoría para el análisis, con la finalidad de mejorar la salud y disminuir la inequidad. Su aplicación en la evaluación de los proyectos dará una mayor credibilidad y calidad a la investigación.

En la realización de este trabajo se aplicó un diseño cualitativo que incluyó dos técnicas: grupo de discusión y encuentro grupal de expertas.

1) El equipo investigador se constituyó como grupo de discusión. Su metodología de trabajo incluyó la lectura y el comentario de sesenta textos. Se seleccionó la documentación de los últimos diez años, procedente de los grupos de investigación sobre género y salud pública de la Sociedad Española de Salud Pública y Administración Sanitaria (SESPAS) y de la Red Temática de Investigación de Salud y Género (RISG), de la información disponible en las webs de la Sociedad Española de Epidemiología, la OMS, la Organización Panamericana de Salud, los Canadian Institutes of Health Research y el United Nations International Research and Training Institute for the Advancement of Women (Un-Instraw).

El grupo de investigación realizó un análisis dialéctico de los conceptos base sobre investigación y género, que pasaron a constituir el esquema conceptual común del equipo. Cada una de las componentes del grupo realizaba una lectura en profundidad y elaboraba las cuestiones que consideraba pertinentes, dando lugar a un primer borrador que agrupó 185 cuestiones. En las siguientes fases de trabajo se fueron eliminando las ambiguas y repetitivas. Se decidió seguir las etapas de un proyecto de investigación, eliminando por tanto el apartado de resultados y la elección del tema, y se añadió un apartado general para aplicar a lo largo de todo el proyecto.

2) Encuentro grupal de expertas. Para su selección, se consideró «experta» en género y salud aquella persona que tuviera formación específica acreditada en el tema o perteneciera a alguna de las redes de investigación sobre género y salud. Participaron seis profesionales nacionales del ámbito de la salud pública, la salud mental y la atención primaria, con experiencia en investigación, práctica asistencial y docencia. Se realizaron dos sesiones en junio de 2008 y la metodología de trabajo se organizó en torno a las pre- 
guntas relevantes a formularse en cada una de las etapas de un proyecto de investigación para evaluar si incluye la perspectiva de género. El discurso de las sesiones se analizó a partir de la información codificada, y se procedió a su organización y sistematización con el programa informático Atlas.ti. La coordinación del encuentro grupal se realizó con la técnica de grupo operativo, por una persona experta en el tema.

3) Se elaboró el protocolo final por consenso, incluyendo también, como material de trabajo, las aportaciones del grupo de expertas. El protocolo final consta de 15 preguntas.

El grupo de investigadoras partió de 185 cuestiones distribuidas en los siguientes apartados: elección del tema (15), introducción (45), objetivos (25), metodología (56), resultados (24) y utilidad-finalidad (20). Entre febrero de 2008 y junio de 2009 el grupo realizó dieciséis reuniones de trabajo. El resultado final, obtenido por consenso entre las investigadoras, es un cuestionario de 15 preguntas, las 12 primeras para aplicar en los diferentes apartados de un proyecto de investigación y el resto a considerar a lo largo del desarrollo del proyecto.

A) En la introducción se incluyen:

1) Si en el tema de salud investigado hay conocimiento científico con perspectiva de género, ¿se han incluido estas referencias?

La introducción del proyecto tendrá que hacer referencia al conocimiento científico existente con perspectiva de género en el ámbito de la salud sobre el cual se investiga, o hacer referencia a su carencia (Harding, 1988; Ruiz-Cantero, Vives Cases, Artazcoz et al., 2007; Rolfh, Borrel, Anitua, 2000; Castaño, Carvajal, 2001; Nieuwenhoven, Bertens, Klinge, 2007).

2) ¿Hace referencia a la magnitud del problema en mujeres y hombres? En el marco teórico y la definición del problema habrá que tener en cuenta si hay diferencias entre hombres y mujeres, y si estas son injustas y evitables. En este apartado es importante atender a los indicadores utilizados en la definición del problema. Mortalidad, morbilidad, incidencia y prevalencia pueden ser diferentes entre hombres y mujeres, y tomarlo o no en consideración puede provocar una invisibilización de los problemas de salud que afectan más a las mujeres.

3) ¿Tiene en cuenta la categoría de género como un determinante de salud?

En el marco teórico y la definición del problema habrá que tener en cuenta si hay conocimiento científico acerca del modo en que la categoría «género» influye en el problema de salud objeto de investigación, que estará sustentado en el análisis de los determinantes de género.

\section{RESULTADOS}


4) ¿Se incluye el término «género» en las palabras clave?

Se utilizan 10 términos del MESH que ayudan a identificar los estudios de género: prejudice, feminism, gender and identity, interpersonal relations, women's health, sexual and gender disorders, sex differentiation disorders, sex factors, sex characteristics y sex distribution.

B) En la formulación de objetivos, preguntas de investigación e hipótesis se incluyen:

5) ¿Busca, a través de los objetivos/hipótesis formuladas, la asociación entre el tema de salud investigado y alguno de los determinantes de género?

Por determinantes o condicionantes de género entendemos aqueIlas características dependientes del rol social, actitudes, creencias, división sexual del trabajo, identidad sexual, rol familiar, ciclo vital, etc., asignadas a hombres y mujeres por los modelos culturales de género. Esta cuestión aporta información para comprender cómo la construcción social de hombres y mujeres afecta al nivel de salud, a la expresión de los problemas de salud, a los modos de atención sanitaria y a la organización de los servicios y la distribución de los recursos (Velasco, 2008).

6) ¿Hay sesgos o estereotipos de género en la formulación de las hipótesis/objetivos?

Los sesgos y los estereotipos pueden influir en el desarrollo de una investigación. Sesgo de género se define como el «planteamiento erróneo de igualdad o de diferencias entre hombres y mujeres, en cuanto a su naturaleza, a sus comportamientos o a sus razonamientos; el cual puede generar una conducta desigual en los servicios sanitarios, incluida la investigación, siendo esta conducta discriminatoria para un sexo respecto al otro» (Ruiz-Cantero, 2001: 163-164). Estereotipo de género se define como aquellas «ideas y creencias comúnmente aceptadas en la sociedad sobre cómo han de ser y comportarse hombres y mujeres. Los estereotipos determinan aquello que es correcto e incorrecto en unos y otras» (Amo Alfonso, 2008).

C) En la metodología:

7) ¿Se ha estratificado la muestra por sexo y grupo de edad?

El análisis separado por sexos ayuda a diferenciar lo específico de hombres y mujeres, aspecto que se pone de manifiesto si se estudian conjuntamente. El análisis separado por grupos de edad es necesario para poner de manifiesto las diferencias a lo largo del ciclo vital entre mujeres y hombres (Ruiz-Cantero, Papí Gálvez, 2007).

8) ¿Se identifican posibles sesgos de género en los criterios de inclusión o exclusión en la muestra?

Cuando se seleccionan los participantes en los estudios por el diagnóstico de la enfermedad hay que tener en cuenta las diferentes manifestaciones de los síntomas o los resultados analíticos que avalan ese diagnóstico en las mujeres y los hombres. De no tenerse en cuenta, quedarían excluidas las 
personas en que la enfermedad se manifiesta de forma diferente (Ruiz-Cantero, 2007).

9) ¿Las variables utilizadas hacen posible poner de relieve la relación existente entre el tema de salud investigado y alguno/s factor/es de género: características dependientes del rol social, actitudes, creencias, división sexual del trabajo (trabajo productivo/reproductivo), identidad sexual, rol familiar, ciclo vital?

Las desigualdades en salud surgen de las diferencias de los roles de género, de la división genérica del trabajo, de la distribución desigual de beneficios y recursos, y de las que generan las relaciones sociales (Amo Alfonso, 2008).

D) En la finalidad:

10) ¿Contribuye a poner de manifiesto diferencias o desigualdades entre hombres y mujeres en el tema de salud investigado?

Las diferencias en salud entre mujeres y hombres, en las diversas etapas de la vida, se pueden justificar por la exposición a los distintos determinantes de salud. Un proyecto con perspectiva de género detectará aquellos determinantes de género que colocan a las mujeres y a los hombres en una posición de vulnerabilidad a las enfermedades y al acceso a los servicios de salud.

11) ¿Contribuye a incrementar el conocimiento de la salud de las mujeres o de los hombres y la diversidad en su expresión?

La investigación no solo tiene como objetivo identificar las desigualdades entre mujeres y hombres. Cuando la investigación se realiza en grupos de mujeres o en grupos de hombres es imprescindible identificar cómo afectan los determinantes de género a quienes se han visto expuestos a lo largo de la vida y analizar la diversidad de su expresión, que puede estar relacionada con los distintos modelos de género existentes (Velasco, 2008).

12) ¿Contribuye a señalar cambios en la estructura de género que pueden repercutir en igualdad o equidad, entre hombres y mujeres, en salud?

Puesto que la finalidad de la investigación es promover cambios en la mejora de la salud de las personas, en caso de reconocer o identificar discriminación, esta debería hacerse evidente y plantear las modificaciones para que no se perpetúe en el tiempo.

E) Para finalizar se incluyen tres cuestiones a aplicar en todo el proyecto de investigación:

13) ¿Utiliza un lenguaje sexista?

Utilizar un lenguaje sexista a lo largo de la elaboración del proyecto es expresión de que las mujeres son sujeto de discriminación (Garí Pérez, 2006; Ley Orgánica 3/2007).

14) ¿Se presentan los datos desagregados por sexo?

Hace referencia a la recogida y el desglose de datos y de información estadística que hacen posible un análisis comparativo entre los sexos. 
15) ¿Utiliza «género» como sinónimo de «sexo»?

Considerar «sexo» como sinónimo de «género» en los proyectos de investigación conduce a conclusiones no científicas. El sexo es una variable y el género es una categoría de análisis, para el cual se requiere considerar los condicionantes de género pertinentes al tema de salud investigado. Sexo y género no son intercambiables en el proceso de investigación; los datos deberán estar desagregados por sexo y el análisis de género se basará en la interrelación del tema de salud investigado con los determinantes de género incluidos en el estudio (Rohlfs, Borrell, Artazcoz, et al., 2007: ii20-ii25; Harding, 1988).

El protocolo elaborado es una herramienta que posibilita valorar si la investigación en salud incorpora la perspectiva de género, criterio recomendado por las leyes vigentes, la comunidad científica y las administraciones autonómicas en sus planes de salud (Ministerio de Igualdad, s.f.; Council of Europe, 2008; Organización Mundial de la Salud, 2002; Ministerio de Sanidad y Consumo, 2007). Consideramos este protocolo como un instrumento de evaluación dinámico que se puede ir modificando e incluyendo nuevas aportaciones. Incorporar la perspectiva de género es complejo y requiere un proceso de reflexión y cuestionamiento personal y científico sobre las implicaciones que los roles tradicionales y el androcentrismo de la ciencia han tenido y tienen en el conocimiento científico de los procesos de enfermar, así como en la utilización y el acceso a los recursos sanitarios (Velasco, 2008; Valls-Llobet, 2001: 186-191).

En la elaboración del protocolo surgieron muchas incertidumbres, ya que al no estar en la línea del paradigma biomédico imperante se pueden generar resistencias a la inclusión de la perspectiva de género. No obstante, nos apoyamos en guías (Ruiz-Cantero, Papí Gálvez, 2007; Ruiz-Cantero, Vives Cases, Artazcoz et al., 2007), protocolos (Castaño, Carvajal, 2001; Hammarström, 2007: S123-S132), reuniones de expertos del GenderBasic Project (Klinge, 2008: 183-189) y otras investigaciones (Risberg, Hamberg, Johansson, 2006: 4-20) que reflejan una inquietud en el ámbito científico por considerar el género una condición básica a introducir en la investigación, pues la racionalidad científica de la medicina se ampliaría con la inclusión de la perspectiva de género.

En relación con las distintas cuestiones planteadas cabe hacer varias consideraciones. En el apartado de introducción debemos destacar que como el acceso al conocimiento científico sobre las desigualdades en salud se realiza mediante búsqueda bibliográfica, la ausencia de palabras clave que identifiquen los estudios de género dificulta obtener información relevante para el análisis de género, y esto puede constituir un sesgo de an- 
drocentrismo (Harding, 1988; Castaño, Carvajal, 2001; Fraisse, 2001; Velasco, 2006). También puede ocurrir que no se haya generado hasta el momento conocimiento científico sobre el tema de salud investigado; por ejemplo, sabemos mucho de la cardiopatía isquémica, pero no de otros procesos, y en este caso será importante señalar esta carencia (Castaño, Carvajal, 2001; OSM, 2005; OSM, 2006).

En la metodología destacamos que es imprescindible partir de la estratificación por sexo y grupo de edad (Clougherty, 2010: 118, 167-176). Pero para incluir el género como categoría de análisis, aspecto clave de las investigaciones con perspectiva de género, se requiere considerar los determinantes sociales que permiten valorar las desigualdades de género, y además incluir las variables que aportan la diversidad existente en el colectivo de mujeres o de hombres (Hammarström, 2007: S123-S132). La consideración de los sesgos debe hacerse para evitar errores en la selección de la muestra, el análisis de los resultados y la formulación de las conclusiones (Ruiz-Cantero, 2007; Ruiz-Cantero, Papí Gálvez, 2007).

La finalidad de la investigación debe tener presentes las necesidades y los problemas de la población, y no estar limitada a los temas que se consideran pertinentes desde el ámbito biomédico. Se podrían priorizar las investigaciones a la hora de distribuir los recursos disponibles, en función de la relevancia del género en la salud. Todos los temas referidos a las personas, y a problemas de salud, pueden abordarse desde la perspectiva de género.

La utilización de un lenguaje no sexista se considera un requisito indispensable a tener en cuenta en el desarrollo del proyecto. Por ejemplo, la categorización de las mujeres mediante el lenguaje, como cuidadoras de las personas dependientes, resulta limitante y reduccionista para ellas (Garí Pérez, 2006).

La cuestión relativa a desagregar los datos por sexo es un imperativo técnico, puesto que hombres y mujeres presentan diferencias y similitudes, y es un requisito básico en los estudios de investigación que no implica en sí mismo que el estudio incorpore la perspectiva de género, pero que es imprescindible para poder analizarla.

La diferenciación conceptual entre sexo y género está ampliamente documentada, pero se tiende a utilizar estos términos de forma indistinta, por desconocimiento de lo que supone utilizar el género como categoría de análisis. Supone una falta de rigor científico y puede anular la repercusión científica y social que tienen los estudios de género (Ministerio de lgualdad, s.f.).

Algunas propuestas a incluir en la valoración de los proyectos tienen que ver con la elección del tema de investigación, que este sea importante para la vida de las personas y que amplíe el conocimiento científico sobre la salud de las mujeres, las desigualdades por razón de género o la repercusión que tienen los determinantes de género en la vida de hombres y mujeres. Además, los proyectos de investigación con perspectiva de género deberían 
incorporar un apartado de «principios y valores» del enfoque de género, que para la teoría feminista son los principios y valores relativos a la desaparición de las desigualdades de género en la salud (Velasco, 2008; Ruiz-Cantero, Papí Gálvez, 2007; Velasco, 2006).

\section{BIBLIOGRAFÍA}

ALFonso, Mercedes (2008). Guía para facilitar la incorporación de la perspectiva de género en los planes integrales de salud. Consejería de Salud. Junta de Andalucía.

Canadian Institutes of Health Research (2006). Gender and sex-based analysis in health research: a guide for CIHR researchers and reviewers.

Castaño, José, Carvajal, Isabel (2001). La nueva acepción de gender. Disponible en: https://ec.europa.eu/translation/bulletins/puntoycoma/69/pyc692.htm

ClougheRTY, Jane (2010). «A growing role for gender analysis in air pollution epidemiology» Environmental Health Perspectives (118/2),167-76. DOI: 10.1289/ehp.0900994

Council of Europe (2008). Recommendation CM/Rec (2008)1 of the Committee of Ministers to member states on the inclusion of gender differences in health policy. Disponible en: https://eige.europa.eu/library/resource/ aleph_eige000001587

FraISSE, Genèvieve (2001). El concepto filosófico de género. Disponible en: https:// www.academia.edu/6989391/ El concepto filosofico del genero

García Calvente, M. ${ }^{a}$ del Mar (coord.), Jiménez Rodrigo, M. ${ }^{a}$ Luisa, Martinez MoranTE, Emilia (2010). Guía de recomendaciones para la incorporación de la perspectiva de género. Madrid: Observatorio de Salud de las Mujeres. Políticas de investigación en salud. Disponible en: http://www.mscbs. gob.es/organizacion/sns/planCalidadSNS/pdf/equidad/PROPUESTA DE GUIA NIVEL POLITICAS DE INVESTIGACION EN SALUD.pdf

- Informe de revisión de guías sobre la incorporación de la perspectiva de género a las políticas de investigación en salud. Madrid: Observatorio de Salud de las Mujeres. Disponible en: http://www.mscbs.gob.es/organizacion/sns/planCalidadSNS/pdf/equidad/INFORME REVISION DE LAS GUIAS Politicas de investigacion-OSM.pdf

Gari Perez, Aitana (2006). Hablamos de salud. Instituto de la Mujer y Observatorio de Salud de la Mujer. Disponible en: http://www.mscbs.gob.es/organizacion/sns/planCalidadSNS/pdf/equidad/hablamosDeSalud.pdf HAMMARSTRÖM, Anne (2007). «A tool for developing gender research in medicine: examples from the medical literature on work life». Gender Medicine (4), S123-S132. DOI: 10.1016 / S1550-8579 (07) 80053-2 
HARDING, Sandra (1988). «ls there a feminist method?». En Harding, Sandra (ed.). Feminism and methodology. Indiana University Press.

KLINGE, Ineke (2008). «Gender perspectives in European research». Pharmacological Research (58), 183-189. DOI: 10.1016/j.phrs.2008.07.011

LEY 30/2003, de 13 de octubre, sobre medidas para incorporar la valoración del impacto de género en las disposiciones normativas que elabore el Gobierno. Disponible en: https://boe.es/buscar/doc.php?id=BOE-A-2003-18920

Ley Orgánica 3/2007, de 22 de marzo, para la igualdad efectiva de mujeres y hombres. Disponible en: https://www.boe.es/boe/dias/2007/03/23/ pdfs/A12611-12645.pdf

Ministerio de IGUALDAD. Gobierno de España (s.f.). Glosario del plan estratégico 2008-2011 lgualdad de oportunidades.

Ministerio de SANIDAd y Consumo (2007). Plan de calidad para el Sistema Nacional de Salud. Madrid: Ministerio de Sanidad y Consumo. Secretaría General de Sanidad. Agencia de Calidad del SNS. Disponible en: $\underline{\text { http:// }}$ www.mscbs.gob.es/organizacion/sns/planCalidadSNS/docs/planCalidad2007.pdf

Nieuwenhoven, Linda, Bertens, Madelief, KLinge, Ineke (2007). Gender. Awakening tool. Bibliography: sex and gender in research. Maastricht University. Disponible en: http://www.cwhn.ca/en/node/43342

Organización Mundial de LA SAlud (2002). Integración de las perspectivas de género en la labor de la OMS. Política de la OMS en materia de género. Disponible en: https://www.who.int/gender/mainstreaming/ESPwhole.pdf

OSM Observatorio de Salud de la Mujer (2005). Informe Salud y Género. Disponible en: http://www.mscbs.gob.es/organizacion/sns/planCalidadSNS/ pdf/equidad/InfomeSaludyGenero2005.pdf

OSM Observatorio de Salud de la Mujer (2006). Informe Salud y Género.

PéREz, Glòria (2007). «La ley de igualdad efectiva de mujeres y hombres: un paso adelante», Gaceta Sanitaria (21), 367-370. Disponible en: http://scielo.isciii.es/scielo.php?script=sci_arttext\&pid=S0213-91112007000500001

Risberg, Gunilla, HamberG, Katarina, Johansson, Eva E. (2006). «Gender perspective in medicine: a vital part of medical scientific rationality. A useful model for comprehending structures and hierarchies within medical science». BMC Medicine (4), article 20. Disponible en: $\underline{\text { https://bmcme- }}$ dicine.biomedcentral.com/articles/10.1186/1741-7015-4-20

Rohlfs, Izabella, Borrel, Carme, Anitua, Cecilia et al. (2000). «La importancia de la perspectiva de género en las encuestas de salud», Gac Sanit., (14/2), 146-155. DOI: 10.1016/S0213-9111(00)71448-8

Rohlfs, Izabella, Borrell, Carme, Artazcoz, Lucia, et al. (2007). «The incorporation of gender perspective into Spanish health surveys», J Epidemiol Community Health (61), ii20-ii25. http://dx.doi.org/10.1136/jech.2007.059956 
Ruiz-Cantero, M. Teresa (2001). «lgualdad de oportunidades en los servicios sanitarios: sesgo de género como determinante de la estructura de salud de la comunidad». En Miqueo Miqueo, Consuelo, Tomás, Concepción, Tejero Vela, Cruz et al. (coord.). Perspectivas de género en salud: fundamentos científicos y socioprofesionales de diferencias sexuales no previstas. Madrid: Minerva, 163-177.

— (2007). «El sistema sexo-género en investigación sobre atención sanitaria». En Borrell, Carme y Artazcoz, Lucía (coord.). 5a Monografía. Sociedad Española de Epidemiología. Investigación en género y salud, Sociedad Española de Epidemiología, 79-96. Disponible en: https://www.seepidemiologia.es/documents/dummy/5aMonSEEGenSalud.pdf

Ruiz-Cantero, M. a Teresa, Papí Gálvez, Natalia (2007). Guía de estadísticas de salud con enfoque de género: análisis de internet y recomendaciones. Madrid: OSM. Disponible en: http://www.mscbs.gob.es/organizacion/sns/ planCalidadSNS/e02 t01.htm

Ruiz-Cantero, M.a Teresa, Vives Cases, Carmen, Artazcoz, Lucía et al. (2007). «A framework to analyse gender bias in epidemiological research», JECH (61/2), ii46-ii53. DOI: 10.1136 / jech.2007.062034

Un-INSTRAW United Nations International Research and Training Institute for the Advancement of Women (2007). Three common gender research methodologies.

Valls-LLobet, Carme (2001). «El estado de la investigación en salud y género». En Miqueo Miqueo, Consuelo, Tomás, Concepción, Tejero Vela, Cruz et al. (coord.). Perspectivas de género en salud: fundamentos científicos y socioprofesionales de diferencias sexuales no previstas. Madrid: Minerva, 179-195.

- (2006). Evolución de los enfoques de género en salud. Intersección de teorías de la salud y teoría feminista. Escuela Nacional de Sanidad y OSM. Disponible en: http://coslada.es/semsys/tesauro/visorlmagenes. do:jsessionid=FF5A48A6A181361703F316E37C03C6E3?operacion=pintarlmagen\&codigoTermino=1245\&codigoAtributo=1997\&nombreFichero=Teorias-y-enfoque-de-genero-2008.pdf

Velasco, Sara (2008). Recomendaciones para la práctica del enfoque de género en programas de salud. Observatorio de Salud de la Mujer (OSM).

WHO (2001). European Policy Health Impact Assessment (EPHIA) - A guide. Disponible en: https://ec.europa.eu/health/ph projects/2001/monitoring/ fp_monitoring 2001_a6 frep_11_en.pdf 


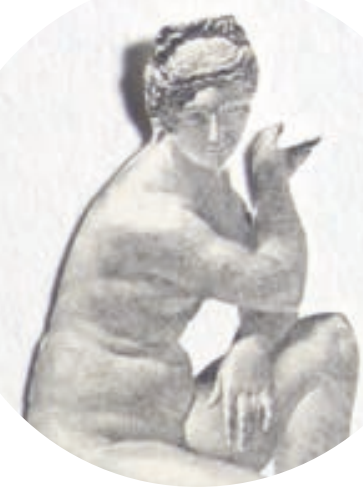

